This work was financially supported by Vitens BV.

\title{
Ikenna Ngene
}

\section{Real time visual characterization of membrane fouling and cleaning}

PhD Thesis, University of Twente, The Netherlands

ISBN: 978-90-365-3033-0

(c) Ikenna Ngene, Maasland, 2010

No part of this work may be reproduced by print, photocopy or any other means without permission of the author.

Cover design by lkenna Ngene

Showing membranes with star shaped structures after biofouling, with the images digitally enhanced.

Printed by Ipskamp B.V., Enschede. The Netherlands 
".... Father, Lord of heaven and earth, thank you for hiding these things from those who are wise and clever and for revealing them to the childlike......" 
This dissertation has been approved by:

Promotor: $\quad$ Prof. Dr. Ir. W.G.J. van der Meer

Assistant-promotor: $\quad$ Prof. Dr. Ir. R.G.H. Lammertink 


\title{
REAL TIME VISUAL CHARACTERIZATION OF MEMBRANE FOULING AND CLEANING
}

\section{DISSERTATION}

\author{
to obtain \\ the doctor's degree at the University of Twente, \\ on the authority of the rector magnificus, \\ prof. dr. H. Brinksma, \\ on account of the decision of the graduation committee, \\ to be publicly defended \\ on Thursday $27^{\text {th }}$ May, 2010 at 15:00
}

by

\author{
Ikenna Sunday Ngene \\ born on $24^{\text {th }}$ June, 1979 \\ in Enugu, Nigeria.
}

$$
\text { P a g e | iv }
$$


1.1 MEMBRANE FILTRATION 2

1.2 Membrane PREPARATION 3

1.3 Membrane tRansport theORY 4

1.4 Membrane fouling 5

$\begin{array}{lll}1.5 & \text { VISUAL MONITORING OF FOULING } & 6\end{array}$

1.6 Membrane ModUles - SPIRAL WOUND MOdULES 8

1.7 MICROFLUIDICS AND STRUCTURED MEMBRANES 10

1.8 PROJeCt AIM AND OVERVIEW OF THESIS

REFERENCES $\quad 16$

CHAPTER 2. A MICROFLUIDIC MEMBRANE CHIP FOR IN SITU FOULING CHARACTERIZATION 20

$1 \quad$ INTRODUCTION 21

$\underline{2}$ MATERIALS AND METHODS

2.1 Materials $\quad 25$

2.2 Methods $\quad 25$

2.2.1 FLATSHEET MEMBRANES

$\begin{array}{ll}\text { 2.2.2 STRUCTURED MEMBRANES } & 25\end{array}$

2.2.3 CHIP PREPARATION/SETUP 26

$\begin{array}{ll}\text { 2.2.4 ANALYSIS AND CHARACTERIZATION } & 27\end{array}$

3 RESULTS AND DISCUSSIONS 29

$\begin{array}{llr}3.1 & \text { TEMPLATING } & 29\end{array}$

$\begin{array}{lll}3.2 & \text { Sealing } & 30\end{array}$

3.3 Pure WATER fluX 31

$\begin{array}{lll}3.4 & \text { LIQUID VELOCITY GRADIENT } & 33\end{array}$ 
CHAPTER 3. VISUAL CHARACTERIZATION OF FOULING WITH BIDISPERSE SOLUTION 41

1 INTRODUCTION 42

$\underline{2}$ MATERIALS AND METHODS 45

2.1 MATERIALS 45

2.2 METHODS 45

2.2.1 MEMBRANE CHANNELS 45

2.2.2 FEED SOLUTION 45

2.2.3 ChIP PREPARATION/SETUP 46

2.2.4 CHARACTERIZATION METHOD 47

3 RESULTS AND DISCUSSIONS 49

3.1 MEMBRANE CHARACTERIZATION 49

3.2 FOULING CHARACTERIZATION 49

3.3 CAKE POROSITY 52

3.4 CAKE RESISTANCE 53

4 CONCLUSION 55

REFERENCES 56

CHAPTER 4. PARTICLE DEPOSITION AND BIOFILM FORMATION ON MICROSTRUCTURED MEMBRANES 60

1 INTRODUCTION 60

2 MATERIALS AND METHODS 65

2.1 MATERIALS 65

2.2 Methods 65 
2.2.2 STRUCTURED MEMBRANES 65

2.2.3 SETUP 66

$\begin{array}{lll}2.2 .4 & \text { FOULING } & 67\end{array}$

$\begin{array}{lll}2.3 & \text { CFD SIMULATION } & 67\end{array}$

$\begin{array}{lll}2.3 .1 & \text { GEOMETRY } & 67\end{array}$

$\begin{array}{lll}2.3 .2 & \text { SIMULATION CONDITIONS } & 67\end{array}$

3 RESULTS AND DISCUSSIONS 70

$\begin{array}{lll}3.1 & \text { CFD HYDRODYNAMICS } & 70\end{array}$

\begin{tabular}{ll}
3.2 & WALL SURFACE SHEAR \\
\hline 2
\end{tabular}

$\begin{array}{lll}3.3 & \text { BIOFILM FORMATION } & 74\end{array}$

$\begin{array}{lll}3.4 & \text { Particulate fouling } & 76\end{array}$

4 CONCLUSIONS 77

REFERENCES $\quad 79$

CHAPTER 5: $\mathrm{CO}_{2}$ NUCLEATION IN MEMBRANE SPACER CHANNELS REMOVE BIOFILMS AND FOULING DEPOSITS $\quad 82$

$1 \quad$ INTRODUCTION

$2 \quad$ MATERIALS AND METHODS $\quad 86$

$\begin{array}{lll}2.1 & \text { Setup } & 86\end{array}$

$\begin{array}{lll}2.2 & \text { MATERIALS } & 87\end{array}$

$\begin{array}{lll}2.3 & \text { Methods } & 87\end{array}$

$\begin{array}{lll}2.3 .1 & \mathrm{CO}_{2} \text { SATURATION } & 87\end{array}$

2.3.2 HYDRAULIC RESISTANCE

$\begin{array}{lll}2.3 .3 & \text { FOULING } & 88\end{array}$

$\begin{array}{lll}2.3 .4 & \text { CLEANING } & 88\end{array}$ 
$\begin{array}{lll}2.3 .5 & 88\end{array}$

3 RESULTS AND DISCUSSIONS

$\begin{array}{lll}3.1 & \text { FOULING } & 90\end{array}$

$\begin{array}{lll}3.2 & \text { Cleaning } & 92\end{array}$

3.3 Bubble coverage $\quad 94$

REFERENCES $\quad 98$

CHAPTER 6. CONCLUSIONS AND OUTLOOK 101

1 CONCLUSIONS 102

$\underline{2}$ OUTLOOK 104

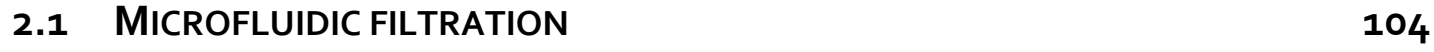

$\begin{array}{llr}2.2 & \text { FREE STANDING SPACERS } & 105\end{array}$

$\begin{array}{lll}2.3 & \text { BIOFOULING ON STRUCTURES } & 106\end{array}$

$\begin{array}{lll}2.4 \mathrm{CO}_{2} \text { CLEANING PROPERTIES } & 107\end{array}$

\begin{tabular}{lr} 
REFERENCES & 108 \\
\hline
\end{tabular}

\begin{tabular}{lr} 
SUMMARY & 109 \\
\hline
\end{tabular}

SAMENVATTING

ACKNOWLEDGEMENTS $\quad 113$ 
Chapter 1. Introduction

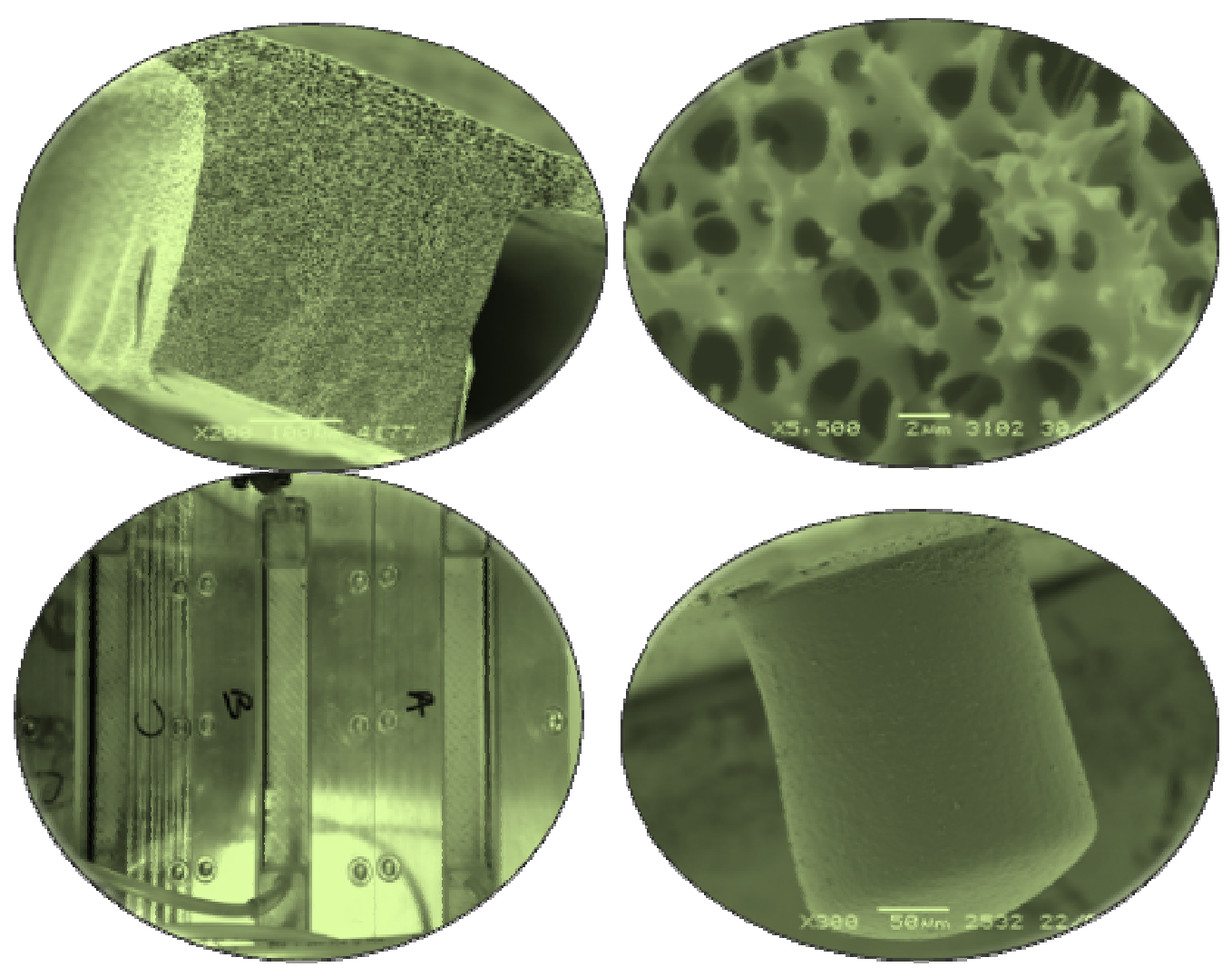

P a g e | 1 


\subsection{Membrane filtration}

Recently, membrane filtration systems are being increasingly applied in water treatment industries. They are used in desalination of seawater, purification of surface water and process water. The application of membranes in water treatment is a rapidly growing field due to improvements in membrane properties resulting in longer lifespan and enhanced performance. Membrane processes are broadly grouped according to the driving forces applied; pressure, electrical potential and concentration driven processes [1]. Aside from water treatment, membrane filtration units are finding use in several industries. Membranes separation processes are used in concentration of components, gas separation, energy production, desalination, dehydration purposes, amino acid separations, tissue regeneration, selective adsorption and reactions.

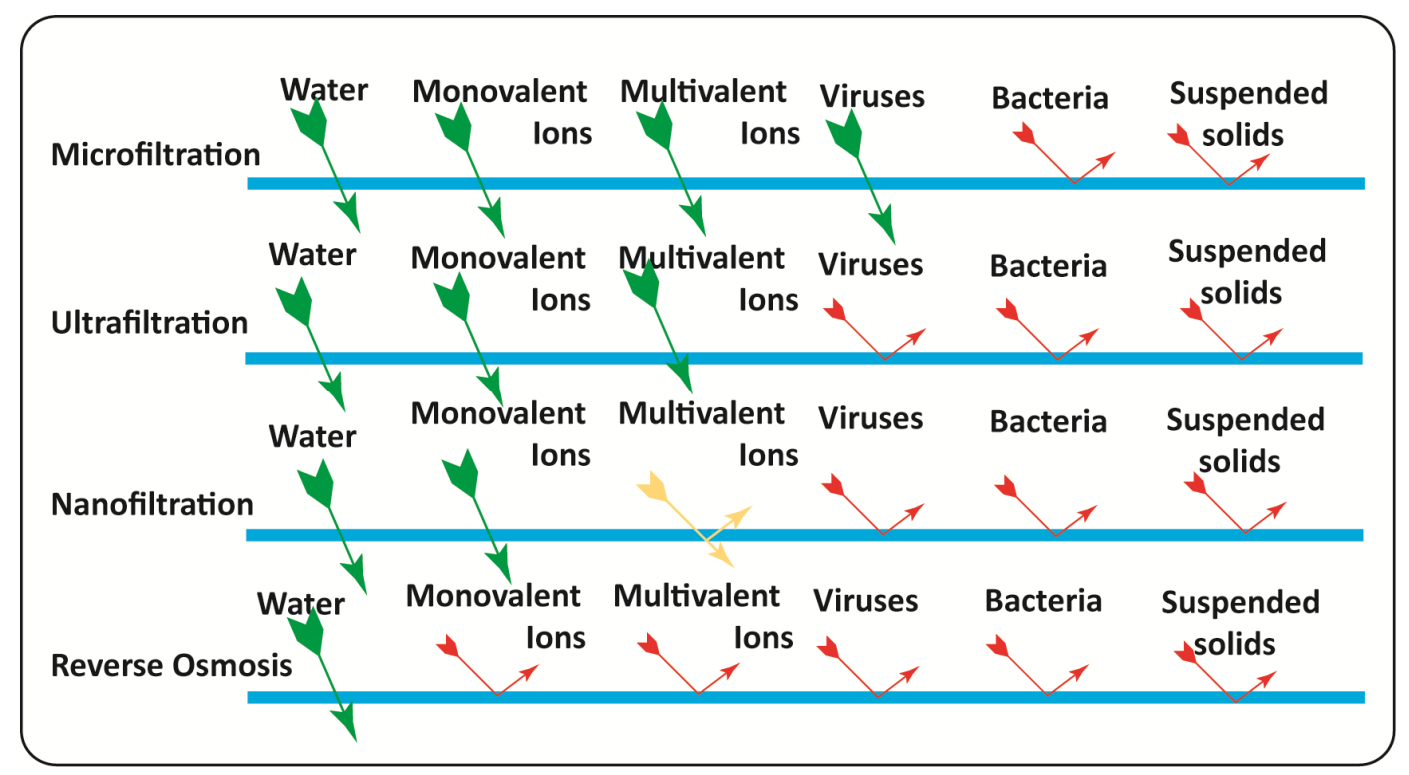

Figure 1. Pressure driven membrane processes, green arrows indicate permeating components while red arrows indicate components which are retained by the membranes.

Pressure driven membrane processes are further subdivided according to the size of particles they retain. Figure 1 shows the pressure driven membrane processes alongside typical retainable components. These pressure driven processes currently applied in water treatment are 
microfiltration (MF), ultrafiltration (UF), nanofiltration (NF) and reverse osmosis (RO). Microfiltration membranes have pore sizes in the range of 0.05 to $10 \mu \mathrm{m}$ and as such are used in separation of particulate and colloidal matter. Ultrafiltration membranes on the other hand, have smaller pores ranging from $1-100 \mathrm{~nm}$. They are typically asymmetric membranes with a thin active separation layer and a more porous support layer. Nanofiltration and reverse osmosis membranes are considered to have pores up to $1 \mathrm{~nm}$. These membranes are asymmetric having a thin dense top layer supported by the thicker porous layer with the membrane resistance dependent on the top layer. They can be prepared by placing a dense top layer on an ultrafiltration membrane either by dip coating or interfacial polymerization.

\subsection{Membrane preparation}

Membranes can be prepared from a variety of materials including alumina, glass, metals and various polymers. These materials can be structured resulting in the desired properties using several methods which include track etching, coating, sintering and phase separation [1]. Sintering is typically used in preparation of inorganic membranes and involves heating of the materials at elevated temperatures (below the melting point) resulting in the particles adhering to each other. Coating is used in preparing dense membranes or composite membranes requiring a thin active layer on a supporting layer. Track etching can be used in the preparation of membranes with well controlled pore sizes. Thin films are exposed to high energy radiation which creates tracks within the polymer matrix and by etching away material along these tracks, pores are formed.

Phase separation (inversion) processes involve the conversion of a liquid polymer solution into a solid membrane. This can be done by evaporation of the solvent, thermal precipitation or by immersion precipitation. In immersion precipitation, the polymer solution is cast on a substrate, and subsequently placed in a suitable non solvent bath. The exchange of solvent and non-solvent results in phase separation of the solution, the polymer rich phase forming the membrane matrix and the polymer lean phase results in the pores. This is a highly versatile method which can easily be tuned to give 
membranes with differing properties. Presently, a large fraction of commercial synthetic membranes are made using this method.

\subsection{Membrane transport theory}

In pressure driven processes, permeate transport through the membrane has been described using Darcy's law. The law relates the flux of permeate through the membrane to the transmembrane pressure (driving force) and the resistance to flow.

$$
J=\frac{\Delta P}{\eta * R_{\text {tot }}}
$$

Where $J$ is permeate flux $\left(\mathrm{m}^{3} / \mathrm{m}^{2} . \mathrm{s}\right), \Delta \mathrm{P}$ is transmembrane pressure $(\mathrm{Pa}), \eta$ is liquid viscosity (Pa.s) and $R_{\text {tot }}$ is total resistance $(1 / \mathrm{m})$. Assuming that the resistances are connected in series, one can calculate the total resistance to flow using equation 2 .

$$
R_{\text {tot }}=R_{m}+R_{c}+R_{g}+\ldots
$$

$R_{m}$ is the membrane resistance (clean water resistance), $R_{c}$ is cake resistance and $R_{g}$ is gel resistance. Equation 2 is used in membrane filtration by regarding the membrane system as a black box, thus the membrane characteristics (pore size, porosity and tortuosity) are not explicitly defined.

The pore characteristics of membranes can differ ranging from straight cylindrical pores (track etched membranes) to tortuous pores (phase separated membranes). Two different models have been used in describing the flow through these membranes, namely the Hagen Poisseuille and Kozeny Carman relations. The Hagen Poisseuille relation has been used to describe the flow of liquid through a pipe. Assuming that the membrane has cylindrical pores of similar radius, this can be used to describe the permeate flux through such membranes.

$$
J=\frac{\varepsilon^{*} r^{2}}{8 * \eta * \tau} * \frac{\Delta P}{\Delta x}
$$

\section{Equation 3}


Where $\varepsilon$ is membrane porosity $(-), r$ is pore radius $(m), \tau$ is pore tortuosity $(-)$ and $\Delta \mathrm{x}$ is membrane thickness $(\mathrm{m})$. In equation 3 , the flux is related to the driving force using a proportionality factor incorporating the basic characteristics of the membrane.

Kozeny Carman relation on the other hand has been used to describe the flow of liquid through a packed bed of spheres. This relation describes the flux through a packed bed as being directly related to the pressure drop across the bed as well indirectly proportional to the viscosity of solution flowing through.

$$
J=\frac{\varepsilon^{3}}{K * \eta * S^{2} *(1-\varepsilon)^{2}} * \frac{\Delta P}{\Delta x}
$$

Equation 4

Where $\mathrm{K}$ is the Kozeny Carman constant (-) and $\mathrm{S}$ is the specific surface area $(1 / \mathrm{m})$.

\subsection{Membrane fouling}

a)

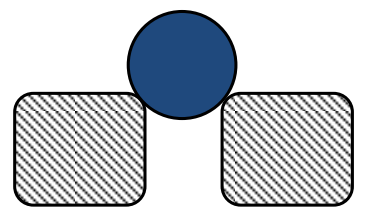

c)

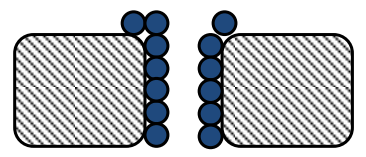

b)

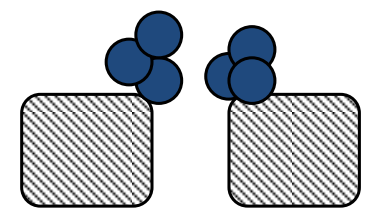

d)

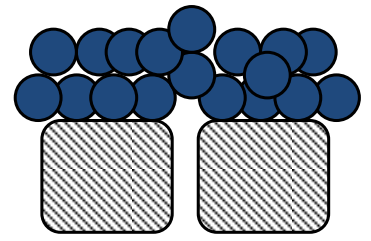

Figure 2. Illustration of particle fouling mechanisms a) Complete pore blockage $\left.\left(d_{p} \geq d_{\text {pore }}\right), b\right)$ and $\left.c\right)$ Incomplete pore blockage or pore narrowing $\left(d_{p}<d_{\text {pore }}\right)$ and $\left.d\right)$ Cake or gel filtration $\left(d_{p} \gg d_{\text {pore }}\right)$

Membrane fouling is one of the biggest challenges facing the membrane community, effectively disrupting the viability of the process [2]. It is a result of the deposition and retention of particles on the membrane thereby increasing the resistance to permeation. Deposition of particles onto and 
into the porous membrane, gel formation and concentration polarization are collectively termed fouling [1,3-4].

Figure 2 shows a schematic of particle deposition mechanisms in membrane filtration. Pore blockage arises when the particulate matter, present in the feed solution, is of the same size as the membrane pores or slightly larger. Pore blockage leads to a dramatic decrease in flux due to the reduction in available pores for permeate passage. Incomplete pore blockage and pore narrowing can occur due to adsorption of particles smaller than the membrane pores. Particles can also deposit on the membrane surface (fig. 2b) partially blocking the membrane pores. Cake filtration occurs due to the existence of a deposit of particles larger than the membrane pores on the membrane surface. These particles are packed together forming an additional barrier to membrane filtration. In the presence of some organic matter (proteins, large molecular weight polymers), this form of fouling is referred to as gel formation due to the gel-like structure of cake formed. Membrane fouling can be distinguished based on the type of deposited matter. Based on this definition, there are colloidal (particles, flocs), biological (bacteria, fungi), organic (oils, polyelectrolytes, humics) and scaling (mineral precipitates) types of fouling.

Membrane fouling can be monitored by indirect techniques such as pressure and flow measurement like the flux step method [5]. Invasive techniques like "autopsies" have also been used in the study of fouling. The need for more direct and yet real time based techniques has led to the development of several visual, non-invasive and direct monitoring tools [6]. Aside from visual techniques, studies are on-going in fouling monitoring using sound waves, NMR imaging and spectroscopic techniques.

\subsection{Visual monitoring of fouling}

High magnification lenses can be attached to cameras and used in monitoring membrane fouling [6]. These images can be taken in real time, are non-invasive and directly give information on membrane fouling. These techniques can be extended using fluorescence to increase contrast and 
confocal imaging to improve the resolution. However, these techniques generally require modifications to the membrane and/or module to enable visualization. Direct visual observation (DVO) has been used in the study of membrane surface during the deposition of foulants. This technique requires a transparent module for visualization. Mores and Davis [7] used this method to observe the deposition of dyed yeast cells onto the surface of membranes and their subsequent removal during backwash. This method suffers from the inability to observe the growth of foulants in time as the optical technique is able to observe only the outer layer on the membrane surface. Wakeman [8] used a modified DVO system that was able to observe cake growth in crossflow microfiltration. For this study, the camera was placed at right angles to the bulk liquid flow and parallel to the membranes enclosed between two glass plates. Using this method, they were able to follow the movement of particles across the membrane while measuring the cake thickness. An adaptation of this technique was used by Marselina et al. [9] in studying membrane fouling. They used a hollow fibre with the feed solution over the exterior surface and collected the permeate inside (outside - in filtration), and observed the deposition characteristics and removal of bentonite particles from the membrane surface.

Direct observation through the membrane (DOTM) is another optical technique which has been used in observing membrane fouling in real time. The method involves the use of specially modified membranes which have straight through pores (typically Anopore (Whatman UK) anodized alumina), which become transparent when wetted. Using this membrane, one can observe particles through the membrane surface from the permeate side [10-12]. Li et al. [10] used this method in observing the deposition characteristics of latex particles below and above the critical flux. The major drawback of this method like DVO is its inability to observe more than one layer of foulants on the membrane surface. Also the membrane pore structure is different from typical commercially applied membranes.

Laser based optical techniques have also been used in real time observation of membrane fouling. Laser triangulometry/reflectometry utilizes laser light 
shone onto the membrane surface while recording the reflected light. With the build-up of a cake on the membrane surface, there is a shift in the angle of reflection which is used to determine the cake thickness. Mendret et al. [13] used laser reflectometry to study the deposition of clay particles onto a membrane surface. They were able to monitor the growth in cake thickness at two positions within the membrane module and correlated this to the resistance data. Altmann and Ripperger [14] used a similar technique to study membrane fouling with diatomaceous earth. They observed at a certain point, a constant cake thickness with increasing cake resistance due to the deposition of smaller particles.

\subsection{Membrane modules - Spiral wound modules}

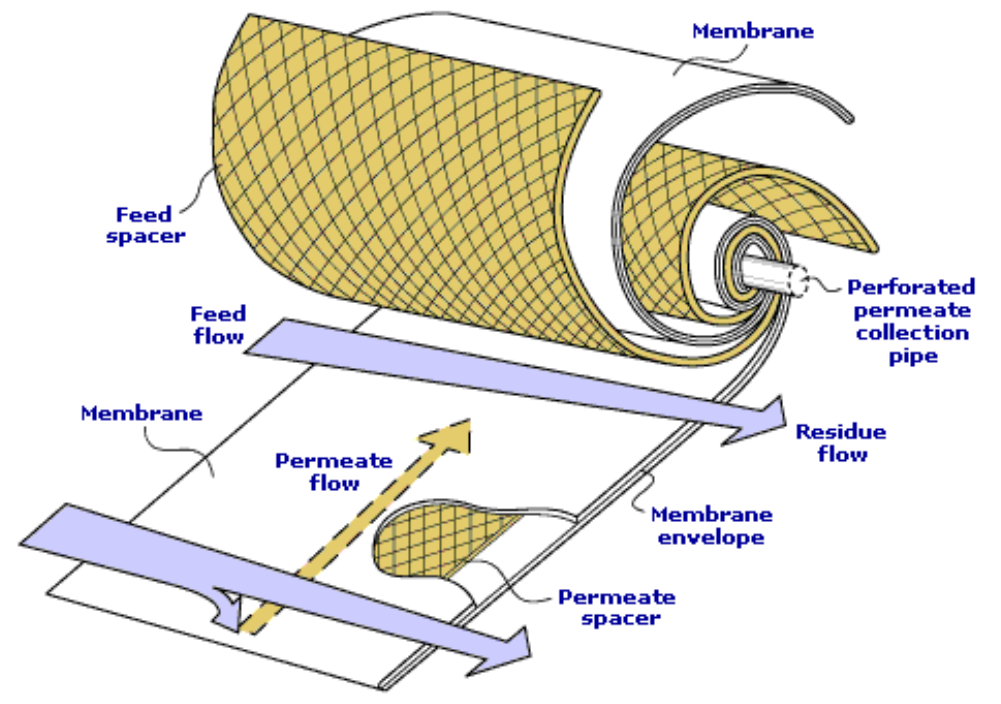

Figure 3. Illustration of spiral wound module showing membrane leaves and spacers (www.mtrinc.com/faq.html)

RO and NF membranes are typically used in the spiral wound module (SWM) configuration. This module consists of a collection of membrane leaves wrapped around a central collection pipe. The membranes are separated by spacers, thus giving a membrane spacer sandwich roll (figure 3). The spacer filled channel heights are typically in the sub millimetre range. Due to the small dimensions in terms of channel height, Reynolds numbers within these modules are relatively low (between 100 and 500) [15]. The feed solutions 

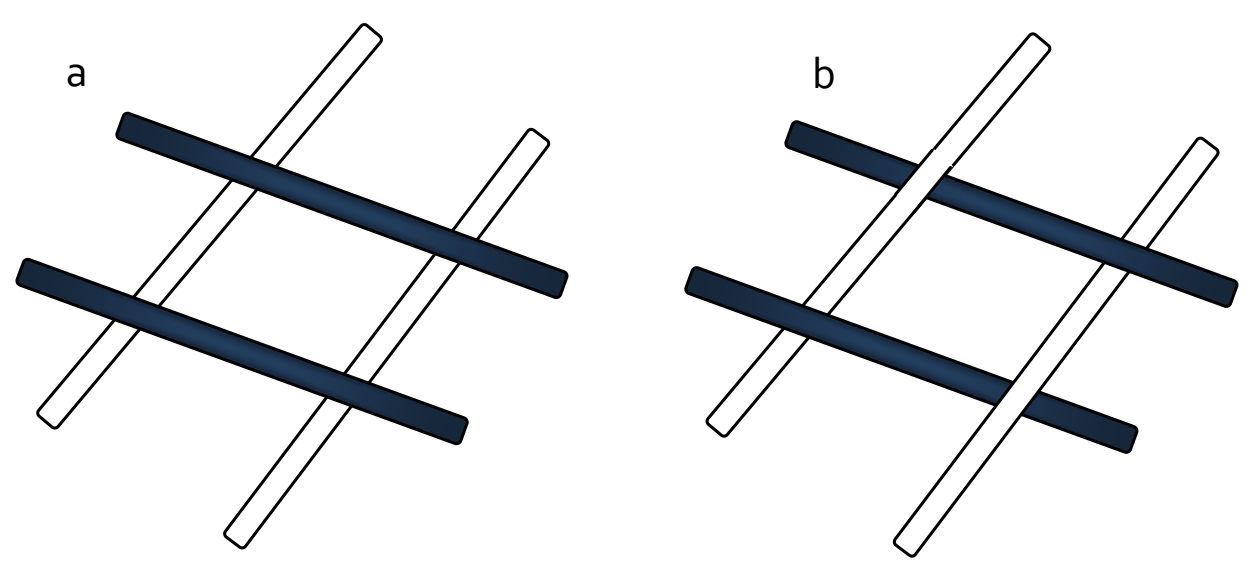

Figure 4. Schematic illustration of types of spacers - a) Non-woven and b) Woven

flow axially across the membrane envelope with a portion (typically $20 \%$ ) of the feed permeating into the envelope and spiralling towards the collection tube. The design of SWM provides a large surface to volume ratio for these modules.

The membrane module market is rapidly growing due to enhancements in efficiencies. A recent study expects the market in membrane filtration to grow from $\$ 8.3$ billion in 2007 to $\$ 11$ billion in 2011 [16]. Segmenting the market by membrane type, the report suggests that RO modules as well as replacement membranes will make up about $45 \%$ of the total sales. The growth in the desalination industry explains the rapid rise seen/expected in the SWM market. Besides this, there has been a significant decrease in price of spiral wound modules in the last decade with continuing improvements in performance.

Spacers are used in SWMs for improving the module structural integrity and enhancing mass transfer. These are net shaped structures which are available in woven and non-woven forms (see figure 4) [15]. Typically, a SWM has two spacers being the feed spacer and permeate spacer. The permeate spacer is thinner and contains smaller spacer cells compared to the feed spacer. The presence of the feed spacer is designed to act as a "turbulence" promoter, but due to the low Reynolds numbers, it is actually 
more like a "shear rate enhancer" due to its ability to promote the formation of wakes and flow disturbances within the channel. These disturbances have been described as being effective in the reduction of concentration polarization and fouling [17]. The presence of spacers within these modules results in larger pressure drops across the channels, which translates to higher running costs. There are also suggestions that spacers could be responsible for biofilm formation with the microbes attaching on them [18].

Several researchers have used computational fluid dynamics studies to simulate the liquid flow around spacers [17, 19-25]. Usually, in 2D, these studies are focused on three different configurations of structures submerged, cavity and zigzag (see fig 5). Subramani et al. studied the influence of these different configurations on the flow profile and pressure drop and compared this to flow in an empty channel [17]. Ahmad et al. studied the influence of spacer geometry on hydrodynamics within a $2 \mathrm{D}$ channel [19]. They simulated the flow around three different shapes (square, triangular and circular objects) in cavity orientation (figure 5 a) and observed that the triangular object gave the best performance in terms of reduction of concentration polarization. However, this also results in the highest pressure drop.

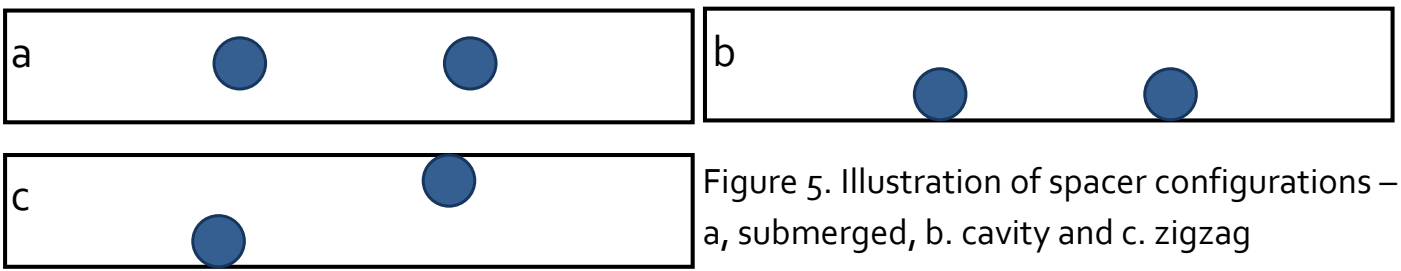

\subsection{Microfluidics and structured membranes}

Microfluidics refers to the field of study dealing with the manipulation of flows in small (sub millimetre) length scales. Due to the small dimensions used, the fluid flows are most often in the laminar regime. Today, many applications make use of microfluidic devices including flow sensors, pressure regulators, capillaries, ink cartridges, chemical and biological sensors and complete lab on a chip devices. These devices offer many advantages like small reagent volumes, shortened reaction times, 
portability, low power requirement, ease of parallelization etc. SWM resemble microfluidic devices in terms of large surface to volume ratio and sub millimetre flow channel dimensions which results in low Reynolds numbers.

Development of the modern field of microfluidics was observed in the 1990's. During this period the work of Manz came to the fore [26-27]. They coined the concept of miniaturized total analysis system, the foundation for the present day "lab on a chip" devices. Presently, such devices are incorporated into processes, including environmental monitoring, point-ofcare diagnostics and drug screening processes. In 1995, Ramsey founded the first (and currently one of the biggest) company in microfluidics - Caliper Life Sciences. Currently, several companies operate within the field of microfluidics. Giant strides have been made in the development of microfluidics in terms of miniaturization and management of miniaturized flows.

Usually, microfluidic devices are made in silicon, glass or polymers. Microfluidic devices can be fabricated either by direct or indirect methods. Direct fabrication methods like photolithography and etching are used for glass and silicon while the indirect methods are preferred for the "softer" materials - polymers. Replication methods can be used for polymeric materials like PDMS (polydimethylsiloxane) and PMMA (polymethylmethacrylate). Hot embossing techniques can be used in imprinting desired structures onto the surface of PMMA slabs. Curing PDMS results in replication of the mould structure in the polymer. PDMS is a widely used elastomer in microfluidic applications due to its properties transparent, easily moulded, cheap and elastic. Direct methods are typically time consuming and expensive and this increased the potentials of indirect methods. The indirect methods are able to utilize the accuracy of photolithography and yet reduce the overall cost of preparing the structures. 
Phase separation micromolding (PS $\mu \mathrm{M})$ is a replication technique based on membrane fabrication [28-29]. Initially, negatives of the desired structures are etched into silicon wafers using photolithographic techniques. A replica of the structure is fabricated by a phase separation process of polymer solutions in contact with the structures (figure 6 ). The polymer solution is cast on the structured mould, which is placed in a non-solvent bath and due to an exchange between the solvent and non-solvent, the polymer solution solidifies into a membrane which can be removed from the mould.

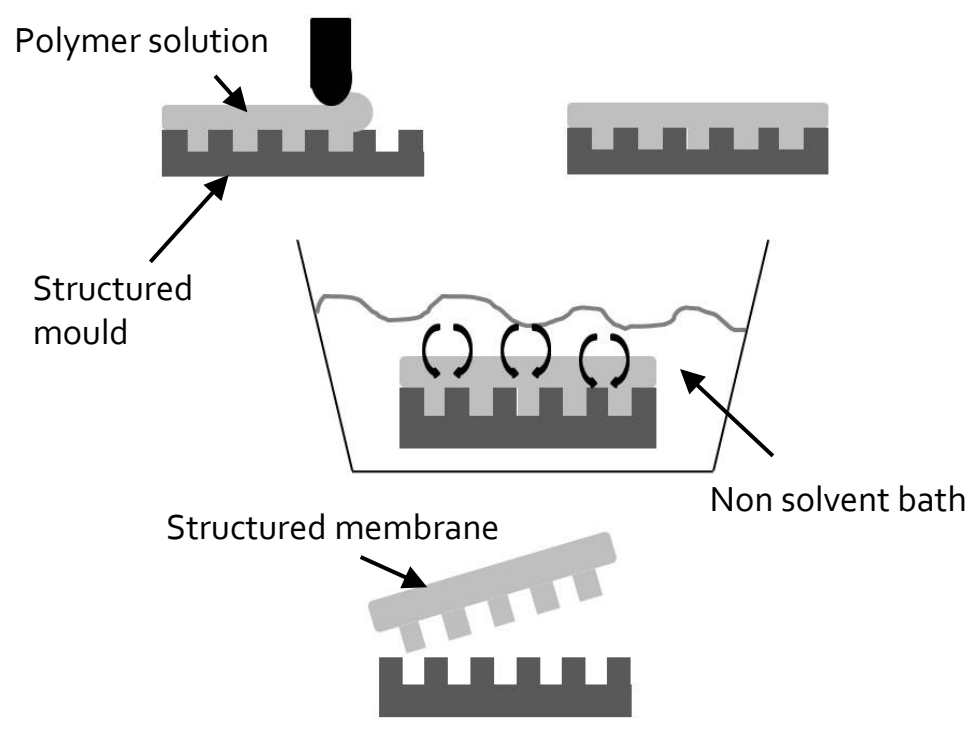

Figure 6. Illustration of fabrication method for PS $\mu \mathrm{M}$ 
Figure 7 shows some examples of structured membranes prepared using this method. $\mathrm{PS} \mu \mathrm{M}$ is a versatile technique for the fabrication of microfluidic devices. Using this technique, the desired structures are well replicated and the properties of the membrane can be easily tuned. The ability to tune membrane properties can lead to the fabrication of devices with different properties. The inherent porosity of the membranes produced using this technique can further enhance the performance of the device.
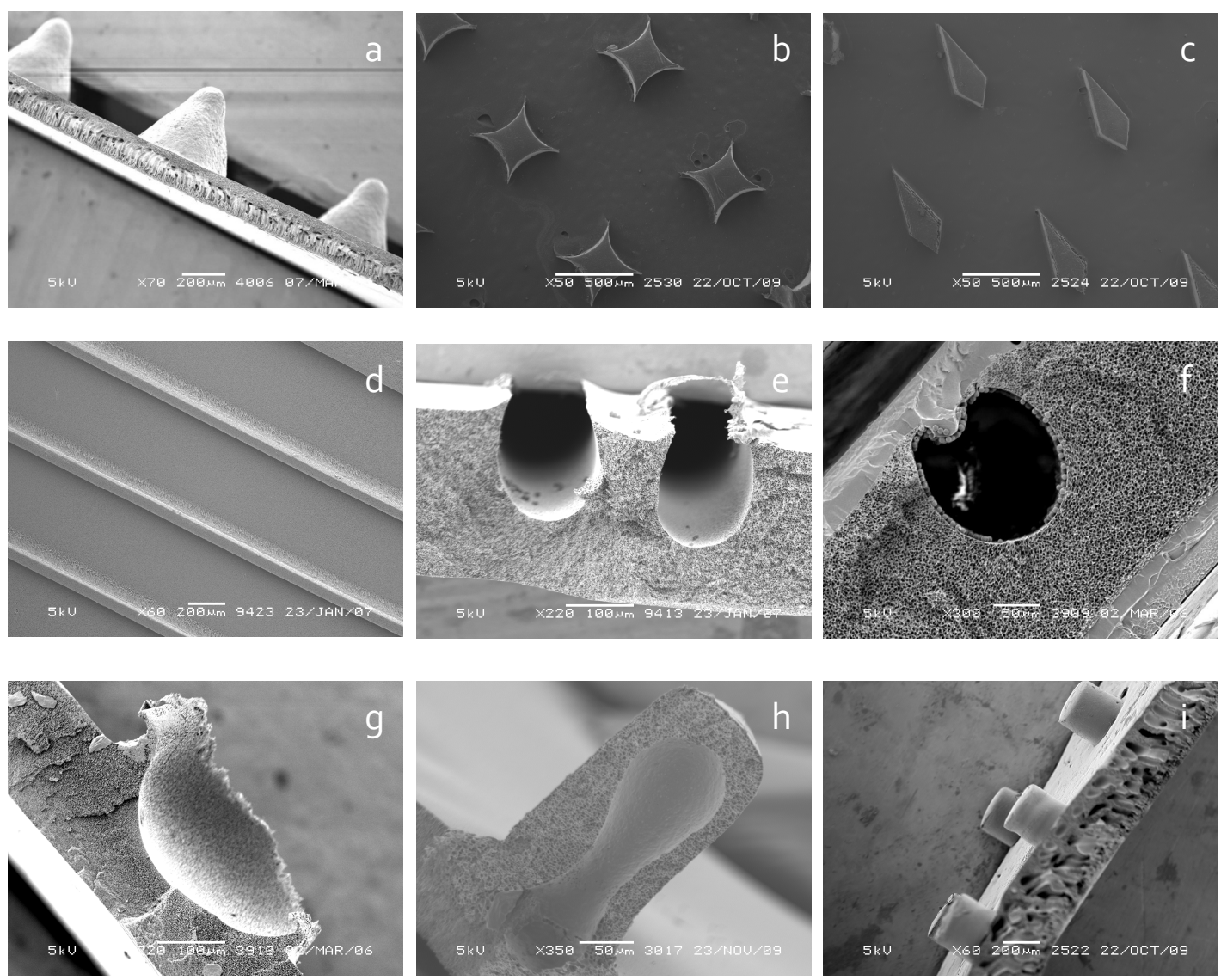

Figure 7. SEM images showing structured membranes made by PS $\mu M$ (a. structured membranes from powder blasted mould, b and c. star and kite shaped structured membranes, $d$. lined structured membranes, e and f. channelled membranes with semicircular structures, $g$. as a. but with incomplete mould filling, h. cross section of kite structured membrane and i. circular structured membranes. 


\subsection{Project aim and overview of thesis}

The motivation for this project is the study of membrane fouling using microfluidic systems. The project aims to visually characterize membrane fouling by using PS $\mu \mathrm{M}$ to fabricate a device and coupling this to a direct visual observation technique. The use of scaled down membrane modules is expected to improve the resolution of fouling visualization.

Chapter two describes the setup used in real time characterization of membrane fouling. PS $\mu \mathrm{M}$ is used for preparing embedded square shaped channelled membranes, with subsequent characterization of the membrane using SEM images and clean water flux determination of membrane resistance. Afterwards, a model feed containing $6 \mu \mathrm{m}$ polystyrene particles in solution is used to foul the membrane with monitoring of the global and local fouling.

In chapter three, we characterize fouling of a bidisperse particle solution at different compositions. For these experiments, a model feed solution containing polystyrene particles with two different sizes $(3.3$ and $5.7 \mu \mathrm{m})$ was studied. We determine the properties of the cake formed. Using the cake resistance information obtained from these results, we compare the results to a simulated cake resistance using the Kozeny Carman relation.

Membranes with integrated structures to mimic the nodes of net shaped spaces were studied in chapter four. These membranes are subsequently (bio)fouled to observe the regions of biofilm formation and compared to a computational hydrodynamic study of the flow around these structures.

A novel cleaning protocol is described in chapter five. Membrane/spacer channels are (bio)fouled and cleaned using three different methods. One cell is cleaned using water rinsing (forward flush), the second using nitrogen/water sparging and the third is cleaned using $\mathrm{CO}_{2}$ /water nucleation. 
The entire work opens up avenues for further research and this is discussed in chapter six alongside general conclusions drawn from the work. This chapter contains personal views and recommendations for further research. 


\section{References}

(1) Mulder, M. Basic principles of membrane technology. 1991,

(2) Belfort, G., Davis, R. H., and Zydney, A. L. The behavior of suspensions and macromolecular solutions in crossflow microfiltration. Journal of Membrane Science, 1994, 96 (1-2), 1.

(3) Song, L. and Elimelech, M. Particle Deposition onto a Permeable Surface in Laminar Flow. Journal of Colloid and Interface Science, 1995, 173 (1), 165.

(4) Chellam, S. and Wiesner, M. R. Particle transport in clean membrane filters in laminar flow. Environmental Science and Technology, 1992, 26 (8), $1611-1621$.

(5) van de Ven, W. J. C., Sant, K. V., Punt, I. G. M., Zwijnenburg, A., Kemperman, A. J. B., van der Meer, W. G. J., and Wessling, M. Hollow fiber dead-end ultrafiltration: Influence of ionic environment on filtration of alginates. Journal of Membrane Science, 2008, 308 (1-2), 218-229.

(6) Chen, V., Li, H., and Fane, A. G. Non-invasive observation of synthetic membrane processes - A review of methods. Journal of Membrane Science, 2004, 241 (1), 23-44.

(7) Mores, W. D. and Davis, R. H. Direct visual observation of yeast deposition and removal during microfiltration. Journal of Membrane Science, 2001, 189 (2), 217-230.

(8) Wakeman, R. J. Visualisation of cake formation in crossflow microfiltration. Chemical Engineering Research and Design, 1994, $72\left(\mathrm{~A}_{4}\right)$, 530-540.

(9) Marselina, Y., Le-Clech, P., Stuetz, R., and Chen, V. Detailed characterisation of fouling deposition and removal on a hollow fibre membrane by direct observation technique. Desalination, 2008, 231 (1-3), 311. 
(10) Li, H., Fane, A. G., Coster, H. G. L., and Vigneswaran, S. Direct observation of particle deposition on the membrane surface during crossflow microfiltration. Journal of Membrane Science, 1998, 149 (1), 83.

(11) Li, H., Fane, A. G., Coster, H. G. L., and Vigneswaran, S. Observation of deposition and removal behaviour of submicron bacteria on the membrane surface during crossflow microfiltration. Journal of Membrane Science, 2003, $217(1-2), 29-41$.

(12) Li, H., Fane, A. G., Coster, H. G. L., and Vigneswaran, S. An assessment of depolarisation models of crossflow microfiltration by direct observation through the membrane. Journal of Membrane Science, 2000, 172 (1-2), 135147.

(13) Mendret, J., Guigui, C., Schmitz, P., Cabassud, C., and Duru, P. An optical method for in situ characterization of fouling during filtration. AIChE Journal, 2007, 53 (9), 2265-2274.

(14) Altmann, J. and Ripperger, S. Particle deposition and layer formation at the crossflow microfiltration. Journal of Membrane Science, 1997, 124 (1), 119-128.

(15) Li, F., Meindersma, W., De Haan, A. B., and Reith, T. Optimization of commercial net spacers in spiral wound membrane modules. Journal of Membrane Science, 2002, 208 (1-2), 289-302.

(16) Solid growth forecast for filtration membranes. Membrane Technology, 2007, $2007(5), 3-4$.

(17) Subramani, A., Kim, S., and Hoek, E. M. V. Pressure, flow, and concentration profiles in open and spacer-filled membrane channels. Journal of Membrane Science, 2006, 277 (1-2), 7-17.

(18) Vrouwenvelder, J. S., Graf von der Schulenburg, D. A., Kruithof, J. C., Johns, M. L., and van Loosdrecht, M. C. M. Biofouling of spiral-wound nanofiltration and reverse osmosis membranes: $A$ feed spacer problem. Water Research, 2009, 43 (3), 583-594. 
(19) Ahmad, A. L., Lau, K. K., and Abu Bakar, M. Z. Impact of different spacer filament geometries on concentration polarization control in narrow membrane channel. Journal of Membrane Science, 2005, 262 (1-2), 138-152.

(20) Koutsou, C. P., Yiantsios, S. G., and Karabelas, A. J. Numerical simulation of the flow in a plane-channel containing a periodic array of cylindrical turbulence promoters. Journal of Membrane Science, 2004, 231 (12), 81-90.

(21) Cao, Z., Wiley, D. E., and Fane, A. G. CFD simulations of net-type turbulence promoters in a narrow channel. Journal of Membrane Science, 2001, 185 (2), 157-176.

(22) Lau, K. K., Abu Bakar, M. Z., Ahmad, A. L., and Murugesan, T. Feed spacer mesh angle: $3 \mathrm{D}$ modeling, simulation and optimization based on unsteady hydrodynamic in spiral wound membrane channel. Journal of Membrane Science, 2009, 343 (1-2), 16-33.

(23) Shakaib, M., Hasani, S. M. F., and Mahmood, M. CFD modeling for flow and mass transfer in spacer-obstructed membrane feed channels. Journal of Membrane Science, 2009, 326 (2), 270-284.

(24) Li, Y. L. and Tung, K. L. CFD simulation of fluid flow through spacerfilled membrane module: selecting suitable cell types for periodic boundary conditions. Desalination, 2008, 233 (1-3), 351-358.

(25) Picioreanu, C., Vrouwenvelder, J. S., and van Loosdrecht, M. C. M. Three-dimensional modeling of biofouling and fluid dynamics in feed spacer channels of membrane devices. Journal of Membrane Science, (26) Verpoorte, E., Manz, A., LÃ¹/4di, H., Bruno, A. E., Maystre, F., Krattiger, B., Widmer, H. M., van der Schoot, B. H., and de Rooij, N. F. A silicon flow cell for optical detection in miniaturized total chemical analysis systems. Sensors and Actuators: B. Chemical, 1992, 6 (1-3), 66-70.

(27) Manz, A., Graber, N., and Widmer, H. M. Miniaturized total chemical analysis systems: A novel concept for chemical sensing. Sensors and Actuators: B. Chemical, 1990, 1 (1-6), 244-248. 
(28) Vogelaar, L., Lammertink, R. G. H., Barsema, J. N., Nijdam, W., BolhuisVersteeg, L. A. M., Van Rijn, C. J. M., and Wessling, M. Phase separation micromolding: A new generic approach for microstructuring various materials. Small, 2005, 1 (6), 645-655.

(29) Vogelaar, L., Barsema, J. N., Van Rijn, C. J. M., Nijdam, W., and Wessling, M. Phase Separation Micromolding - PS?M. Advanced Materials, 2003, 15 (16), 1385-1389. 


\section{Chapter 2. A Microfluidic Membrane Chip For In Situ Fouling Characterization}

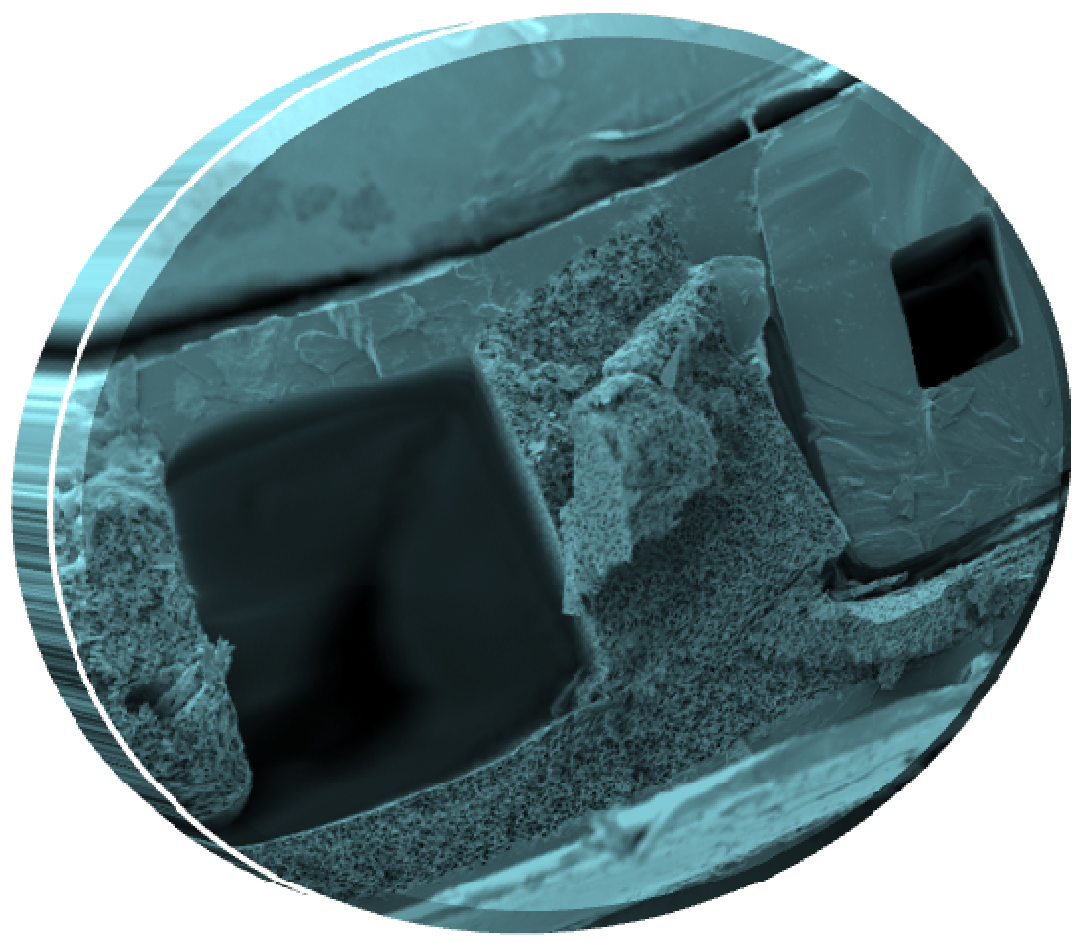

This work has been published as Ngene, I.S., et al., A microfluidic membrane chip for in situ fouling characterization. Journal of Membrane Science, 2010. 346(1): p. 202-207

$$
P \text { a g e } \mid \mathbf{2 0}
$$




\section{Introduction}

The commercial viability of membrane applications is hampered by the flux decline observed during the process. This flux decline is a result of several phenomena, which occur at the surface of and inside the membrane. In microfiltration, particle retention on the surface of the membrane causes an increase in resistance. The deposition of particles on the membrane surface is termed fouling $[1],[2]$. Due to the increase in resistance, it is necessary to "clean" the membrane, to recover the initial flux. Typically, cleaning can be done by (back)washing the cake off the membrane surface in case of reversible fouling and with the use of chemical agents in case of irreversible fouling.

Microfiltration is a pressure driven membrane process where suspended particles of approximate size ranges 0.1 to $20 \mu \mathrm{m}$ are retained by a membrane. The typical pore size of membranes used is between 0.05 and 10 $\mu \mathrm{m}$. There is a high permeate flux associated with the process due to the low resistance of the membranes (a result of high porosity and large pore size). Due to the high flux, there is an increased rate of particle deposition on the surface. This class of membrane filtration is typically operated in cross-flow whereby the liquid feed flow is tangential to the surface of the membrane. In cross-flow filtration, the cake growth due to convection of particles results in a constriction of the channel, thus increasing the shear rate on the cake surface [3]. Due to the high velocities, the shear mediated transport back to the bulk of the feed dominates, resulting in a lower cake thickness on the surface.

The study of fouling phenomena in membrane filtration is usually restricted to non-invasive or post experimental techniques such as monitoring pressure, concentration, fluxes and even "autopsies" of the modules. This restriction is due to the difficulty in observing the surface of a membrane during a filtration process. There is however a need to directly study the surface of the membrane in real time as this increases the understanding of the complex phenomena which result in flux decline in the process. This necessity has 
given rise to a number of optical methods which are now adapted for use in monitoring fouling online [4].

Altmann and Ripperger [5], experimented on the use of laser triangulometry to monitor the build-up of a cake on the surface of the membrane. They were able to measure in situ the deposition of diatomaceous earth and silica particles on the membrane using this method. Laser refractometry is another method that has been used to monitor the particle build-up on the membrane surface. This technique measures the deflections from the original path of a laser beam which is applied to the surface of the membrane [6]. A similar method has been described by Mendret et al. [7], where a laser sheet was used to illuminate the surface of a membrane. Mendret et al. were able to measure the local thickness of the clay deposited on the membrane, determine the change in the angle of reflection and relate the change to the thickness of a cake on the membrane surface. The major drawback is the relative high cost and low resolution associated with the method.

Direct visualization of the surface of the membrane has also been studied and used to monitor the build-up of a fouling layer. Direct observation through the membrane (DOTM) is such a method. DOTM employs the use of a microscope objective lens placed on the permeate side of the membrane module. (It is necessary to use special membranes for these applications). When these membranes are wetted, they become transparent and enable monitoring of the deposition of particles on the membrane surface. Li et al. [8-9] used high porosity membranes from Anopore (Whatman, UK) to observe the deposition of latex particles on the membrane during operation. They observed the deposition characteristics of these particles at fluxes below and above the critical flux measured for the system. They have also used fluorescent labelling to improve the contrast and thus the quality of images obtained with this method. The drawback of this system is the requirement of a specialized membrane that differs from the commercially used membranes, hence reducing comparability. Another restriction of the system is that only one monolayer of particles on the surface of the membrane is enough to block the view. This restriction implies that the exact cake thickness cannot be quantified using this approach. 
Direct visualization on the membrane (DVO) is another optical method used to examine the surface of the membrane in real time. The deposition and removal characteristics of particles on the surface of the membrane can be followed in real time using this method. The observation is carried out by the use of a transparent window on the feed side of the membrane module, with a microscope objective. Unlike DOTM, DVO does not require a special membrane. Mores and Davis [10] observed the deposition and removal properties of Saccharomyces cerevisiae on the surface of membranes using this method. However, the method still retains the drawback that only the top layer of foulants on the surface of the membrane can be observed. This method is restricted to flat membranes and is thereby not able to observe the fouling of membrane fibres because of the inability to look through the fibres.

Wakeman [11] experimented with a version of DVO whereby he studied the thickness of the cake layer on the surface of a membrane in cross-flow microfiltration. They placed the membrane in between two optical quality glass plates, with the camera at right angles to the bulk flow. The high speed camera was placed parallel to the membrane to enable observation of the thickness of the cake layer. A solution of particles was fed across the surface of the membrane and the resulting cake thickness was measured. However, due to the wide area of investigation, they had to make images of different parts over the surface of the membrane to observe the cake thickness along the length of the membrane.

The focus of this paper is to present a new method that can be used to monitor the build-up of foulants on the surface of the membrane in real time. The technique is able to monitor the cake thickness in real time by observing the side of the membrane during filtration. A laboratory - scale setup with direct visualization was made to observe polystyrene particles across the surface of the membrane in real time. Polyetherimide microfiltration membranes with embedded channels were used in the setup. The method can easily be adapted to any synthetic membrane, only requiring the replication of the channel structures into the membrane. The fact that we look at the filtration unit from the side ensures that the thickness of the fouling layer can be determined. The permeation characteristics of the 
embedded channel membrane used in the experiment also compares favourably with a flat sheet membrane.

This paper presents details of the fabrication of a microfluidic membrane chip. A particle tracking method is used to characterize the velocity gradient inside the field channel. 


\section{Materials and methods}

\subsection{Materials}

For the membrane fabrication, the polymers - polyetherimide (PEI, Ultem 1000), polyvinylpyrrolidone (PVP, K90 $360000 \mathrm{~g} / \mathrm{mol}$, Fluka) were used without further purification. N-methylpyrrolidone (NMP, Acros Organics) was used as a solvent for the membrane preparation. Square shaped fused silica capillaries with external sides $300 \mu \mathrm{m}$ and internal sides $100 \mu \mathrm{m}$ (Polymicro, USA) were used for templating of the membranes and for feeding the channels. Polystyrene particles with diameter of $6 \mu \mathrm{m}$ (Polysciences) dispersed in Millipore water was used as a model feed. Lamination sheets (Acco Brands Europe, UK) were used for sealing the membranes.

\subsection{Methods}

\subsubsection{Flat sheet membranes}

For the preparation of flat sheet membranes, a $0.7 \mathrm{~mm}$ steel roller casting knife of was used. A solution of PEI/PVP/NMP (19/11/70 w/w) was cast on a clean glass plate at room temperature.

\subsubsection{Structured membranes}

To prepare the embedded channel membrane, square silica capillaries (Polymicro, USA) with their polyimide coating burnt off were glued to a glass plate with double sided tape (Tesa ${ }^{\circledR}$ ). Afterwards, a solution of PEI/PVP/NMP $(19 / 11 / 70 \mathrm{w} / \mathrm{w})$ was cast on the glass plate at room temperature with a $0.7 \mathrm{~mm}$ steel roller casting knife see Figure 1 (step 2).

Substrates with cast solutions were immediately placed in a vapour bath with a continuous flow of $\mathrm{N}_{2}$ saturated with water vapour (VIPS) for 1 minute. After the vapour stage, they are transferred to a tap water bath at room temperature for complete coagulation and phase separation. Upon phase separation, the membrane is released from the glass plate due to shrinkage. The membrane formed is now left in the water bath - while refreshing the 
water - for one day to completely remove the solvent Figure 1 (step 3). Afterwards, it is placed in a solution of water and sodium oxochlorate (4000 $\mathrm{ppm}$ ) for 48 hours to remove the PVP. The membranes were finally rinsed with Millipore ${ }^{\circledR}$ water to remove the $\mathrm{NaOCl}$. After the rinsing step, the membrane is dried by placing it between two sheets of tissue paper, with a weight placed on it initially to prevent the membrane from curving.

\subsubsection{Chip preparation/Setup}

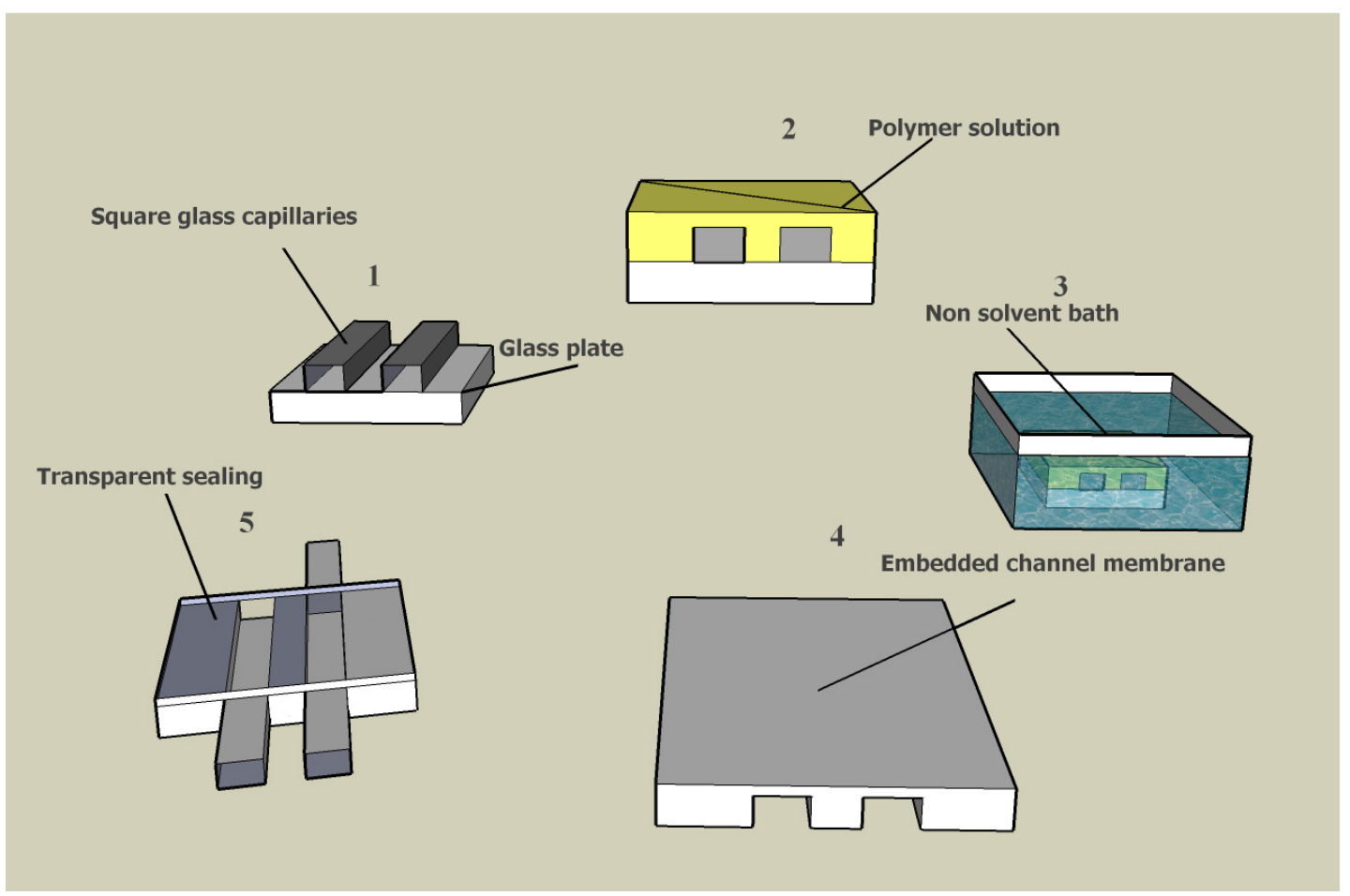

Figure 1. Illustration of templating method for fabrication of embedded channels in a membrane

The fused silica capillary (without the polyimide coating) is placed in the channels of the structured membrane. Due to the minimal shrinkage in the lateral direction, the glass capillaries fit snugly into the channels. The membrane with the capillaries is placed between two lamination sheets (Figure 1). This is heated to seal the chip. The chip is connected to a pressurized mixing vessel using Upchurch ${ }^{\circledR}$ connectors. In between, a mass flow controller (Bronkhorst, The Netherlands) is attached to regulate the feed flow and two mass flow meters (Bronkhorst, The Netherlands) are attached to the retentate and permeate streams. A shut off valve is placed at the 
retentate channel to enable switching from cross flow to dead end filtration (see Figure 2). The feed pressure difference was monitored with a pressure sensor placed after the mass flow controller. For visualization of the channels during the filtration, a camera (Pixelfly VGA, PCO AG, Germany) attached to magnifying lenses was used (Optem Zoom ${ }_{125} C$, Quioptiq, USA). This was all connected to a computer for controlling and monitoring. Single frame images are made every minute, and after 50 minutes, 4 second movies were recorded at 25 frames per second (fps).

The 4 second movies were used to determine the particle velocity vectors and trajectories as is seen in Figure 6 . Image J (freeware) was used to subtract the background of the image stack obtained from the camera. This was done by duplicating the image stack, deleting the first frame from one and the last frame from the other. Afterwards, the stacks were subtracted from one another thus eliminating solitary objects. The movement of the particles was tracked using a MATLAB script file to obtain the velocity vectors as shown in Figure 6 . Tracking of the particles was done using an adapted method as described by Schaertl and Sillescu [12]. The application of this method is due to the relatively low number of particles tracked per frame in comparison to particle image velocitmetry.

\subsubsection{Analysis and characterization}

The morphology of the membranes was observed using SEM (JEOL 5600) at $5 \mathrm{kV}$. The membranes were sputtered with a thin layer of gold to improve conductivity.

Pure water flux measurements for the flat sheet membranes were carried out using Millipore water in stirred dead end units (Amicon). Initially, the setup is run for 45 minutes to ensure complete saturation of the chip with water. Thereafter, clean water fluxes are obtained via multiple pressure measurements with differing liquid flows. 


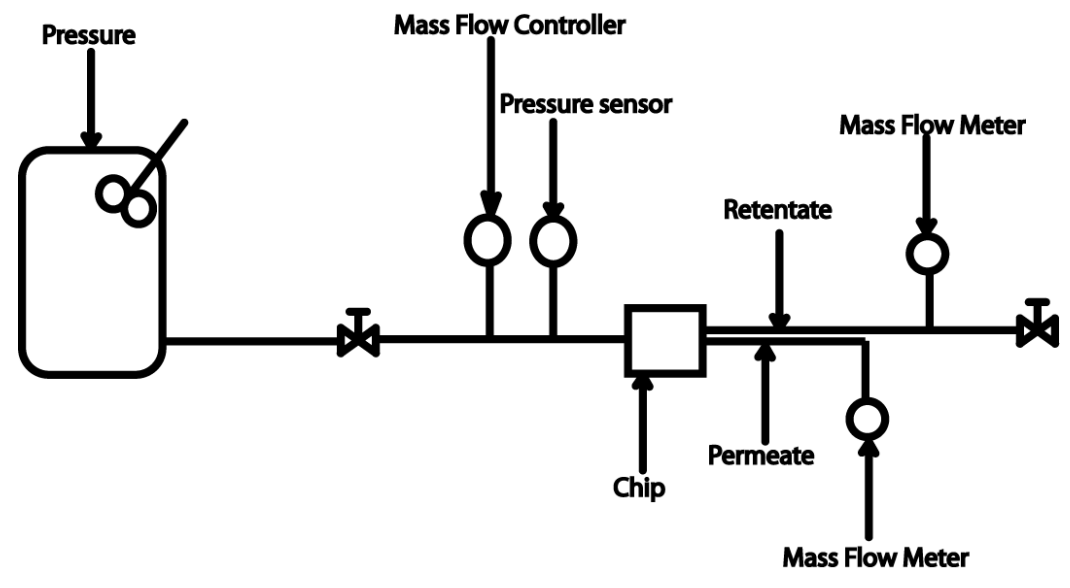

Figure 2. Microfluidic filtration setup 


\section{Results and Discussions}

\subsection{Templating}

The membrane with embedded channels shrinks during phase separation. This ensures that it lifts off the substrate easily. Figure za shows the channelled membrane obtained from the templating method.

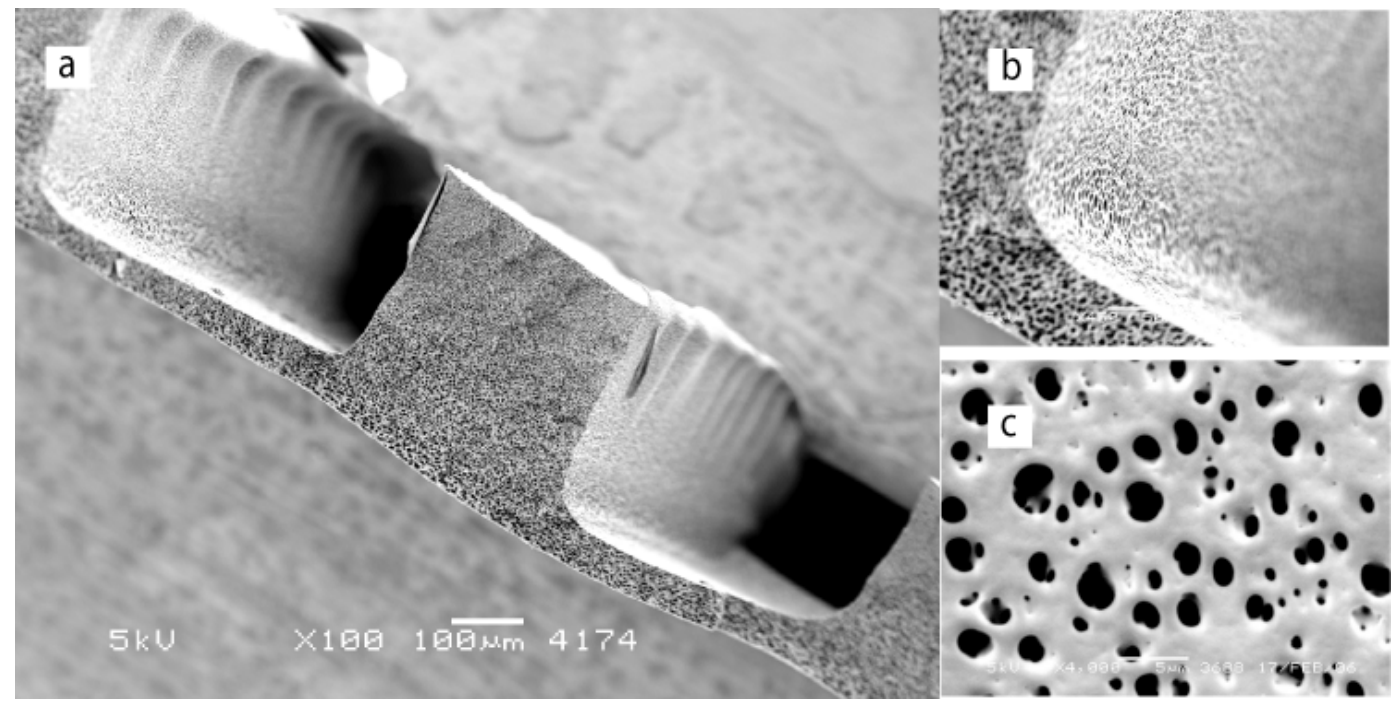

Figure 3. (a) Cross section of channelled membrane showing channels and active membrane, (b) cross section showing uniformity of pore distribution and (c) Surface of

Figure $3 \mathrm{~b}$ shows a close up of the corner between the active membrane and the channel bottom and Figure $3 c$ shows the surface of the membrane with similar pore characteristics as the cross section. This method yields a membrane that replicates the structures placed on the substrate [13-14], which in this case are square shaped capillaries. This gives a micro-structured membrane containing two rectangular grooves which can be used as feed and permeate channels. In Figure 3a, the grooves formed by the glass capillaries are separated by a thin wall, which is hereby referred to as the active membrane. By covering the top of the grooves with a transparent sheet, we obtain two closed channels separated by an active membrane. The active membrane allows for permeation from one channel to the other, which in turn allows direct observation of the filtration process through the transparent cover sheet. 
Prior to the fouling experiments, it is necessary to saturate the membrane chip with water, (to ensure that the permeation is only through the active membrane). A flat sheet membrane was also prepared using the same polymer recipe but cast without any structures. This was done for comparison with the channelled membrane. For the applied method, it is necessary that the characteristics of both membranes are similar to ensure that the filtration process mimics a flat sheet filtration. The observed pore distribution across the membrane was uniform, thus giving a symmetric membrane with comparable porosities as seen in Figure $3 \mathrm{~b}$. It was also observed that the surface of the channels have similar characteristics as the surface of the flat sheet membrane. The membranes are observed to have average pore sizes of 3-8 $\mu \mathrm{m}$. There is however, the possibility to tune the pore sizes during the phase separation process [15], which alters the membrane type, depending on the study requirement. This ensures that the method can be used to study morphologically different membrane systems with the only requirement being the need for a synthetic membrane (homemade).

\subsection{Sealing}

For the observation process, it is important that the material used to seal the membrane chip is transparent and yet provides adequate sealing to ensure that the liquid permeates from one channel to the next through the active membrane and not between the seal and membrane. Here, we used lamination sheets (Acco Brands Europe, UK) in covering the grooves, and forming the filtration chip. The channels are fed using the same capillaries as were used in casting the membrane. The capillaries are inserted into the channels prior to sealing and enclosed in the chip. The feed and retentate capillary tubing are placed such that the distance available for filtration is ca. $2 \mathrm{~mm}$, which ensures that almost the entire channel can be visually observed (Figure 4). The capillaries are connected to the mass flow controller/meters using Upchurch One-Piece 6-32 PEEK $^{\text {TM }}$ MicroTight ${ }^{\circledR}$ Fittings. The pressure sensor is connected to the line using Upchurch Tee adapters. A shut off valve is placed on the retentate to select between cross-flow and dead end filtration. 


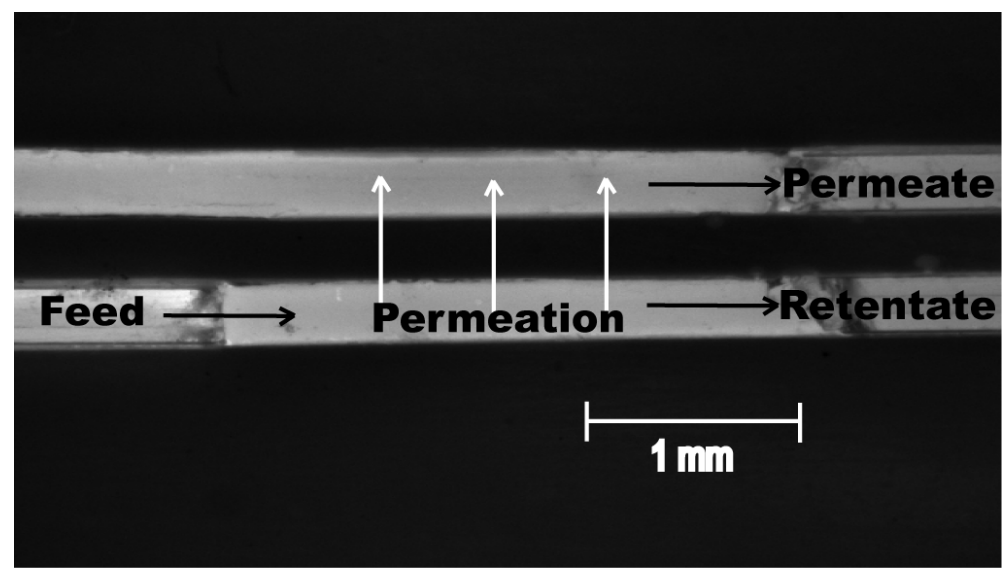

Figure 4. Chip showing channels, flow directions and active membrane

\subsection{Pure water flux}

Considering the fact that the embedded channel membrane is to be used as a flat sheet membrane chip, we compared the pure water flux through the chip to that through a flat sheet membrane. Two microlfuidic membrane chips were compared to flat sheet membranes operated in a dead end cell (Amicon cell). The results showed high comparability and yields high pure water fluxes of $36 \mathrm{~m}^{3} /\left(\mathrm{m}^{2} \mathrm{~h}\right.$ bar) through the membranes (Figure 5) with a membrane thickness of ca. $200 \mu \mathrm{m}$. The high pure water flux observed with the membranes is due to the membrane porosity and pore size which gives an overall low membrane resistance.

The local feed pressure was obtained from the pressure sensor, after correcting for the pressure loss in the capillary between the sensor and membrane channel. Hagen-Poiseuille equation (Equation 1) was used to approximate the pressure drop inside the channels [16].

$$
\Delta P=\frac{8 * \Phi v * \eta * L}{\pi * r^{4}}
$$

Equation 1

The measured pressure $\mathrm{P}(\mathrm{Pa})$ is in this way related to the liquid flow rate into the channel $\Phi v\left(\mathrm{~m}^{3} / \mathrm{s}\right)$, the liquid viscosity $\eta(\mathrm{Pa} . \mathrm{s})$, the length of capillary $\mathrm{L}$ $(\mathrm{m})$ and the hydraulic radius of the capillary $r(\mathrm{~m})$. To obtain the hydraulic 
radius of the capillary tubing, the pressure drop across tubes of varying lengths which were open to the atmosphere were determined. The pressure downstream of the permeate channel is atmospheric and this is used to calculate the pressure at the permeate side.

The pure water experiment was used to determine the resistance of the membrane according to Darcy's law (Equation 2) assuming that the cake resistance $R_{c}$ is zero. This gives the membrane resistance $R_{m}$ which for this case is $1.01 * 10^{10}(1 / \mathrm{m})$.

$J=\frac{\Delta P}{\eta *\left(R_{m}+R_{c}\right)}$

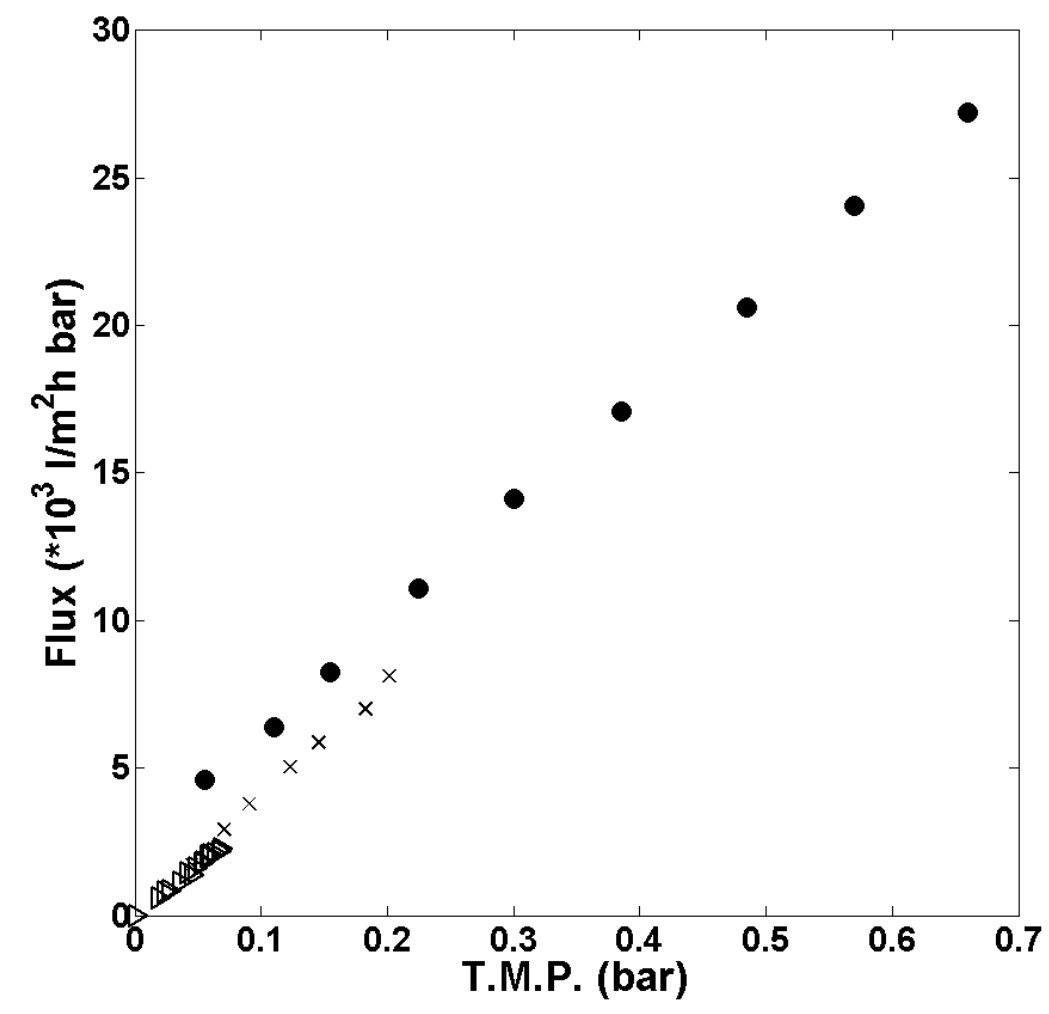

Figure 5. Pure water flux experiment $(\bullet$ Amicon cell, $\Delta$ Microfluidic chip 1, x Microfluidic chip 2) 
The results show that the characteristics of both the flat sheet and embedded channel membrane are comparable. This ensures that the membrane with channels can be effectively used to study membrane fouling. It also shows the reproducibility of the fabrication process.

\subsection{Liquid velocity gradient}

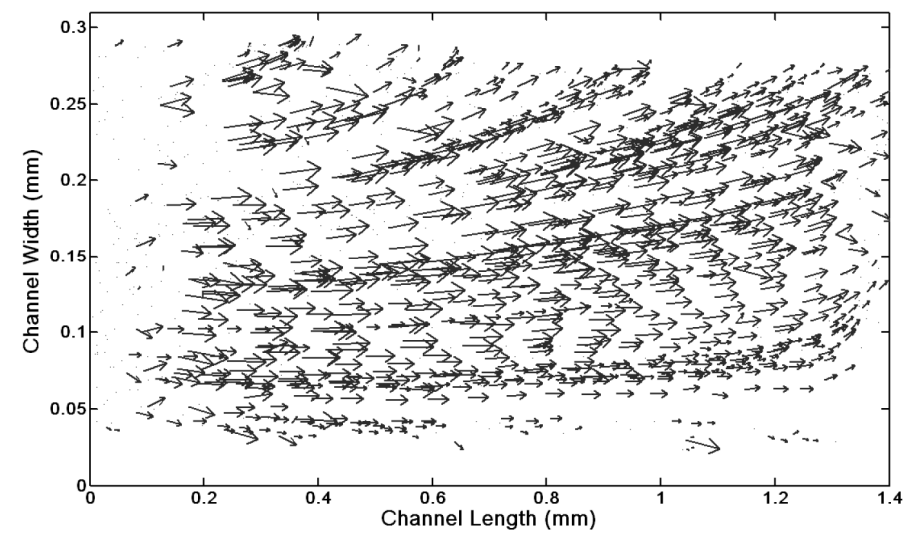

Figure 6. Particle trajectories in the feed channel

To characterize the liquid velocity gradients in the feed channel of the microfluidic membrane chip, $6 \mu \mathrm{m}$ polystyrene particles were suspended in Millipore water at a concentration of $13.45 \mathrm{mg} / \mathrm{L}$. The suspension was placed in an ultrasonic bath for 20 minutes to fully disperse the particles. The suspension was subsequently placed in the feed vessel, which is continuously stirred to reduce settling, and was connected to the pre-saturated chip. The feed flow rate was kept constant at $19 \mu \mathrm{l} / \mathrm{min}$ which translates to an average cross-flow velocity of $3.5 \mathrm{~mm} / \mathrm{s}$ within the channel. The filtration was carried out in dead end mode. The pressure was monitored constantly during the experiment with the initial TMP measured at $8050 \mathrm{~Pa}$. Images were recorded simultaneously with the pressure and flow measurements. The particle trajectories show movement towards the permeable wall separating the feed and permeate channel. The location of particle deposition depends on the position at which it enters the channel (Figure 6). A similar result has been observed by Panglisch and Gimbel [17]. They carried out theoretical analysis using different particle sizes in dead end filtration. For particles of $5 \mu \mathrm{m}$, they report the deposition in the latter end of the channel and showed similar 
streamline flows of the particles undergoing permeation drag. The particle trajectories can be used to determine the onset of cake build up and to characterize cake growth in time.

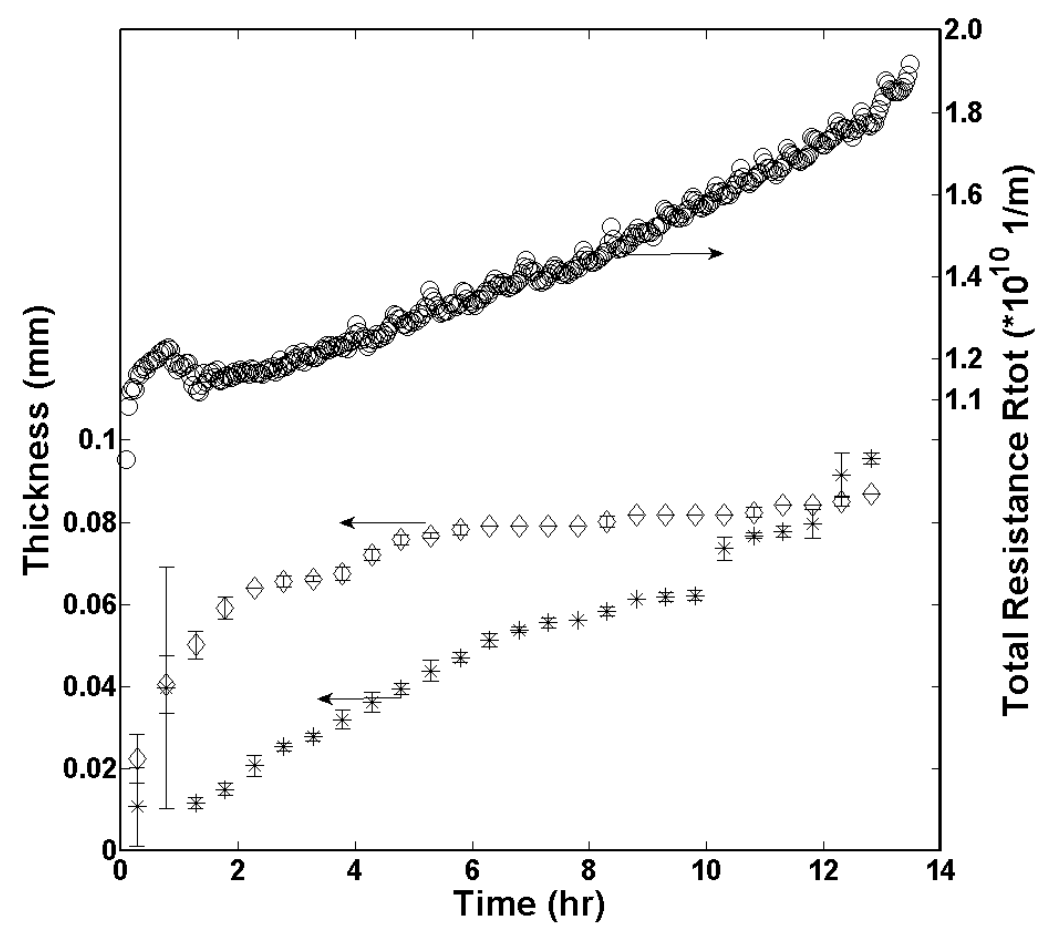

Figure 7 Fouling experiment $(0-$ Rtot $(1 / m)$, * Inlet, $\diamond$-channel exit cake thickness $(\mathrm{mm})$ )

Considering that the experiments were carried out at constant flux, fouling can be monitored by an increase in the trans-membrane pressure [18]. This increase in pressure is a result of added resistance from the fouling layer. Using equation 2 and assuming that at the onset of filtration $R_{c}$ is zero, the membrane resistance can be derived from the pressure data. The membrane resistance obtained from this method as shown in Figure 7 is $1.1{ }^{*} 10^{10}(1 / \mathrm{m})$, which is comparable to that observed with the pure water flux experiments. The total resistance shows a gradual increase due to the deposition of particles on the membrane surface. Figure 7 shows the increasing total resistance monitored in time, plotted alongside the observed cake thickness at two locations in the channel (entrance and exit). The corresponding cake thickness of particles on the surface of the active membrane was continuously monitored (Figure 7). The measured cake resistance is used as a 
comparative tool for the visually observed thickness. It was observed that initially, the particles preferentially deposit towards the end of the channel (Figure 8).

Figure 8 shows images taken at different times during a fouling experiment. Visually, it can be seen that the particle build-up rate is faster towards the end of the channel (right side of figure 8), however this changes as can be seen in Figure 7 .
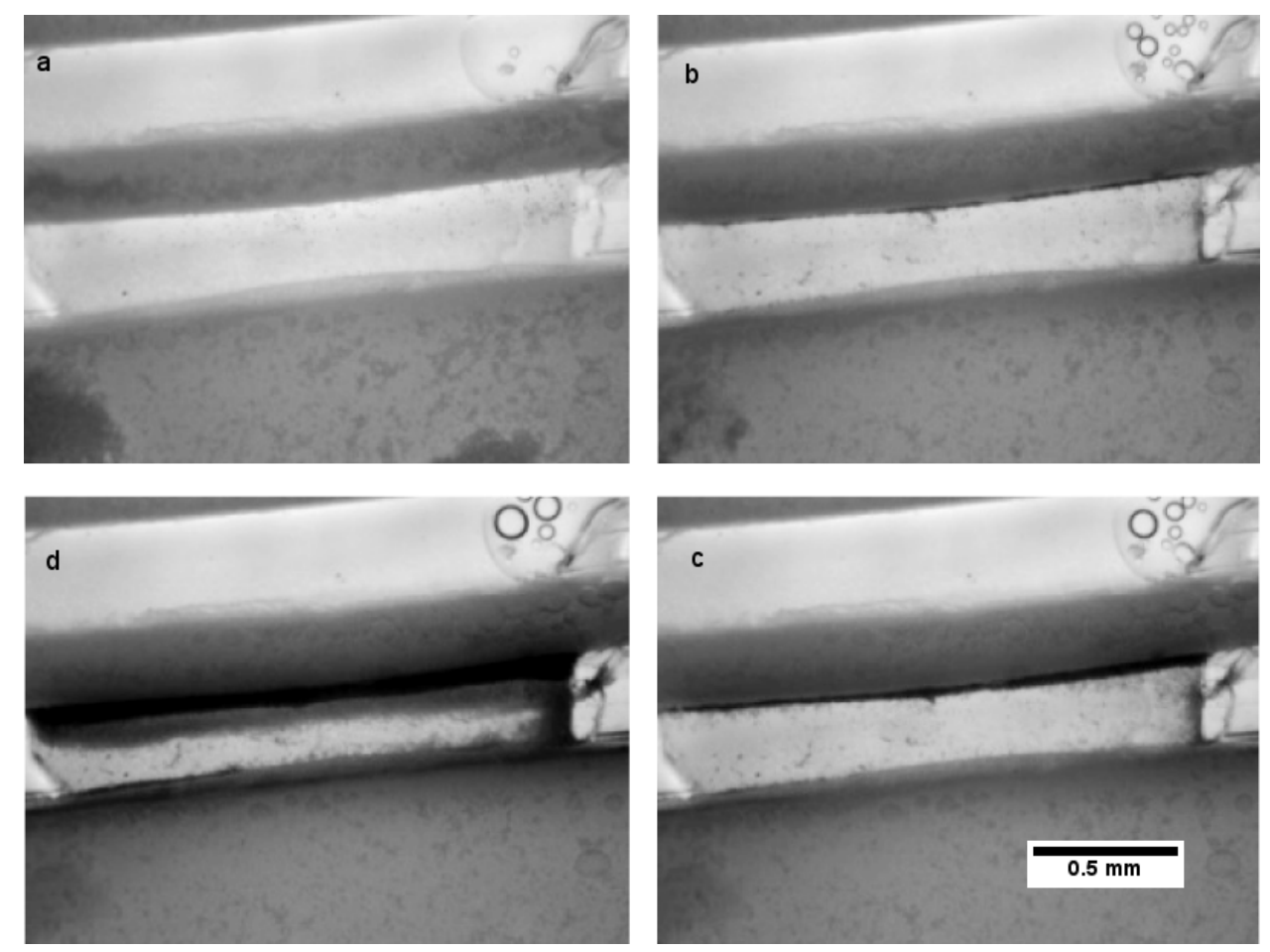

Figure 8 Fouling experiment images at different times (clockwise from top left - 5 mins, 2.7 hrs, 5.5 hrs and 9.5 hrs)

Figure 9 shows the liquid $x$ and $y$ - velocities determined from the particle trajectories and plotted against the channel length. The local liquid y-velocity towards the membrane was observed to be constant across the surface of the membrane. This indicates that the pressure drop across the membrane is constant for all $\mathrm{x}$ - positions.

The cross flow velocity (x-velocity) reduces in the axial direction towards the channel exit as can be seen in Figure 9 . These result in a higher surface shear rate at the inlet of the channel that reduces the particle deposition and the 
particles are thus deposited near the end of the channel. The deposited cake increases the resistance which changes the hydrodynamics of the system. This causes a shift in particle deposition with more particles being deposited at the entrance of the channel. This can be clearly seen from the cake layer thickness data in Figure 9, where initially, there is a steep increase in the cake thickness at the channel exit. However, after two hours, this rate slows, whereas the cake at the entrance of the channel continues to increase.

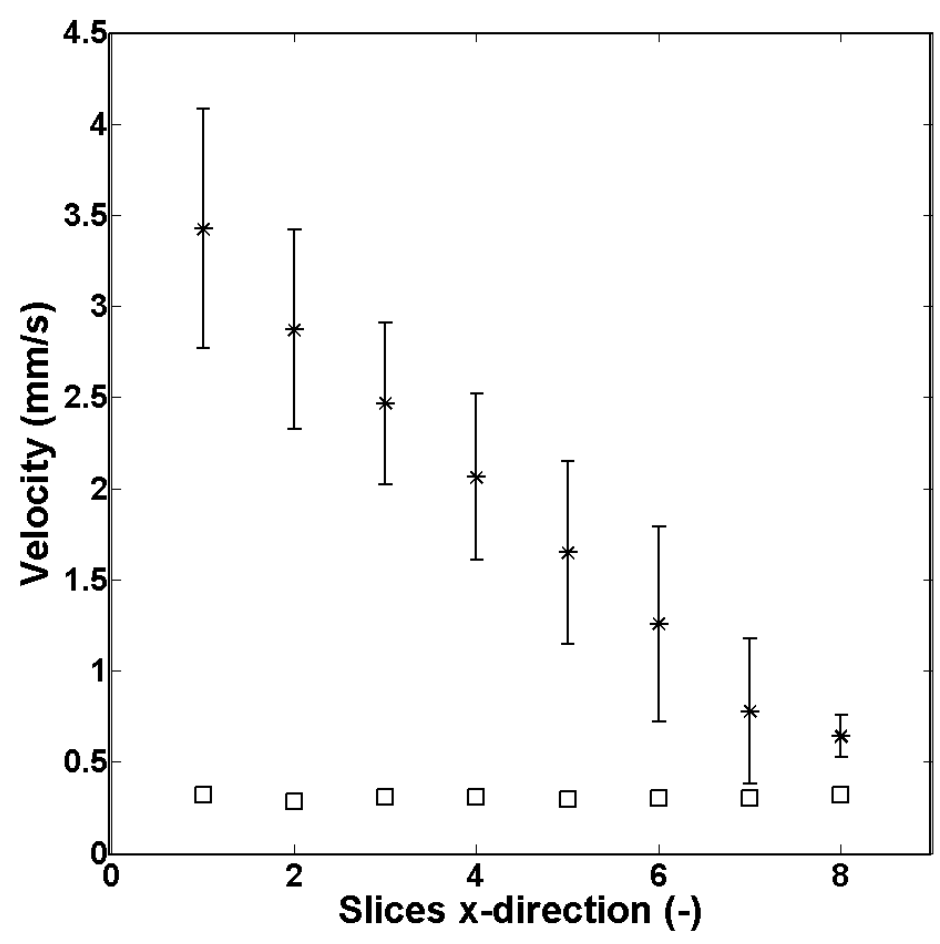

Figure 9 Liquid velocities along channel length $(*-x$ velocity $(\mathrm{mm} / \mathrm{s})$, $0-y$ velocity $(\mathrm{mm} / \mathrm{s})$ 


\section{Conclusions}

A novel particle deposition monitoring setup has been described. The setup is able to monitor the build-up of particles on the surface of a microfiltration membrane. The membrane is observed from a side view making it possible to monitor the thickness of the cake on the wall, and measuring particle trajectories while obtaining pressure and flux data. The observation method is based on the principle of PS $\mu \mathrm{M}[14]$, which is used to make channels in a membrane with permeable walls.

It has been shown that the properties of the membrane channels formed are similar to the properties of a flat sheet membrane prepared from the same recipe. Thus, it is possible to observe the membrane wall from a side view. Particle movements in the channels can be effectively acquired with a camera and tracked using a script file. The trajectories and velocities of the particles can be obtained from the image sequences. The particle movements can be used to determine the local particle velocities in the channel as well as to observe the changes in liquid dynamics as the cake develops on the membrane surface.

It has been observed that initially, cake build up is higher towards the channel exit for a dead end filtration module using $6 \mu \mathrm{m}$ particles. However, the increasing deposition results in a local increase in resistance which favours the deposition at the entrance to the channel. This results in a relatively homogenous final cake thickness across the surface of the membrane.

The combined information on the determination of local deposition characteristics and global flux measurements is an interesting tool for investigating fouling. The described method can be used to monitor the influence of operating parameters on cake build up. The influence of backwashing, particle size and dispersity on cake formation can be monitored on a local scale, providing a better understanding of the processes which occur during fouling. 


\section{References}

(1) Chellam, S. and Wiesner, M. R. Particle transport in clean membrane filters in laminar flow. Environmental Science and Technology, 1992, 26 (8), 16111621.

(2) Song, L. and Elimelech, M. Particle Deposition onto a Permeable Surface in Laminar Flow. Journal of Colloid and Interface Science, 1995, 173 (1), 165.

(3) Belfort, G., Davis, R. H., and Zydney, A. L. The behavior of suspensions and macromolecular solutions in crossflow microfiltration. Journal of Membrane Science, 1994, 96 (1-2), 1.

(4) Chen, V., Li, H., and Fane, A. G. Non-invasive observation of synthetic membrane processes - A review of methods. Journal of Membrane Science, $2004,241(1), 23-44$.

(5) Altmann, J. and Ripperger, S. Particle deposition and layer formation at the crossflow microfiltration. Journal of Membrane Science, 1997, 124 (1), 119128.

(6) Gowman, L. M. and Ethier, C. R. Concentration and concentration gradient measurements in an ultrafiltration concentration polarization layer Part I: A laser-based refractometric experimental technique. Journal of Membrane Science, 1997, 131 (1-2), 95-105.

(7) Mendret, J., Guigui, C., Schmitz, P., Cabassud, C., and Duru, P. An optical method for in situ characterization of fouling during filtration. A/ChE Journal, 2007, 53 (9), 2265-2274.

(8) Li, H., Fane, A. G., Coster, H. G. L., and Vigneswaran, S. Direct observation of particle deposition on the membrane surface during crossflow microfiltration. Journal of Membrane Science, 1998, 149 (1), 83. 
(9) Li, H., Fane, A. G., Coster, H. G. L., and Vigneswaran, S. Observation of deposition and removal behaviour of submicron bacteria on the membrane surface during crossflow microfiltration. Journal of Membrane Science, 2003, $217(1-2), 29-41$.

(10) Mores, W. D. and Davis, R. H. Direct visual observation of yeast deposition and removal during microfiltration. Journal of Membrane Science, $2001,189(2), 217-230$.

(11) Wakeman, R. J. Visualisation of cake formation in crossflow microfiltration. Chemical Engineering Research and Design, 1994, 72 (A4), 530540.

(12) Schaertl, W. and Sillescu, H. Dynamics of Colloidal Hard Spheres in Thin Aqueous Suspension Layers-Particle Tracking by Digital Image Processing and Brownian Dynamics Computer Simulations. Journal of Colloid And Interface Science, 1993, 155 (2), 313-318.

(13) Vogelaar, L., Lammertink, R. G. H., Barsema, J. N., Nijdam, W., BolhuisVersteeg, L. A. M., Van Rijn, C. J. M., and Wessling, M. Phase separation micromolding: A new generic approach for microstructuring various materials. Small, 2005, 1 (6), 645-655.

(14) Vogelaar, L., Barsema, J. N., Van Rijn, C. J. M., Nijdam, W., and Wessling, M. Phase Separation Micromolding - PS?M. Advanced Materials, 2003, 15 (16), 1385-1389.

(15) De Jong, J., Ankone, B., Lammertink, R. G. H., and Wessling, M. New replication technique for the fabrication of thin polymeric microfluidic devices with tunable porosity. Lab on a Chip - Miniaturisation for Chemistry and Biology, 2005, 5 (11), 1240-1247. 
(16) Celata, G. P., Cumo, M., McPhail, S., and Zummo, G. Characterization of fluid dynamic behaviour and channel wall effects in microtube. International Journal of Heat and Fluid Flow, 2006, 27 (1), 135-143.

(17) Panglisch, S. and Gimbel, R. Formation of layers of non-Brownian particles in capillary membranes operated in dead-end mode. Journal of the Chinese Institute of Chemical Engineers, 2004, 35 (1), 77-85.

(18) Field, R. W., Wu, D., Howell, J. A., and Gupta, B. B. Critical flux concept for microfiltration fouling. Journal of Membrane Science, 1995, 100 (3), 259272. 


\section{Chapter 3. Visual Characterization of Fouling With Bidisperse Solution}

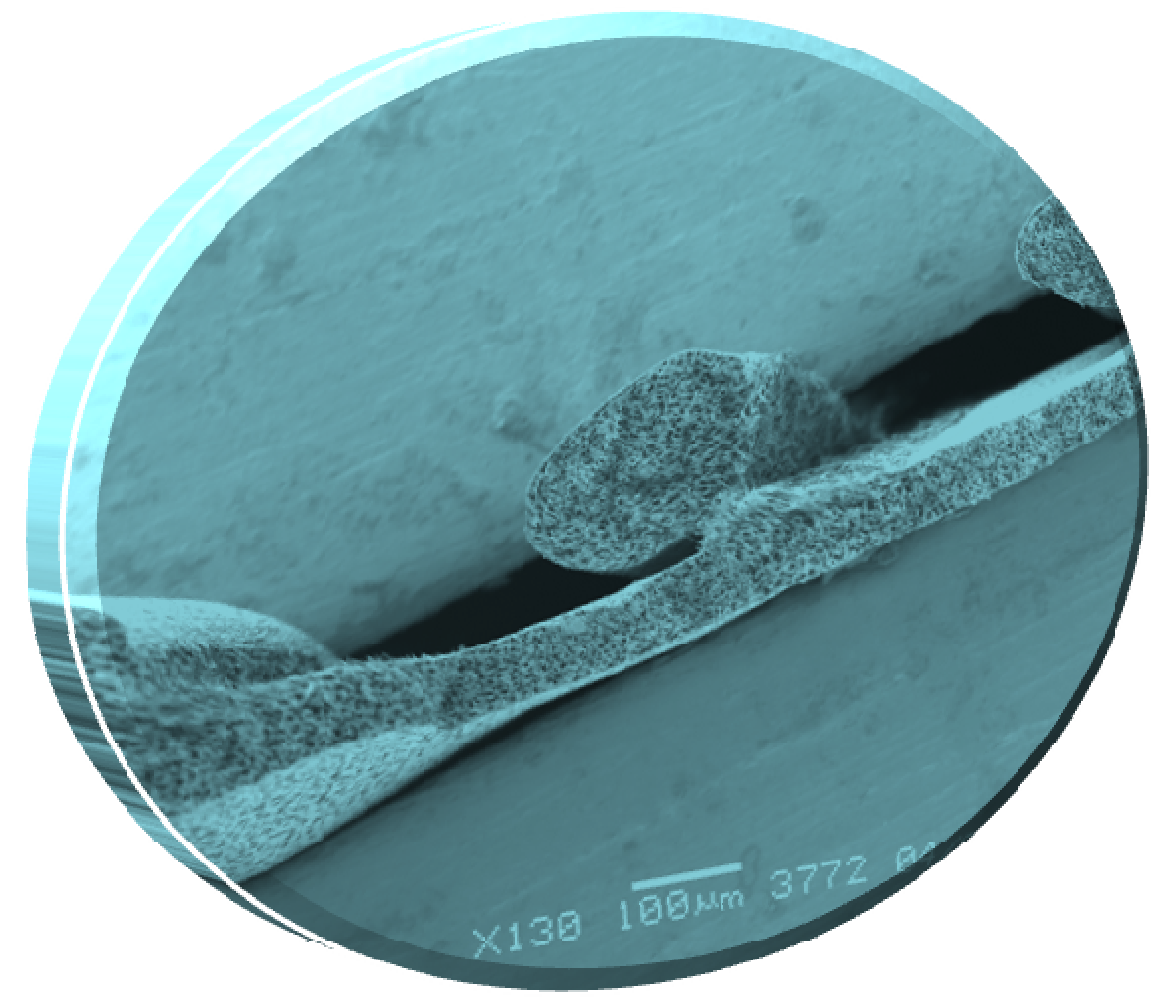

This chapter will be submitted to journal of membrane science

$$
P \text { a g e } \mid \mathbf{4 1}
$$




\section{Introduction}

Microfiltration is a membrane separation process based on size exclusion. Typically, these processes are used in separation of suspended colloidal particles as small as $0.1 \mu \mathrm{m}$ up to particles of $20 \mu \mathrm{m}$. This makes the process very useful for different industries including water treatment, dairy and in biotechnological industries for the separation of microbial cells from fermentation broths. The membranes used in these processes have pore sizes ranging from 0.05 to $10 \mu \mathrm{m}$. The large pores and high porosity result in a low resistance of the membranes and thus high permeate fluxes. However, this results in a high fouling propensity due to the convection of particles towards the surface of the membranes.

The presence of different particle sizes in the typical feed solutions used in microfiltration leads to the formation of filtration cakes with different properties. This interaction between the different components is not easily studied using the typical fouling study techniques. Non-invasive techniques which are able to observe/monitor the cake composition and properties in real time have been developed [1]. These can broadly be divided into optical and non-optical techniques. Laser based optical methods have been studied by various researchers, where the beam of light is used to determine the cake thickness on the surface of the membrane [2-4]. This method has the disadvantage of being cost intensive and also has a low resolution spot size. Normal and fluorescent light microscopy has also been used in observing the membrane surface during the course of filtration [5-7]. The main disadvantage of these techniques is the inability to measure the cake thickness as only the first layer of fouling is observed. NMR imaging has been used in the elucidation of the fouling profile within a membrane module. Airey et al. were able to use this technique to study concentration polarization phenomena of colloidal silica particles in crossflow microfiltration [8]. Vrouwenvelder et al. used this technique to observe the formation and growth of biofouling on a membrane/spacer channel [9]. Spectroscopic, $\mathrm{x}$-ray diffraction and tomography are some other non-optical 
methods that have also been used in observing fouling within membrane modules [1]. These techniques are however expensive and not readily available.

Currently, a number of researchers are focused on improving the optical techniques for better characterization of fouling. Wakeman [10] studied the growth of cake thickness on a microfiltration membrane by placing a camera parallel to the membrane module. An adaptation of this technique was used by Marselina et al. [11], who studied a hollow fibre membrane during operation. The module is operated by pumping the feed solution through the fibre from outside (outside - in). By doing this, they are able to study the deposition characteristics of a bentonite suspension. Mendret et al. studied the cake characteristics of a clay suspension with monodisperse particles using laser reflectometry [12]. They were able to determine the cake thickness on the membrane surface and coupled this with the resistance data. Previously, we used a modified membrane containing embedded channels to observe the deposition of particles on the active membrane surface [13].

Due to the diversity of feed solutions treated with microfiltration, the influence of polydispersity on fouling cannot be neglected. Zhang et al. determined the critical flux of latex particles dispersed in water [14]. They compared the critical flux of monodisperse suspensions to that observed with bidisperse suspensions using an optical technique (DOTM). They reported an increase in the critical flux with the addition of larger particles. They also observed a lower coverage area (membrane surface covered by the particles) compared to that of the monodisperse suspension. Madaeni fouled microfiltration membranes with gold particles of $50 \mathrm{~nm}$ with and without 1 $\mu \mathrm{m}$ latex particles [15]. The study showed an increased cake resistance in the presence of the larger particles.

The properties of randomly packed particles have been investigated by several researchers [16-22]. Wu et al. [16] studied numerically the random close packing of equal hard spheres. They used a rearrangement algorithm which minimizes the overlap between the spheres to determine the packing densities of monodisperse particles to compare with literature results. They 
observed a packing density of 0.635 which is comparable to results from literature. Thies-Weesie and Philipse [17] have investigated the permeation properties of a bidisperse hard sphere packing. They also determined the effect of polydispersity on the scaling function in the Kozeny - Carman relation. They observed a maximum in the volume fraction of particles with increasing fraction of small particles. They also found negligible influence of particle fraction on the scaling factor. Abe et al. [18] observed a similar relation with a minimum in porosity at different particle fractions depending on the size ratio from 0.35 porosity at ca. $82 \%$ large particle fraction (size ratio of 2.38) to 0.25 at $65 \%$ fraction (size ratio of 9.17). They also successfully compared their experimental results to a model using the Kozeny - Carman relation with a correction for the particle fraction. Leitzelement et al [19] used a statistical geometric model to determine the porosity and permeability of three component mixtures. Their model agreed with the experimental data with the addition of a correction factor to the values. They observed a maximum in the porosity for monodisperse suspensions with subsequent decreasing porosity for the mixed solutions, and an increase in permeability with the addition of the larger particles.

The focus of this study is to monitor the build-up of a bidisperse cake on the surface of a membrane using an optical technique previously developed in our group [13]. Using this technique, fouling can be observed locally using optics and globally by flow and pressure measurements. Different compositions of a bidisperse solution containing $3.3 \mu \mathrm{m}$ and $5.7 \mu \mathrm{m}$ particles were used to foul the membranes. The observed cake thickness and specific cake resistance was determined as a function of the suspension composition. This was also compared to the theoretical specific cake resistance obtained with the Kozeny Carman relation. 


\section{Materials and Methods}

\subsection{Materials}

For the membrane fabrication, the polymers - polyetherimide (PEI, Ultem 1000), polyvinylpyrrolidone (PVP, K90 $360000 \mathrm{~g} / \mathrm{mol}$, Fluka) were used without further purification. N-methylpyrrolidone (NMP, Acros Organics) was used as a solvent for the membrane preparation. Square shaped fused silica capillaries with external sides of $300 \mu \mathrm{m}$ and internal sides of $100 \mu \mathrm{m}$ (Polymicro, USA) were used for templating of the membranes and for feeding the channels. Milli-O water with polystyrene particles having diameters of 3.3 and $5.7 \mu \mathrm{m}$ (Polysciences, USA) was used as a model feed solution. Lamination sheets (Acco Brands Europe, UK) were used for sealing the membranes.

\subsection{Methods}

\subsubsection{Membrane channels}

Structured membranes were prepared by casting a polymer solution of PEI/PVP/NMP (19/11/70 w/w/w) on a glass plate with two square shaped fused silica glass capillaries (Polymicro, USA) on its surface using a $0.7 \mathrm{~mm}$ steel roller casting knife at room temperature. The substrate with the capillaries and polymer solution was then placed in a water vapour bath (VIPS) for $3 \mathrm{~min}$. After the vapour stage, the substrate was placed in a tap water bath at room temperature for complete coagulation and phase separation. The embedded channel membranes shrink and detach from the substrate and are rinsed for 1 day while refreshing the tap water. Afterwards, the membranes were rinsed in a solution of water and sodium oxochlorate ( $4000 \mathrm{ppm})$ for $48 \mathrm{~h}$ to remove the PVP. A final water rinsing step was performed and the membranes were dried. Figure 1 shows an illustration of the fabrication process.

\subsubsection{Feed solution}

Bidisperse feed solutions were prepared from two different monodisperse polystyrene particle solutions of sizes -3.3 and $5.7 \mu \mathrm{m}$ (Polysciences, USA). 
The bidisperse solution was prepared on the basis of number of particles with a constant total number of particles per liquid volume ratio. The particles were suspended in ultra-pure water.

Feed solutions were prepared before each start of an experiment and stirred continuously during the experiment to prevent settling. The particle sizes are such that there is complete retention on the membrane surface.

\subsubsection{Chip preparation/Setup}

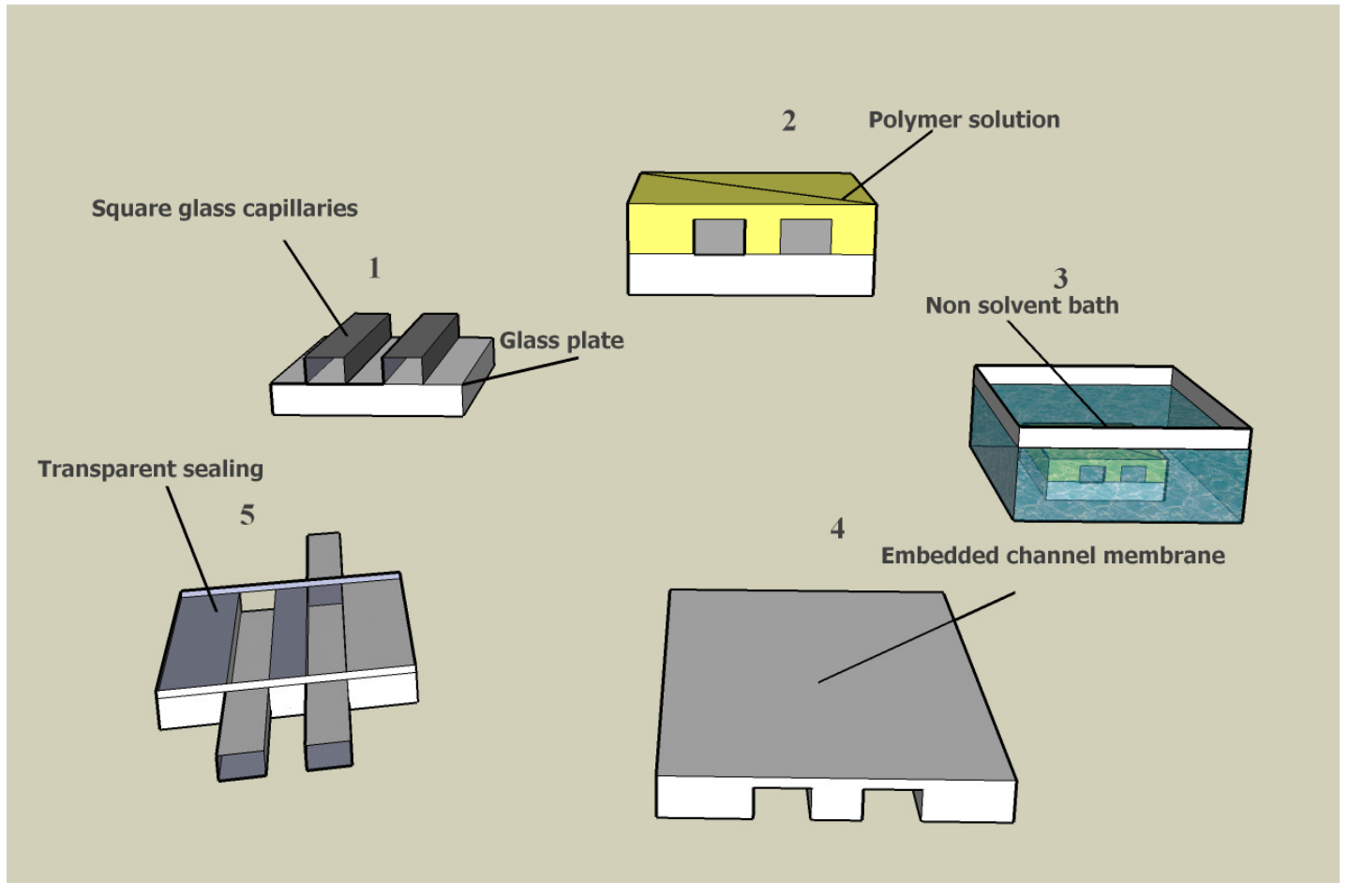

Figure 1. Illustration of templating method for fabrication of embedded channels in a membrane

The square shaped fused silica glass capillaries are partly placed in the channels to act as feed, retenate and permeate channels. The entire chip is sandwiched between lamination sheets and heat sealed. The chip is placed in a direct observation optical device previously developed in our group. The chip is prepared such that there is a gap of ca. $2 \mathrm{~mm}$ between the feed and retentate glass capillaries. This is termed the active filtration area with permeation across the membrane in that region. The entire setup combines global fouling observation using two pressure sensors (EPX series, Entran 
sensors, USA) with local fouling monitoring using a camera (Pixelfly VGA, PCO AG, Germany) attached to a magnifying lens (Optem Zoom ${ }_{125} \mathrm{C}$, Quioptiq, USA). The liquid flow is controlled by mass flow controllers ( $\mu$ Flow, Bronkhorst, Netherlands) connected to a stirred pressure vessel. The setup has been described in an earlier work [13]. The experiments were carried out in dead end and constant flux mode.

\subsubsection{Characterization method}

The morphology of the membranes was observed using SEM (JEOL 5600) at $5 \mathrm{kV}$. The membranes were sputtered with a thin layer of gold to improve conductivity.

The global fouling characterization was carried out by applying Darcy's law to the pressure data. The experiments were carried out at constant flux so the increase in trans membrane pressure (TMP) was used to determine the cake resistance in time. The membrane resistance $\left(R_{m}\right)$ was determined beforehand by pure water flux experiments.

$$
J=\frac{\Delta P}{\eta *\left(R_{m}+R_{c}\right)}
$$

Where $J$ is permeate flux $\left(\mathrm{m}^{3} / \mathrm{m}^{2} \mathrm{~s}\right), \Delta P$ is transmembrane pressure $(\mathrm{Pa}), \eta$ is liquid viscosity (Pa.s), $R_{m}$ and $R_{c}$ are the membrane and cake resistance $(1 / \mathrm{m})$, respectively.

The local fouling characterization was analysed with the obtained image sequence using ImageJ (freeware) and a Matlab script file. ImageJ is used to isolate the region of interest and threshold the image to obtain a binary 8 bit image sequence, with an inversion of the image colour profile (the cake layer now appears white, see fig. 3). The Matlab script file uses the image processing toolbox to determine the boundaries of the cake layer and thus the local cake thickness.

The cake porosity can be obtained from the cake thickness on the membrane surface using equation 2 .

$$
\delta=\frac{v_{D}}{\left(1-\varepsilon_{a}\right)}
$$


Where $\delta$ is cake thickness $(m), v_{D}$ is deposited volume of particles $\left(\mathrm{m}^{3} / \mathrm{m}^{2}\right)$ and $\varepsilon_{\mathrm{a}}$ is average cake porosity (-).

The experimental specific cake resistance was determined from the pressure measurements using equation 3 .

$\alpha_{E}=\frac{R_{c}}{M_{D}}$

Where $\alpha_{E}$ is the experimental specific cake resistance $(\mathrm{m} / \mathrm{kg}), R_{c}$ is the measured cake resistance $(1 / \mathrm{m})$ and $M_{D}$ is the deposited mass of particles $\left(\mathrm{kg} / \mathrm{m}^{2}\right)$.

Kozeny Carman equation was used to determine the theoretical specific cake resistance. The theoretical average cake porosity was used to calculate the specific cake resistance. Equation 4 and 5 below were adapted from the relation described by Abe et al. [18].

$$
\begin{aligned}
& \alpha_{T}=\frac{180 *\left(1-\varepsilon_{a, T}\right)}{\varepsilon_{a, T}^{3}} *\left(\frac{N_{L}}{\phi_{L} * D_{P L}}+\frac{N_{S}}{\phi_{S} * D_{P S}}\right)^{2} * \frac{V_{D}}{M_{D}} \\
& \frac{v_{D}}{M_{D}}=\frac{1}{\left(N_{L} * \rho_{P}\right)+\left(N_{S} * \rho_{P}\right)}
\end{aligned}
$$

Where $\alpha_{T}$ is theoretical specific cake resistance $(\mathrm{m} / \mathrm{kg}), \varepsilon_{\mathrm{a}, \mathrm{T}}$ is theoretical cake porosity $(-), N_{L}$ is number fraction of $5.7 \mu \mathrm{m}$ particles $(-), N_{S}$ is number fraction of $3.3 \mu \mathrm{m}$ particles $(-), D_{p}$ is the diameter of the particles $(\mathrm{m}), \phi$ is the surface factor of the particles $(-)$ and $\rho_{p}$ is density of particles $\left(\mathrm{kg} / \mathrm{m}^{3}\right)$. The theoretical cake porosity $\varepsilon_{\mathrm{a}, \mathrm{T}}$ was obtained from Tokumitsu's theory of particle packing [23]. 


\section{Results and discussions}

\subsection{Membrane characterization}

Figure 2 shows a cross section of the membrane with integrated channels. The fabrication process was tuned to obtain microfiltration membranes with an average pore size of $1.5 \mu \mathrm{m}$ (inset) by increasing the duration of vapour induced phase separation. This is to ensure that the feed particles are completely retained by the membrane. The membrane resistance $\left(R_{m}\right)$ determined by performing pure water flux experiments on the chip was $1.1 * 10^{10}\left(\mathrm{~m}^{-1}\right)$.

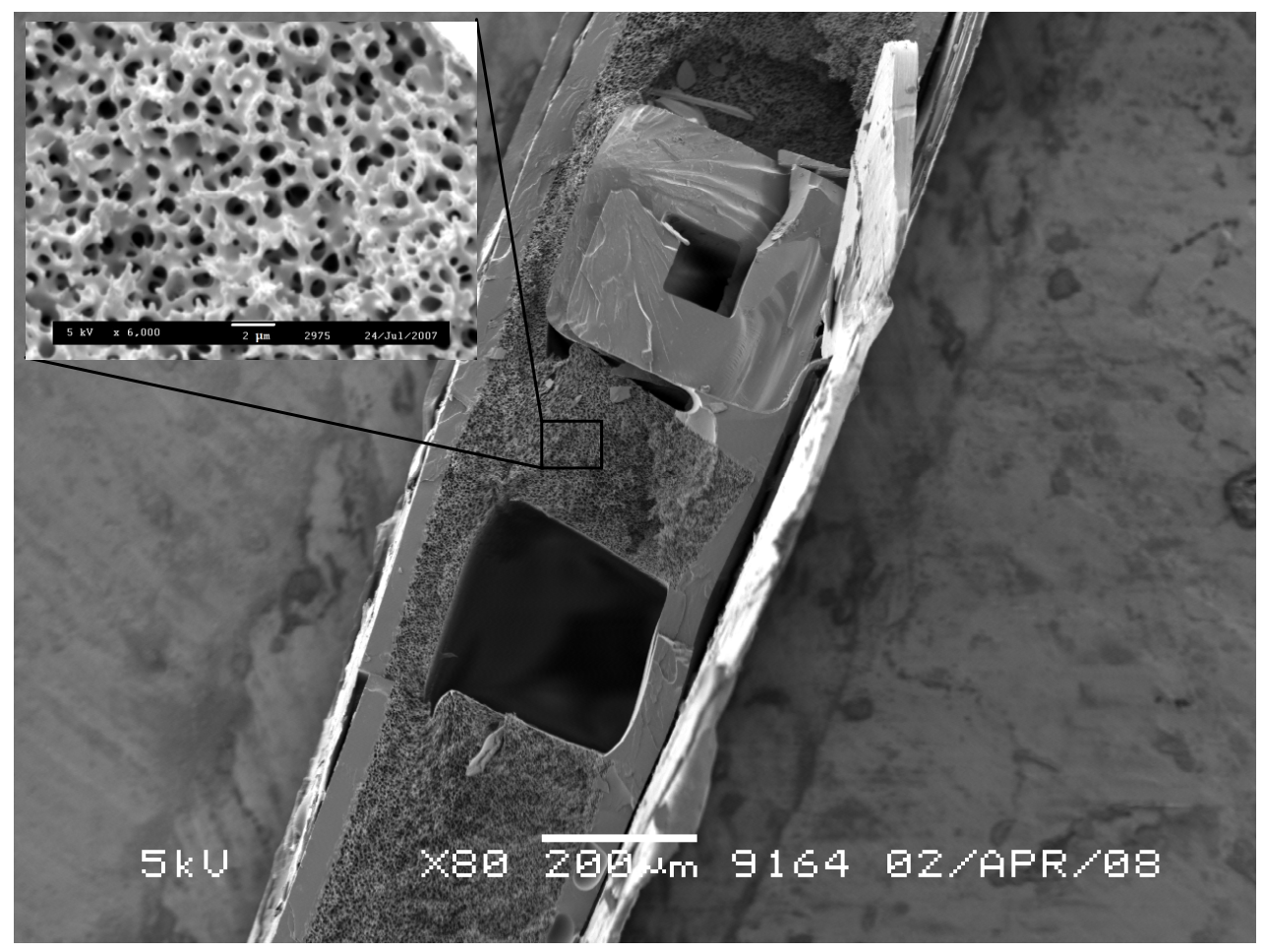

Figure 2. Cross section of sealed embedded channel membrane showing porous structure, embedded channels, glass capillary and active membrane

\subsection{Fouling characterization}

Figure 3 shows a typical image taken during a fouling experiment with the feed flow from left to right and the permeate exits from the top right. The deposition is observed on the active filtration area as a dark layer on channel 
surface. The cake growth is monitored by isolating the region of interest in the image, converting it into a binary image and inverting the colours to make the cake appear white (Fig. 3 inset). Matlab image processing toolbox was used to form a trace line around the cake which is subsequently measured to determine the thickness at various points within the channel in time.

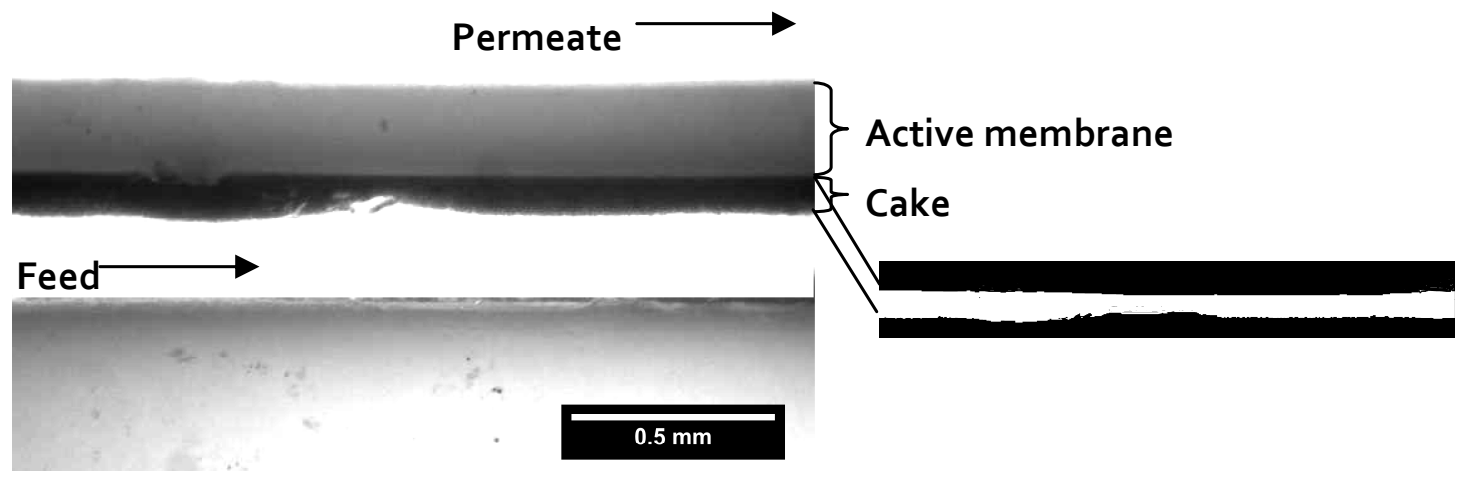

Figure 3. Typical image of fouling experiment after $8 \mathrm{~h}$ (feed from left to right, permeate from top channel), inset image after thresholding

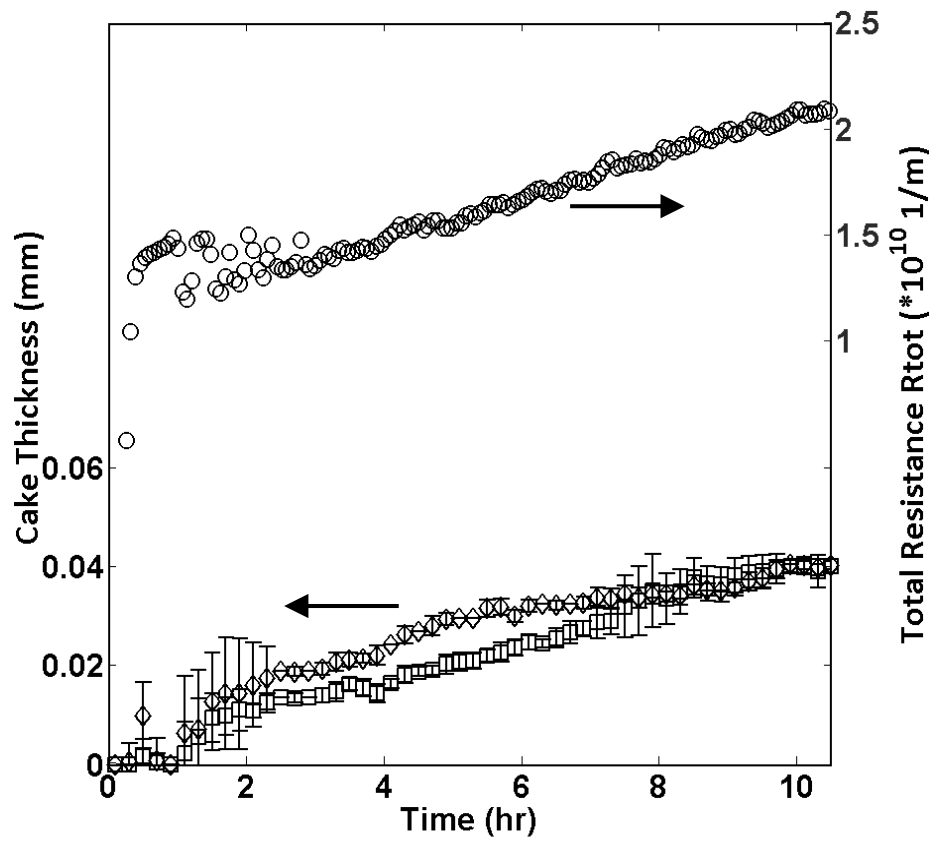

Figure 4. Typical fouling experiment showing total resistance and measured cake thickness at two positions within the channel ( $\square$ - channel inlet and $\diamond$ - channel exit) 
Figure 4 shows a typical result obtained from the fouling experiments. The results combine the global information obtained from pressure data (total resistance) with the local information obtained from image analysis (cake thickness) at two different positions within the chip; the beginning and end of the filtration channel. The flux was kept constant for all the experiments at 1.7 $\mathrm{m}^{3} / \mathrm{m}^{2} \mathrm{~h}$ and operated in dead end mode resulting in an increase in pressure during operation. Images were taken of the entire active filtration area every minute for the duration of the experiments and the pressure was also monitored continuously. It can be seen that there is a deposit thickness of about $0.04 \mathrm{~mm}$ after 10 hours and a subsequent total resistance of more than double the initial membrane resistance. The cake thickness growth rate observed showed initial differences between the cake thickness at the entrance of the channel and the channel exit. The initial cake growth at the channel exit is due to reduced crossflow in comparison to the channel entrance. This results in increasing resistance at the channel exit in time. Hence, the cake thickness at the channel entrance increases at a later stage as well.

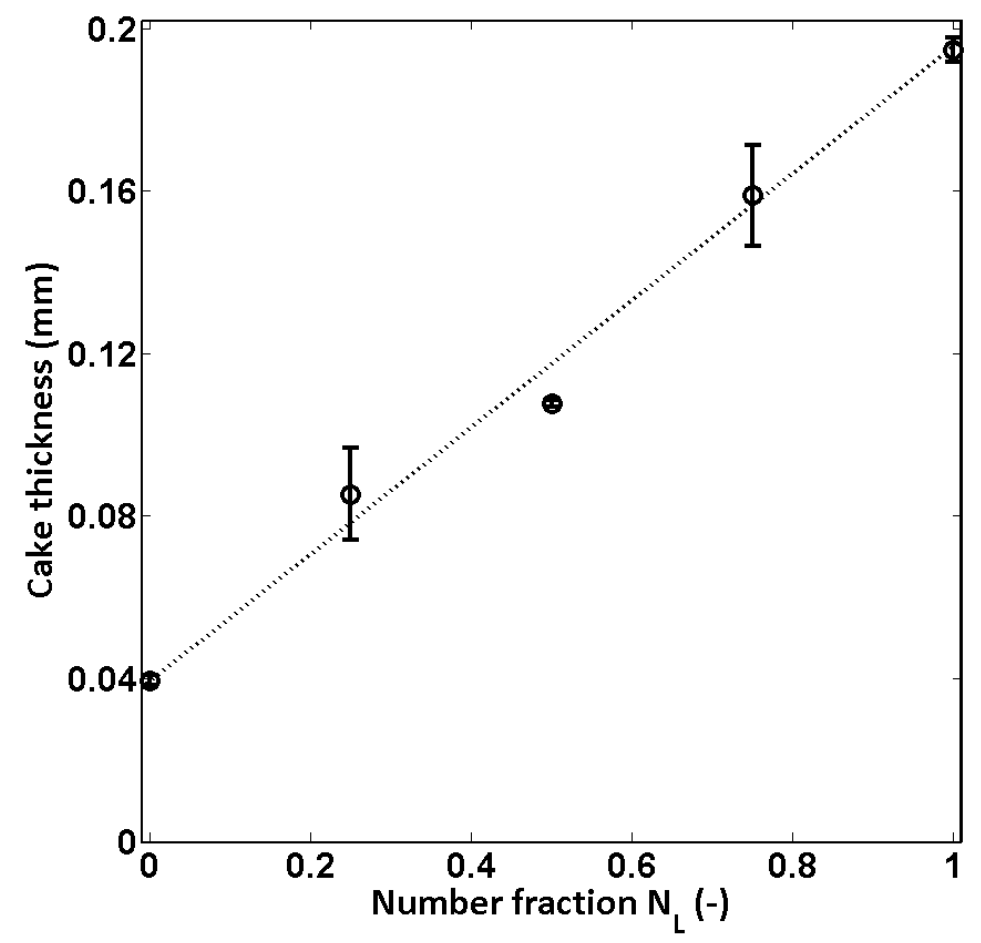

Figure 5. Cake thickness on membrane surface as function of number fraction of $5.7 \mu \mathrm{m}$ particles in $3.3 \mu \mathrm{m}$ particles 
The increase in fraction of the larger particles present in the solution results in an increase in the cake thickness measured on the active membrane surface leading to a maximum cake thickness with the monodisperse solution. This increasing thickness is directly related to the increasing volume of particles present in the solution. Figure 5 shows the cake thickness measured on the membrane surface relative to the particle fraction of larger particles $(5.7 \mu \mathrm{m})$. Considering particle size ratio of $1.73\left(D_{\mathrm{PL}} / D_{\mathrm{PS}}\right)$, a fivefold increase in cake thickness was expected and this correlates with the observations.

\subsection{Cake porosity}

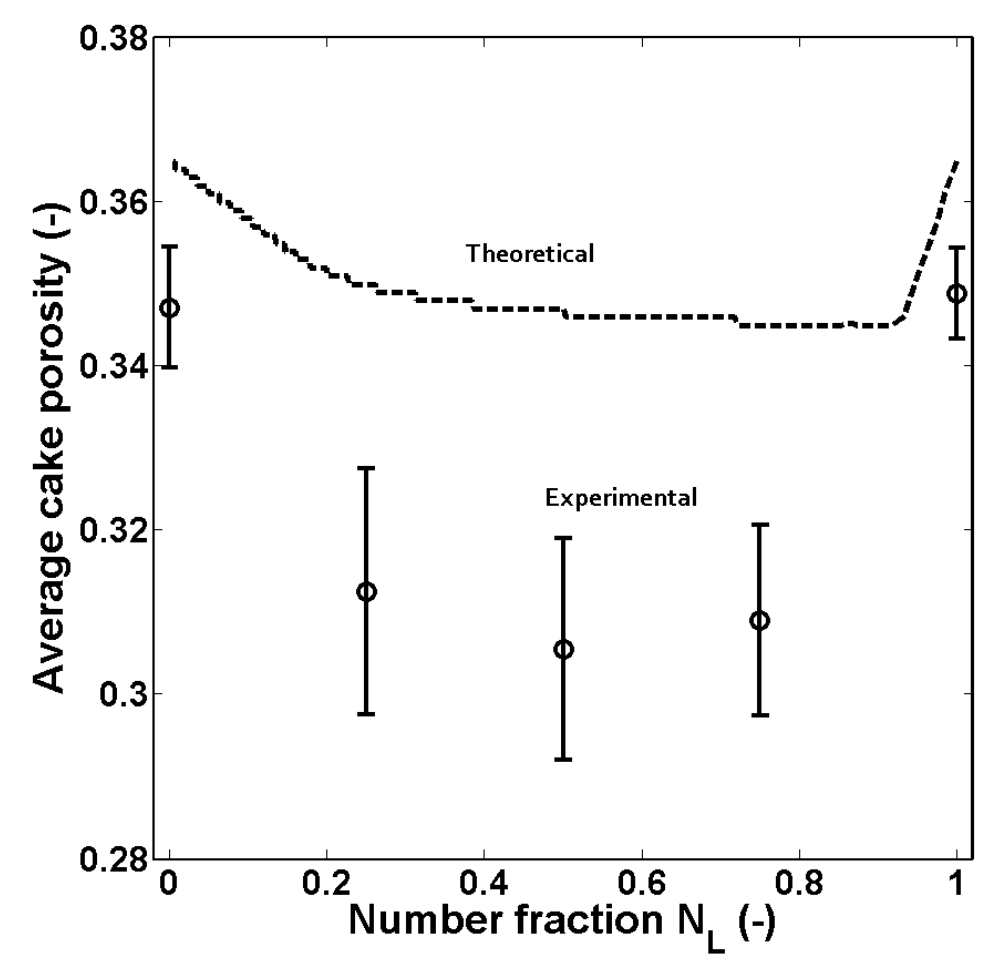

Figure 6. Average cake porosity as function of number fraction (o - experimental data and dashed line is theoretical data from Tokumitsu method)

Figure 6 shows the average cake porosity determined with equation 2 and the theoretical cake porosity determined by the Tokumitsu method [23]. Initially, there is a steeper decrease in the cake porosity with increasing amount of larger particles. The trend changes after a minimum point which in our case is at a number fraction of 0.5 in our experimental results. However, the trend is different for the theoretical cake porosity, after the initial steep decrease with

$$
P \text { a g e } \mid \mathbf{5 2}
$$


increasing larger particle fraction, the rate of cake porosity decrease reduces. As the fraction of larger particles continues to increase (above 0.85), the porosity increases. This trend is comparable to the report of Abe et al. where they observed a decrease in cake porosity within a packed bed with increasing volume fraction of larger particles [18]. Our observation of a minimum porosity at a number fraction of 0.5 coincides with the results of Abe et al. for glass beads. Thies-Weesie and Philipse observed a similar trend, they measured the volume fraction of the packing as a function of the volume fraction of small particles [17]. They also compared experimental values to the theoretical porosities and observed a stronger reduction in absolute values of experimental porosity.

The initial reduction in cake porosity is due to better arrangement of the particles within the cake with the smaller particles occupying the spaces between the larger particles. However with increasing amount of larger particles, the arrangement tends more towards that of a monodisperse packing. The lower porosities observed in our experimental study in comparison to the theoretical porosity could be attributed to better ordering of the particles closer to the membrane surface. This has already been observed in cake filtration studies [11-12]. The lower porosities could also be due to deformations in the particles considering that the models represent hard spheres.

\subsection{Cake resistance}

The experimentally obtained specific cake resistance was compared to the specific cake resistance obtained using the Kozeny Carman relation (equation. 3 and equation 5). The theoretical average porosity obtained from the Tokomitsu method was used in calculating the specific cake resistance (figure 6). Figure 7 shows the specific cake resistance (theoretical and experimental) as a function of the number fraction of large particles present in the solution. The open circles (o) are for the measured specific cake resistance, while the line shows the calculated specific cake resistance. The figure shows a decrease in the specific cake resistance with increasing number fraction of larger particles within the cake. The trend is similar for 
both the experimental and theoretical specific cake resistance. Figure 7 shows that the theoretical specific cake resistance is lower than the experimental resistance, this is as expected considering the porosity calculated for the solutions. The higher absolute values measured experimentally suggests better ordering of the particles within the cake as observed in figure 6 .

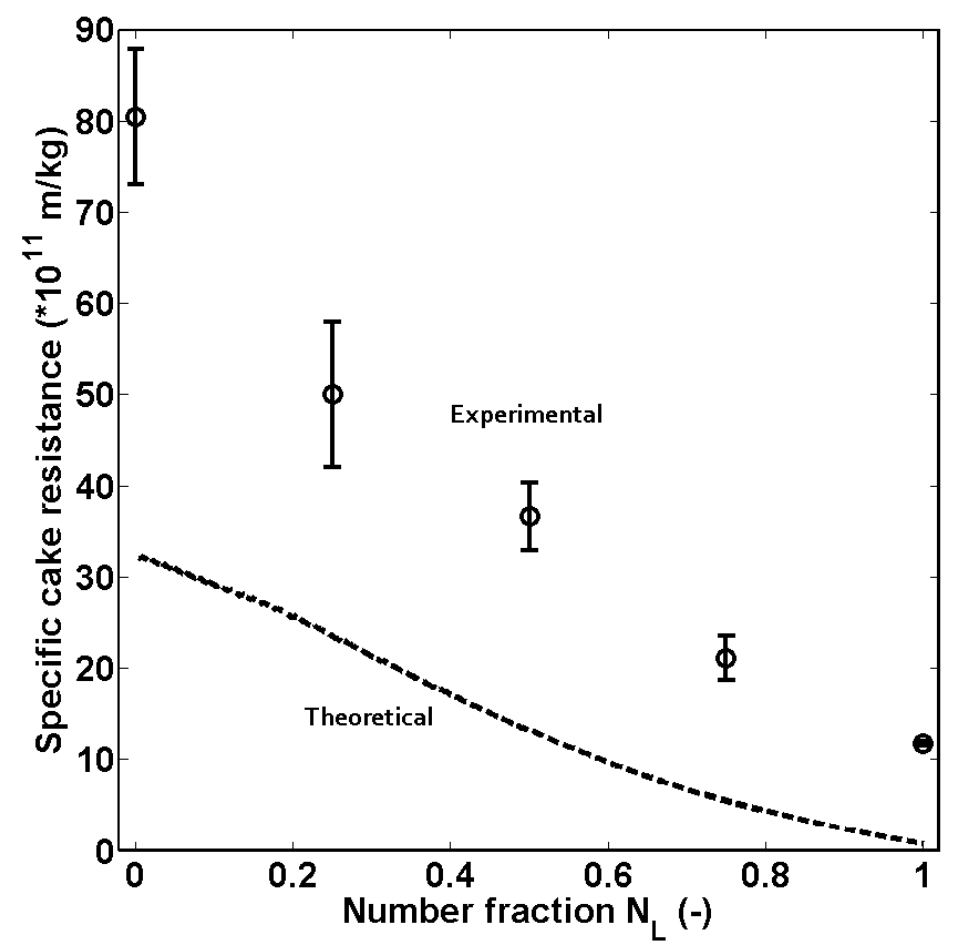

Figure 7. Specific cake resistance as function of particle fraction (o-experimental, dashed line - theoretical)

Kozeny Carman equation suggests an inverse relationship between the specific cake resistance and particle diameter (equation 4). This corresponds to the trend observed in figure 7 which shows a reduction in specific cake resistance with an increase in fraction of larger particles within the cake. Lee and Clark studied the cake properties formed by different particle sizes and observed a reduction in specific cake resistance with increase in particle size [24]. Thies-Weesie and Philipse observed a reduction in cake permeability as a function of increasing fraction of smaller particles [17]. The inverse of specific cake resistance results in permeability and this shows similar trends as that reported. The presence of larger particles results in the formation of increasingly larger pore spaces which have a lower hydrodynamic resistance or specific cake resistance. 


\section{Conclusion}

The effect of bidisperse suspension on fouling of a microfiltration membrane has been studied simultaneously using visual tools and global fouling monitoring. Polystyrene particles of diameters 3.3 and $5.7 \mu \mathrm{m}$ were mixed at different ratios and used in fouling the membrane at constant permeate flux in dead end mode.

The deposition characteristics of the bidisperse suspensions show an increase in the cake thickness with increasing number fraction of $5.7 \mu \mathrm{m}$ particles leading to a maximum with the monodisperse suspension. The average experimental cake porosity showed a minimum at $\mathrm{N}_{\mathrm{L}}$ of 0.5 . The theoretical porosity (using Tokumitsu method) showed an initial strong reduction in porosity, followed by a more gradual decrease. Above $85 \%$ fraction of larger particles, the cake porosity increased. The theoretical porosities showed higher absolute values in comparison to the experimental. This could be due to the presence of more ordered cake structures closer to the membrane surface with a fluidized top layer. Cake compaction could also result in lower porosities observed in the experiments.

Kozeny Carman equation was used to determine the theoretical specific cake resistance, and compared to the measured specific cake resistance. A continuous reduction was observed in the specific cake resistance for both the theoretical as well as the experimental results. This reduction was attributed to the presence of increasing pores with increase in the larger particle fraction. Lower absolute values were observed for the theoretical specific cake resistance, this could be due to the ordering observed with the cake porosities leading to higher measured resistance.

Using this technique, it is possible to combine direct visual measurement of the cake thickness (local) and flux data (global) fouling effects. Thus, it is possible to extract cake properties like porosity and resistance for further studies. This combination can be used to study the influences of various parameters on fouling. 


\section{References}

(1) Chen, V., Li, H., and Fane, A. G. Non-invasive observation of synthetic membrane processes - A review of methods. Journal of Membrane Science, 2004, $241(1), 23-44$.

(2) Altmann, J. and Ripperger, S. Particle deposition and layer formation at the crossflow microfiltration. Journal of Membrane Science, 1997, 124 (1), 119128.

(3) Mendret, J., Guigui, C., Schmitz, P., Cabassud, C., and Duru, P. An optical method for in situ characterization of fouling during filtration. AIChE Journal, 2007, 53 (9), 2265-2274.

(4) Gowman, L. M. and Ethier, C. R. Concentration and concentration gradient measurements in an ultrafiltration concentration polarization layer Part I: A laser-based refractometric experimental technique. Journal of Membrane Science, 1997, 131 (1-2), 95-105.

(5) Li, H., Fane, A. G., Coster, H. G. L., and Vigneswaran, S. Direct observation of particle deposition on the membrane surface during crossflow microfiltration. Journal of Membrane Science, 1998, 149 (1), 83.

(6) Li, H., Fane, A. G., Coster, H. G. L., and Vigneswaran, S. Observation of deposition and removal behaviour of submicron bacteria on the membrane surface during crossflow microfiltration. Journal of Membrane Science, 2003, $217(1-2), 29-41$.

(7) Mores, W. D. and Davis, R. H. Direct visual observation of yeast deposition and removal during microfiltration. Journal of Membrane Science, 2001, 189 (2), 217-230. 
(8) Airey, D., Yao, S., Wu, J., Chen, V., Fane, A. G., and Pope, J. M. An investigation of concentration polarization phenomena in membrane filtration of colloidal silica suspensions by NMR micro-imaging. Journal of Membrane Science, 1998, 145 (2), 145-158.

(9) Graf von der Schulenburg, D. A., Vrouwenvelder, J. S., Creber, S. A., van Loosdrecht, M. C. M., and Johns, M. L. Nuclear magnetic resonance microscopy studies of membrane biofouling. Journal of Membrane Science, 2008, $323(1), 37-44$.

(10) Wakeman, R. J. Visualisation of cake formation in crossflow microfiltration. Chemical Engineering Research and Design, 1994, 72 (A4), 530540.

(11) Marselina, Y., Le-Clech, P., Stuetz, R., and Chen, V. Detailed characterisation of fouling deposition and removal on a hollow fibre membrane by direct observation technique. Desalination, 2008, 231 (1-3), 311.

(12) Mendret, J., Guigui, C., Schmitz, P., and Cabassud, C. In situ dynamic characterisation of fouling under different pressure conditions during deadend filtration: Compressibility properties of particle cakes. Journal of Membrane Science, 2009, 333 (1-2), 20-29.

(13) Ngene, I. S., Lammertink, R. G. H., Wessling, M., and van der Meer, W. A microfluidic membrane chip for in situ fouling characterization. Journal of Membrane Science, 2010, 346 (1), 202-207.

(14) Zhang, Y. P., Fane, A. G., and Law, A. W. K. Critical flux and particle deposition of bidisperse suspensions during crossflow microfiltration. Journal of Membrane Science, 2006, 282 (1-2), 189-197. 
(15) Madaeni, S. S. Effect of large particles on microfiltration of small particles. Journal of Porous Materials, 2001, 8 (2), 143-148.

(16) Wu, Y., Fan, Z., and Lu, Y. Bulk and interior packing densities of random close packing of hard spheres. Journal of Materials Science, 2003, 38 (9), 20192025.

(17) Thies-Weesie, D. M. E. and Philipse, A. P. Liquid Permeation of Bidisperse Colloidal Hard-Sphere Packings and the Kozeny-Carman Scaling Relation. Journal of Colloid And Interface Science, 1994, 162 (2), 470-480.

(18) Abe, E., Hirosue, H., and Yokota, A. Pressure Drop Through A Packed Bed Of Binary Mixture. Journal of Chemical Engineering of Japan, 1979, 12 (4), 302-306.

(19) Leitzelement, M., Lo, C. S., and Dodds, J. Porosity and permeability of ternary mixtures of particles. Powder Technology, 1985, 41 (2), 159-164.

(20) Zou, R. P., Feng, C. L., Xu, J. Q., and Yu, A. B. Prediction of the porosity of multicomponent mixtures of wet coarse spheres. Industrial and Engineering Chemistry Research, 2005, 44 (22), 8401-8408.

(21) Zou, R. P., Feng, C. L., and Yu, A. B. Packing Density of Binary Mixtures of Wet Spheres. Journal of the American Ceramic Society, 2001, 84 (3), 504-508.

(22) Philipse, A. P. and Pathmamanoharan, C. Liquid Permeation (and Sedimentation) of Dense Colloidal Hard-Sphere Packings. Journal of Colloid And Interface Science, 1993, 159 (1), 96-107.

(23) Tokumitsu, Z. Study on packing of powder. J. Materials Sci. Japan, 1964, $13752-758$. 
(24) Lee, Y. and Clark, M. M. Modeling of flux decline during crossflow ultrafiltration of colloidal suspensions. Journal of Membrane Science, 1998, $149(2), 181-202$.

Nomenclature

$D_{P L} \quad$ Diameter of large particles $(m)$

$D_{P S} \quad$ Diameter of small particles $(m)$

$\mathrm{J} \quad$ Permeate flux $\left(\mathrm{m}^{3} \mathrm{~m}^{-2} \mathrm{~s}^{-1}\right)$

$M_{D} \quad$ Deposited mass of cake $\left(\mathrm{kgm}^{-2}\right)$

$\mathrm{N}_{\mathrm{L}} \quad$ Number fraction of large particles (-)

$\mathrm{N}_{\mathrm{S}} \quad$ Number fraction of small particles (-)

$\triangle \mathrm{P} \quad$ Transmembrane pressure $(\mathrm{Pa})$

$R_{m} \quad$ Membrane resistance $\left(m^{-1}\right)$

$R_{c} \quad$ Measured cake resistance $\left(m^{-1}\right)$

$R_{c, t} \quad$ Calculated cake resistance $\left(\mathrm{m}^{-1}\right)$

$V_{D} \quad$ Deposited volume of particles $\left(\mathrm{m}^{3} \mathrm{~m}^{-2}\right)$

Greek symbols

$\alpha \quad$ Specific cake resistance $\left(\mathrm{mkg}^{-1}\right)$

$\delta \quad$ Cake thickness ( $m$ )

$\varepsilon_{\mathrm{a}} \quad$ Average cake porosity (-)

$\varepsilon_{a, t} \quad$ Theoretical cake porosity

$\eta \quad$ Viscosity of solution (Pas)

$\rho_{\mathrm{P}} \quad$ Density of particles $\left(\mathrm{kgm}^{-3}\right)$ 


\section{Chapter 4. Particle Deposition and Biofilm Formation On Microstructured Membranes}

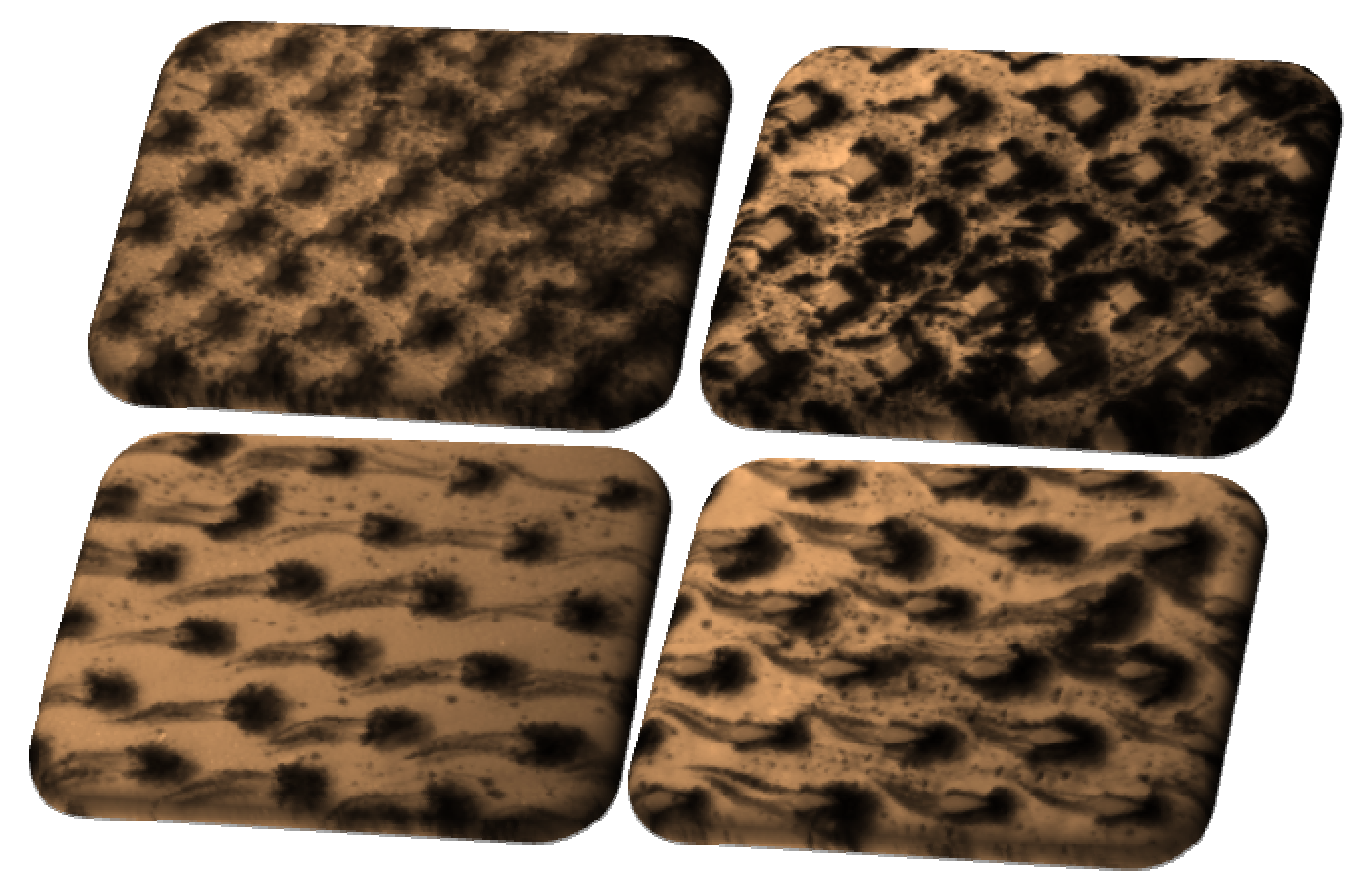

This chapter has been submitted to journal of membrane science

$$
P \text { a g e } \mid 60
$$




\section{Introduction}

Growing importance is being foreseen for membranes within the water production and treatment industries [1]. High pressure membrane processes like reverse osmosis (RO) and nanofiltration (NF) are typically applied in water treatment facilities. These processes are widely accepted due to the high quality permeate which they produce. There is a growing need for such high quality water and this has led to increased research in the area of water treatment.

One of the major challenges facing the membrane community is (bio)fouling, resulting in higher trans-membrane resistances requiring higher pressure drops across the membranes which ultimately increase operational costs. Biofouling is perceived as one of the most stringent challenge facing the membrane industry [2]. This is due to the fact that this form of fouling is not easily prevented, unlike particulate fouling and scaling which can be reduced by pre-treatment and the use of anti-scalants.

Typically, RO and NF membranes are available in spiral-wound configuration. Spiral-wound modules consist of membrane leaves wound around a central perforated collection tube to obtain a high surface to volume ratio. Feed spacers are used to separate the membrane leaves and act as "turbulence" promoters within the membrane module, thereby reducing concentration polarization [3-4]. However, recently it has been suggested that these spacers are the initiation point from which biofilm formation originates [5-6].

Computational fluid dynamics (CFD) techniques have been employed in the study of spacers and its effect on hydrodynamics. Typically, the spacers have been simulated in 2D with different spacer configurations - submerged, cavity and zigzag configurations (looking at the channel from a side view) [3$4,7]$. Subramani et al. studied the influence of these different configurations on the flow profile and pressure drop and compared this to flow within an empty channel [3]. Ahmad et al. studied the influence of spacer geometry on hydrodynamics within a 2D channel [4]. They simulated the flow around three 
different shapes (square, triangular and circular objects) and observed that the triangular object gave the best performance in terms of reduction of concentration polarization and lowest pressure drop. Cao et al [8] studied the influence of cylindrical objects within a flow channel on the wall surface shear. They suggested that there is a maximum in the surface shear directly on top of the object and this decreases towards a minimum downstream of the object. This change in shear could affect the mass transfer on the membrane surface but could also lead to deposition of foulants at points of low shear.

To better simulate the fluid dynamics around net shaped spaces, 3D CFD approaches have been explored [9-15]. Ranade and Kumar [10] studied the influence of spacer shape on the hydrodynamics, pressure drop and wall surface shear. They also investigated the influence of channel shape on the simulation results, concluding that flat modules can be used in simulating the flow conditions within curved modules like spiral wound modules. Koutsou et al. [11] compared simulated flow conditions to experimental data on shear stress and particulate fouling. They investigated the effect of changing the geometrical properties of net shaped spacers on dimensionless numbers like Sherwood, Reynolds and Schmidt. Shakaib et al [12] studied the influence of distance between filaments, filament thickness and flow attack angle on the wall surface shear, flow directions and pressure drop. They observed a recirculation zone downstream of the spacer structure, the length of which is dependent on the distance between the filaments. Li et al. simulated the flow in spacer filled channels focusing on mass transfer enhancement and designed new configurations of spacers to further improve mass transfer [14, 15].

Only recently, Picioreanu et al. coupled the question of biofilm formation and hydrodynamic conditions [13]. They simulated biofilm growth in a spacer filled channel with a more realistic spacer geometry design in a larger computational domain. The biofilm growth was based on the initial attachment of the microbe, governed by the aid of a threshold shear stress value to allow attachment. They simulated three different stress thresholds $(1.5,10$ and $100 \mathrm{~Pa})$, observing the position of microbial growth and the influence on liquid flow within the spacer filled channels. They concluded that 
biofilm formation is governed by local shear stress as well as that the formation and growth of a biofilm significantly alters the hydrodynamics over the membrane/spacer.

Aside from CFD analysis, experimental techniques have been used in the study of membrane spacers and fouling. Membrane module "autopsies" have been used to study membrane/spacer fouling [5-6], where the module is dissected open and the internal surface examined for fouling. Direct optical techniques have also been applied in the study of membrane spacers and fouling [16-19]. Vrouwenvelder et al. designed a flow cell with transparent cover to study fouling within membrane/spacer filled channels [17]. They observed similar conditions within the flow cells as in spiral-wound modules (SWMs), with the added advantage of in situ visual characterization of the (bio)fouling. Neal et al. [18] studied the effect of spacer orientation on particle deposition using direct observation through the membrane (DOTM). They observed different deposition patterns depending on the orientation of the spacer and flow attack angle, for $90^{\circ}$ flow angle (parallel shaped), they observed a clear area directly behind the filament, which they ascribe to the recirculation of flows in that region. For $45^{\circ}$ flow angle (diamond shaped), they observed deposition starting from the centre of the cell, due to a confluence effect because of two flows coming together from either side of the node. For the $0^{\circ}$ flow angle, they observed a less defined deposition pattern with particles found primarily along the side filaments. Vrouwenvelder et al. [5] studied biofilm formation using NMR imaging coupled with visual observation of a membrane spacer channel. They observed the formation of filamentous biofilm streamers on the spacer junctions (nodes). Using NMR, they observed the initial formation of biofilm growth at the spacer junctions close to the module inlet. Subsequent growth of the biofilm resulted in biomass blocking parts of the spacers which leads to a flow field heterogeneity. Vrouwenvelder et al. [20] compared the experimental results to $3 \mathrm{D}$ simulation of biofilm formation within spacer filled channels. They suggested that the formation of biofilm is governed by shear, with a predominance of biofouling downstream of the spacers (due to the lower local shear rates). 
In this work, we aim to systematically address the question of particle deposition and biofouling on obstacles with tailored geometry inside the feed channel. We prepare membranes with such spacing obstacles integrated and study the evolution of deposits as a function of time and geometry. 


\section{Materials and Methods}

\subsection{Materials}

Polyethersulfone (PES) was used without further purification for the preparation of membranes with micro obstacles. N-methylpyrrolidone (NMP, Acros Organics) was used as a solvent for the membrane preparation with water as non-solvent. Tap water was used as a feed solution with added Sodium acetate (Merck). A net shaped spacer of thickness $0.7 \mathrm{~mm}$ and an $\mathrm{ACM}_{5}$ membrane of thickness $0.15 \mathrm{~mm}$ were obtained from TriSep, California, USA. Polystyrene particles with diameter $6 \mu \mathrm{m}$ (Polysciences, USA) dispersed in tap water was used as a model feed.

\subsection{Methods}

\subsubsection{Mold}

The mould was prepared by photolithographic techniques and etching of the structures into a silicon wafer. The structures etched into the mould included four different shapes; circular, kite, tear drop and four tipped star (see fig. 1). These structures were etched to a depth of ca. $350 \mu \mathrm{m}$.

\subsubsection{Structured membranes}

The structured membranes were prepared by pouring the polymer solution of PES/NMP $(13 / 87, w / w)$ on the mould at room temperature. The solution was cast on the mould using an adjustable casting knife set at a height of 0.55 $\mathrm{mm}$. The mould with the polymer solution was afterwards placed in a solvent rich (NMP) atmosphere for 3-4 $\mathrm{h}$ for complete filling of the wells within the mould. Afterwards, the mould containing the polymer solution was immersed in a non-solvent (tap water) bath for coagulation and phase separation (LIPS). The membrane was carefully removed from the mould after rinsing in water for $5 \mathrm{~h}$, and rinsed thoroughly in tap water for 1 day. Afterwards, the structured membranes were dried between tissues with a weight placed on it to prevent folding. 
The morphology of the structures was observed using SEM (JEOL 5600) at $5 \mathrm{kV}$. The structured membranes were sputtered with a thin layer of gold to improve conductivity. Figure 1 shows the SEM images of the structured membranes. The pictures show good reproduction of the mould geometries on the membrane. The structures are ca. 200-300 $\mu \mathrm{m}$ high. This height can be tuned by increasing the depth of features etched into the silicon wafer. To ensure that no issues arise from the height of the channel $(800 \mu \mathrm{m})$ in comparison to the structured membrane $(400 \mu \mathrm{m})$, a flat sheet membrane was placed beneath the structured membrane within the flow cell so the structures can reach the top plate.
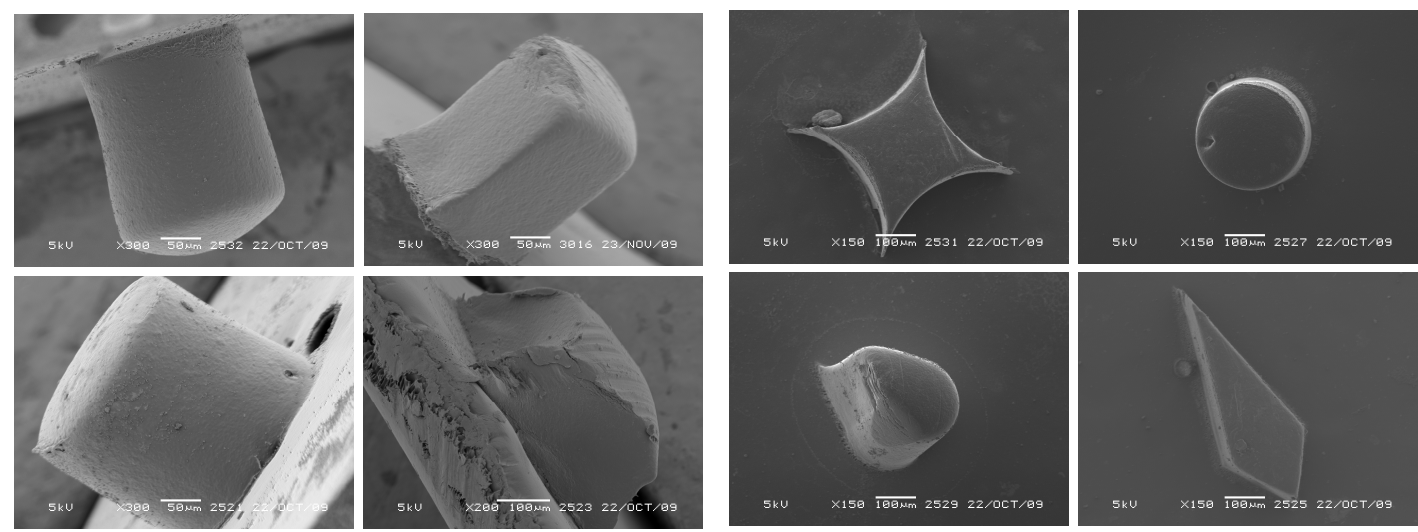

Figure 1. Cross section and surface SEM micrographs of structures on the membrane surface

\subsubsection{Setup}

The structured membranes were placed in a transparent flow cell. The custom made flow cell consists of two pieces of $1 \mathrm{~cm}$ thick PMMA plates. One plate contains a channel of height $0.8 \mathrm{~mm}$, with width and length of $2 \mathrm{~cm} \times 17$ $\mathrm{cm}$. The second plate contains five $1 \mathrm{~mm}$ holes on both ends of the channel for feeding. Both plates are held together by a steel jacket which encloses the entire structure. The flow cell is a modified version of the membrane fouling simulator described by Vrouwenvelder et al. [17]. The cell was modified by making it fully transparent to improve lighting conditions for imaging. The feed flow was managed using a liquid pump (Verder pumps, Leeds, UK). A camera (Pixelfly VGA, PCO AG, Germany) attached to magnifying lenses was used (Optem Zoom ${ }_{125}$ C, Quioptiq, USA) to image the structured membrane within the flow cell. The system operates at a maximum frame rate of $50 \mathrm{~Hz}$. 
The cell was illuminated with a cold light source (Euromex microscope B.V., Arnhem, The Netherlands).

\subsubsection{Fouling}

The structured membranes or the net shaped commercial spacer were placed in the flow cell described above. The feed solution used is tap water enriched with $900 \mu \mathrm{g} / \mathrm{L}$ of sodium acetate as a readily available carbon source. This feed solution is circulated through the flow cell at a flow rate of $1.667 \mathrm{~g} / \mathrm{s}$ which translates to an average cross flow velocity of $0.104 \mathrm{~m} / \mathrm{s}$ for a period of 6 days. Afterwards, pictures were made of the structures and the formed biofilm on the surface of the membranes/spacer.

For particulate fouling, polystyrene particles were dispersed in tap water at a concentration of $10 \mathrm{mg} / \mathrm{L}$. The feed was re-circulated across the flow cell at similar flow rates as above $(1.667 \mathrm{~g} / \mathrm{s})$ for $10 \mathrm{~h}$. Afterwards, images were made of the structured membranes.

\subsection{CFD simulation}

The commercial CFD software COMSOL (COMSOL Multiphysics) was used to simulate the hydrodynamics of the liquid around the geometries in 2D.

\subsubsection{Geometry}

The membrane spacer channel was modelled in 2D. Figure 2 depicts the geometrical domain and different structures used in subsequent simulations based on the actual geometries. Two unit cells were used to simulate the entire channel filled with structures to reduce computational time. Each unit cell contains the structure to be simulated in the centre of a $1.5 \mathrm{~mm}$ square.

\subsubsection{Simulation conditions}

The flow is governed by the Navier-Stokes and continuity equations assuming Newtonian incompressible fluid.

$$
\rho u \cdot \nabla u+\nabla p=\eta \nabla^{2} u
$$


$\nabla \cdot \mathrm{u}=\mathrm{O}$

Equation 2

(where $\rho$ is density $\left(\mathrm{kg} / \mathrm{m}^{3}\right), u$ is the velocity vector $(\mathrm{m} / \mathrm{s}), \eta$ the viscosity $(\mathrm{Ns} / \mathrm{m})$ and $\mathrm{p}$ is pressure $(\mathrm{Pa})$ ).
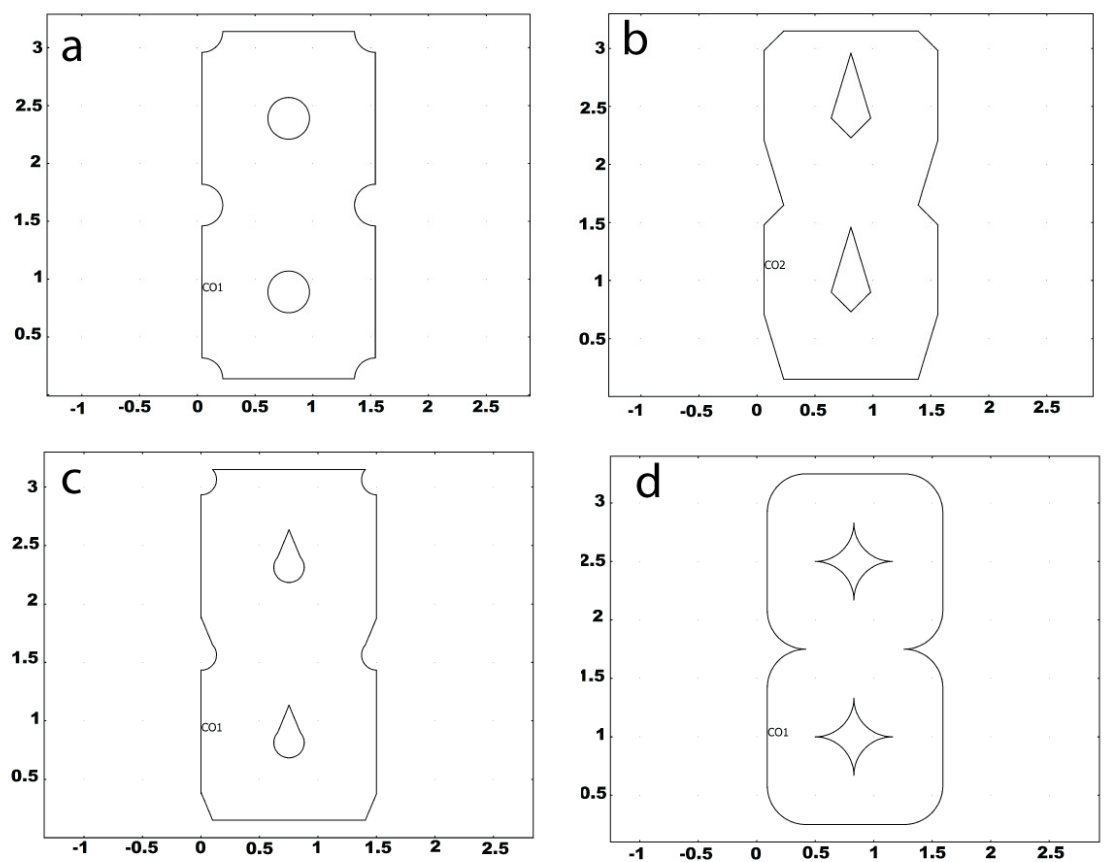

Figure 2. Computational domain for the different structures simulated

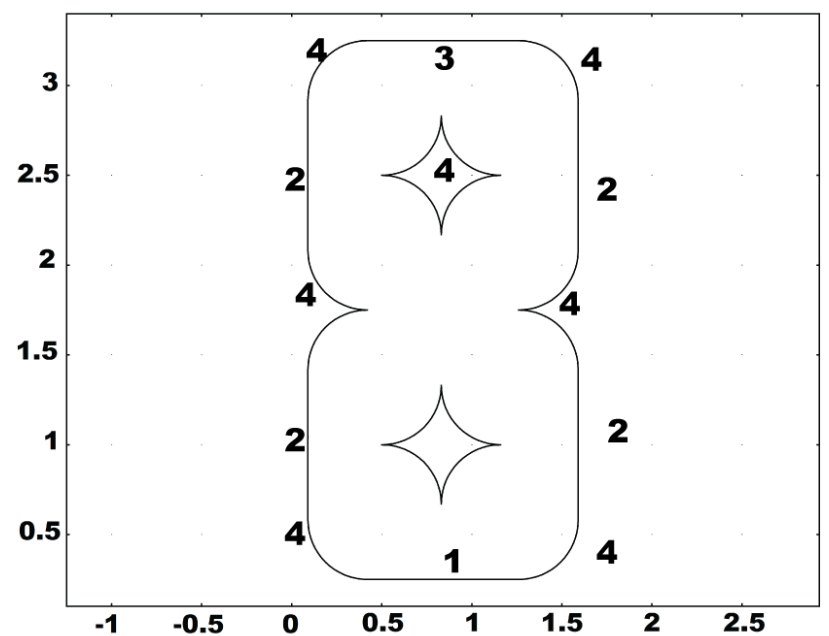

Figure 3. Typical computational geometry showing model boundary conditions [boundaries - 1 - Inlet (pressure), 2 - Symmetric, 3 - Exit (pressure) and 4 - Wall (no slip)] 
Figure 3 illustrates the boundary conditions applied to the geometries. The inlet (1) into the unit cell is described as an inlet pressure boundary. For the exit boundary (3), pressure is also applied and the two boundaries are connected using periodic couplings to ensure that the exit of the unit cell matches the entrance of the next unit cell. The structures (4) are described with no slip wall boundaries $(U=0)$. Symmetry boundaries are used to describe the surroundings (2) of the unit cells. The flow conditions were fixed to obtain an average crossflow velocity of $0.104 \mathrm{~m} / \mathrm{s}$ across the unit cells. 


\section{Results and discussions}

\subsection{CFD hydrodynamics}
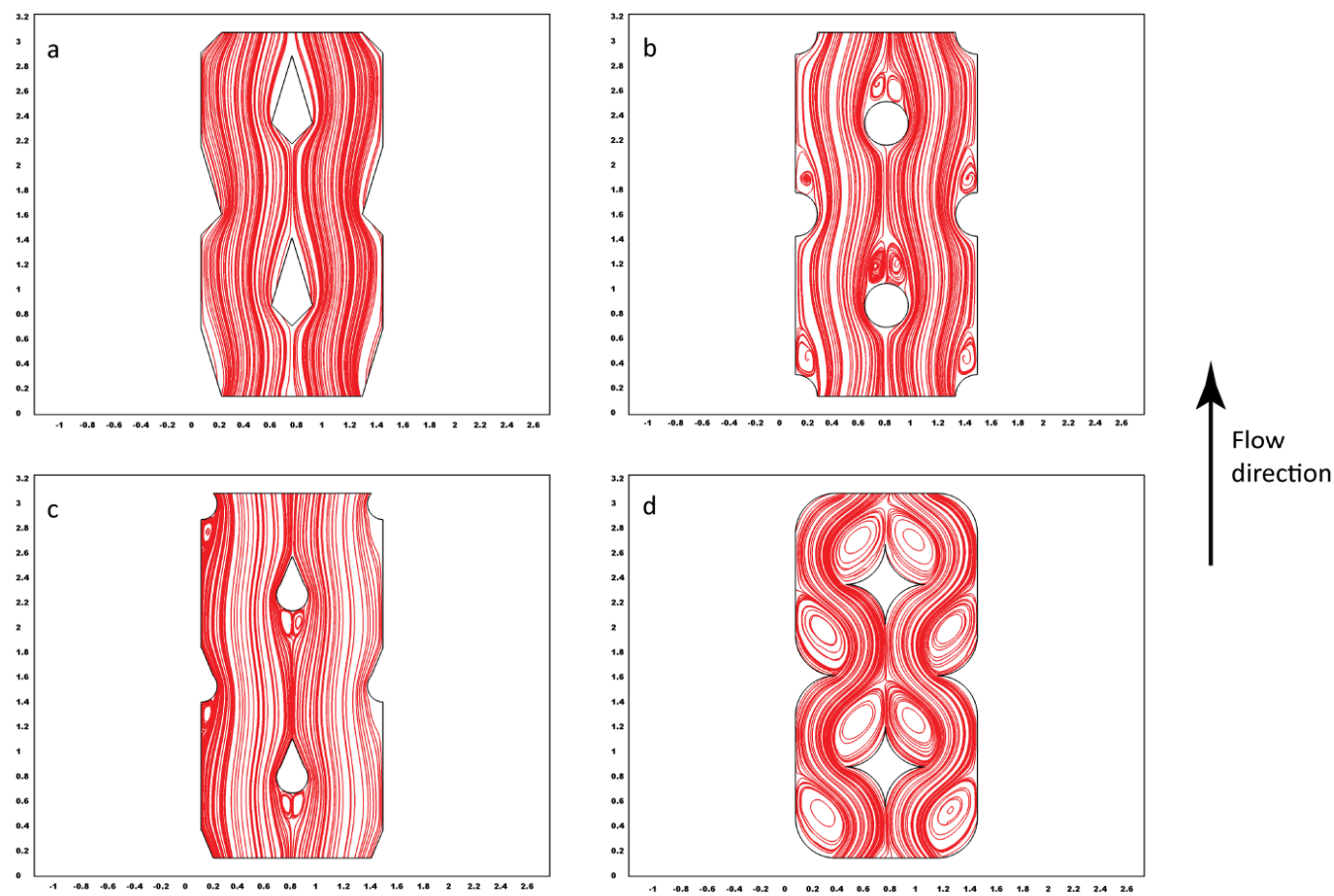

Figure 4. Streamline profiles of flow around structures, showing recirculation zones behind circular and star shapes (feed flow from bottom to top).

Figure 4 shows the streamline plots for the different micro-obstacles under steady state conditions. The plots show the fluid dynamics around the structures with the flow from the bottom to top. The circular and star shaped structures show a recirculation zone behind the structures under the conditions tested. This is not the case for the tear drop and kite shaped structures, which have no recirculation zones downstream of the structures under the flow conditions.

Figure 5 shows the velocity fields around the geometries with the flow from bottom to top. It can be seen that there is a large zone of low flow velocity downstream of the star shape in comparison to the kite and tear shapes (slipstream effect). This is in accordance with the recirculation zones observed with the streamline plots. The low velocity results in lower local

$$
P \text { a g e } \mid 70
$$


Reynolds numbers and lower surface shear rates behind the structures. The kite and tear shapes show smaller regions of low flow compared to the star and circular shapes. The highest velocities are observed alongside the structures, due to a narrowing of the channel available for liquid flow. This leads to an increase in average velocity from $0.104 \mathrm{~m} / \mathrm{s}$ to about $0.16 \mathrm{~m} / \mathrm{s}$. The liquid undergoes a directional shift as it approaches the structures due to the division of liquid flow around the obstacle. This can be seen from the streamlines in Figure 4. This shift in direction leaves a stagnant zone upstream of the structure (front), the size of which depends on the structure. Downstream of the structures, there is an extended stagnant zone which stretches towards the next structure.

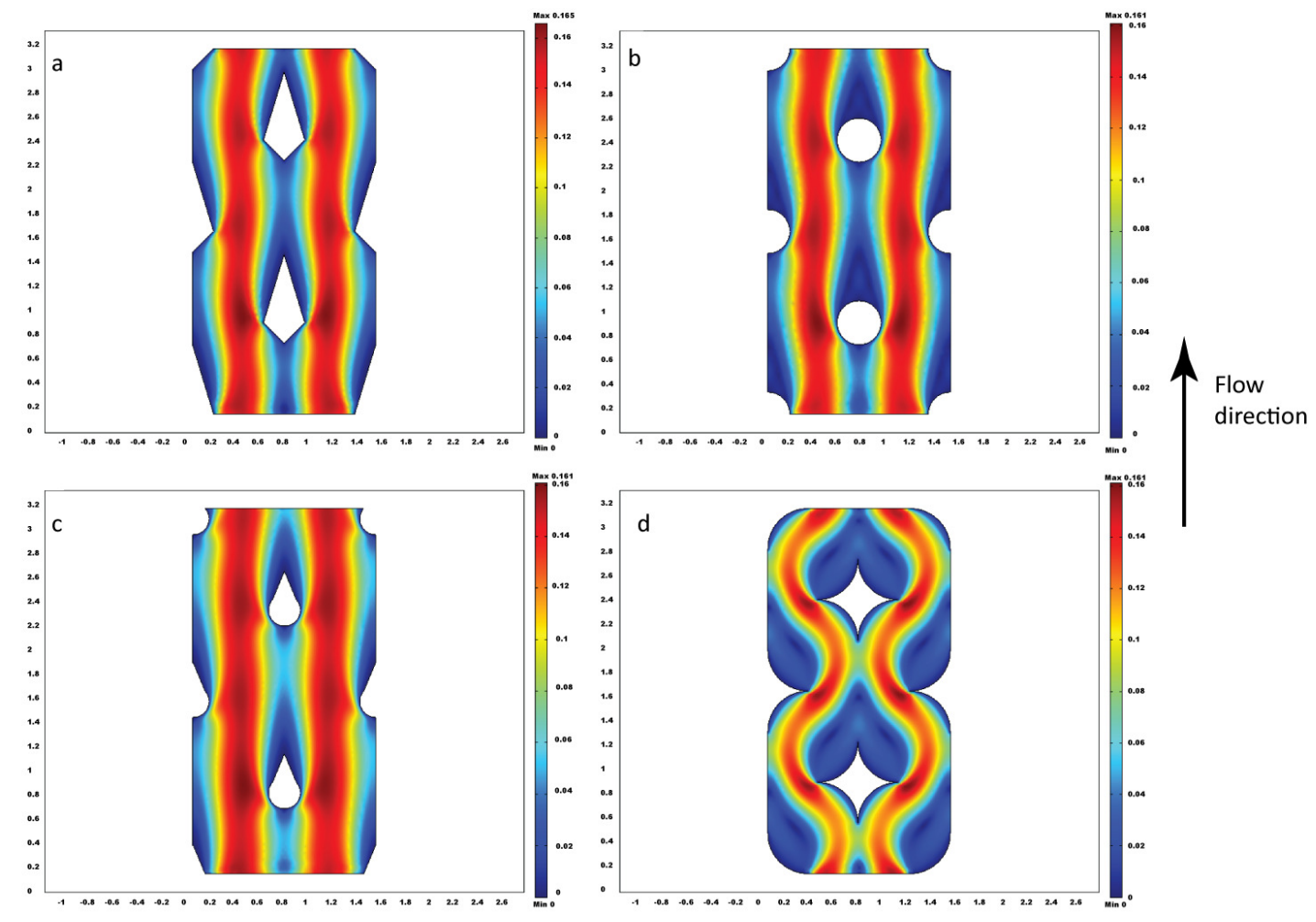

Figure 5. Velocity fields around structures with flow from bottom to top showing zones of low velocity downstream of the structures

Figure 6 shows the streamline and velocity plots for two of the shapes with the flow reversed (top to bottom). Recirculation zones are present downstream of the structures. The change in orientation results in a sharper frontal point meeting the flow with a broader surface behind leading to the formation of a recirculation zone. These recirculation zones are not very large 
compared to that observed near the star shaped obstacles. The tear shaped structure (with a round structure behind) shows an earlier reattachment of the flows with the kite shaped structure leaving a longer trail for the recirculation.
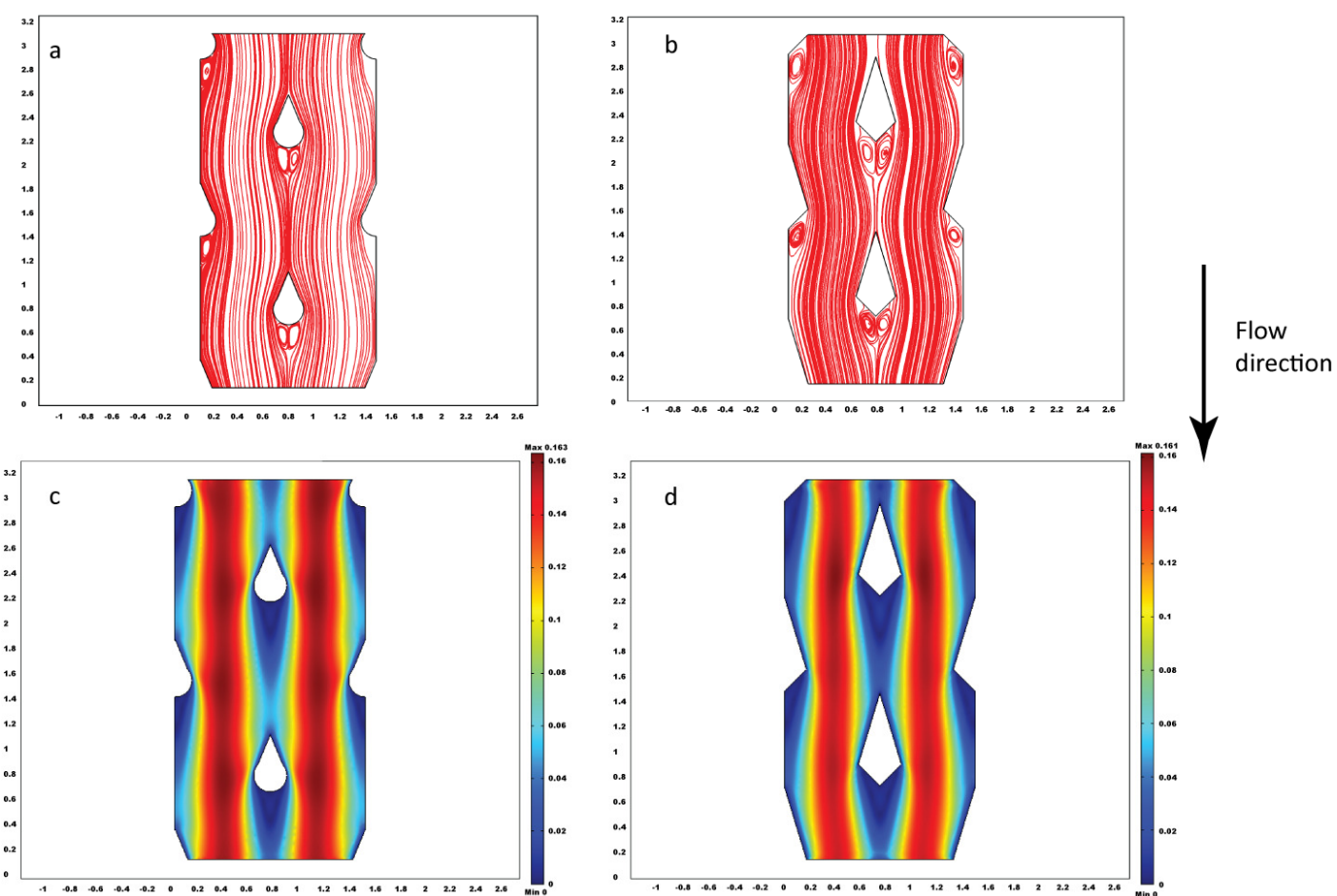

Figure 6. Streamline and velocity plots for 2 structures with change in flow direction (feed flow from top to bottom)

\subsection{Wall surface shear}

Figure 7a shows the local wall surface shear for the simulated geometries. The shear was obtained by determining the velocity gradient near the surface of the object. This was done at nine equidistant points counting in a clockwise direction from the point downstream of the flow to the point directly facing the flow (representing half of the structure) see Figure $7 \mathrm{~b}$. 

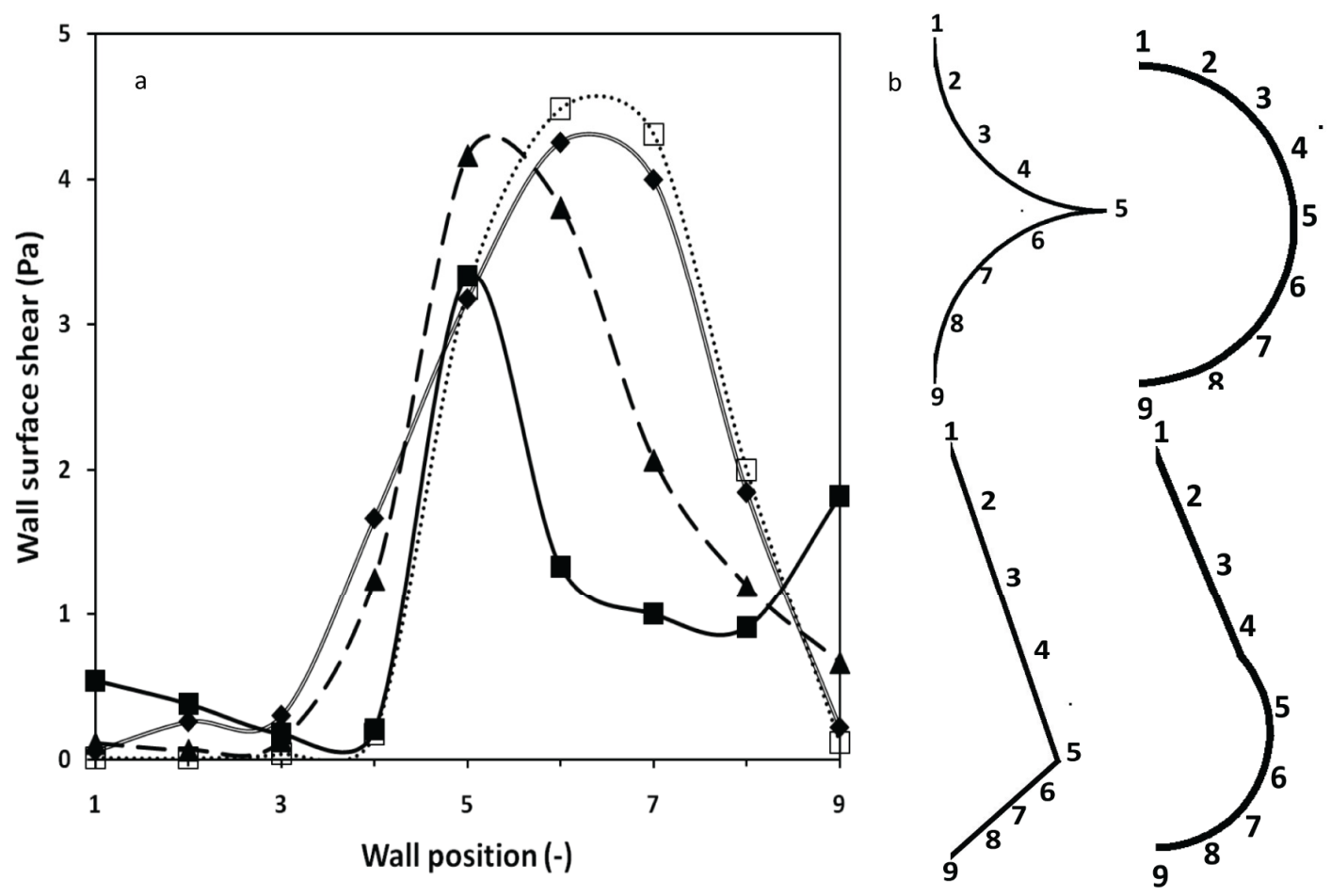

Figure 6a. Wall surface shear dependent on position numbered from downstream of the structure towards the front. ( $\square$-tears (rounded front), $\mathbf{\Delta}$ kite (shorter front), $\boldsymbol{\square}$ - star, $\boldsymbol{\bullet}$ circular structures) b) Illustration of points used in obtaining wall surface shear (6a.) with flow from bottom to top

From the figure, it can be seen that there is a maximum in the surface shear corresponding to the points on the sides of the structures. This corresponds to regions of higher velocities (Figure 5) and agrees with what has been observed in other 2D CFD simulations [8, 11-12]. It has also been suggested that these points of highest shear correspond to points with the largest mass transfer coefficient [12]. It can be seen from Figure 7 that the lowest surface shear rates are observed downstream of the structures. Slightly higher shear rates are observed in front of the structures. Moving along the structure perimeter, there is an increase in the shear for all the structures. After the maximum in surface shear at the side points of the structure, there is a decrease in wall shear going towards the back, with very low shear observed behind the structures. This is similar to what has been observed elsewhere with a maximum in surface shear at the top of round structures by Cao et al. 
[8]. It has been suggested that these regions of low shear could lead to fouling [11].

\subsection{Biofilm formation}

Tap water spiked with $900 \mu \mathrm{g} / \mathrm{L}$ of sodium acetate was re-circulated through the module for 6 days to allow for biofilm growth. Figure 8 shows images taken after six days, with the feed flow from right to left in all cases. It can be seen from the images that there is predominance of biofilm formation upstream of the structures, independent of their orientation. Downstream of the structures, a streamer filamentous biofilm is sometimes evident, anchored to the back of the structure.
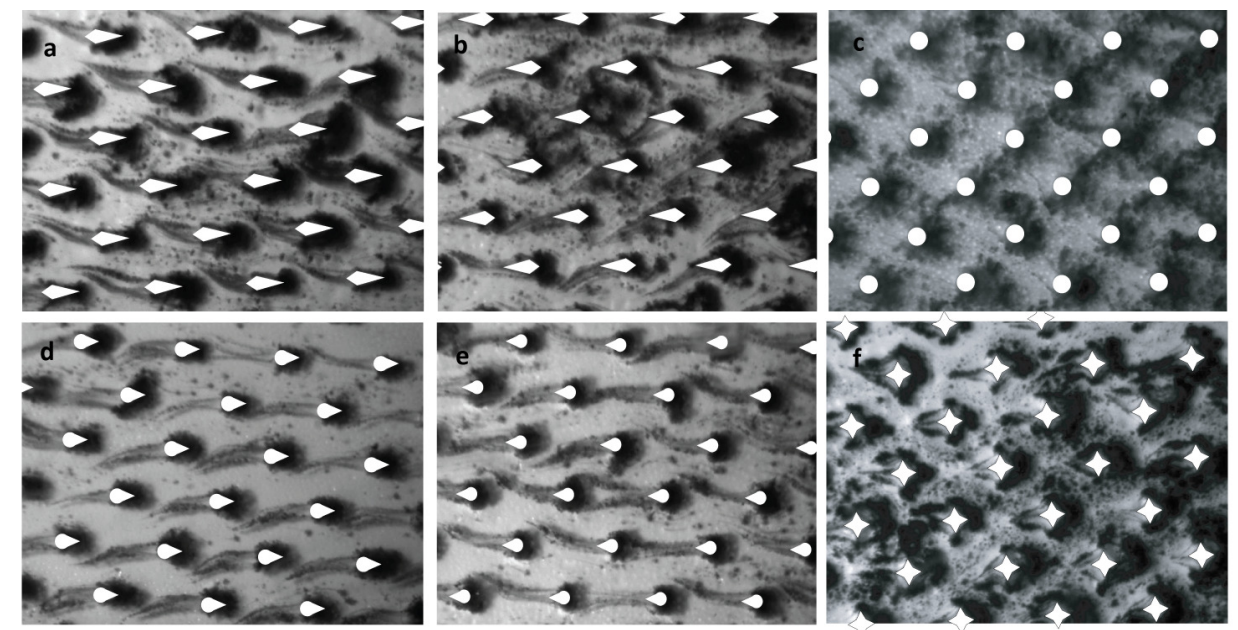

Flow direction

Figure 8. Images of fouled structured membranes (feed flow from right to left in all cases) showing biofouling as dark areas attached to micro obstacles (white shapes)

Indeed biofilm formation could be observed on the surface of the micro obstacles as comparably as on spacers [5]. This could be due to the use of these structures as points of attachment by the microbes. However, growth of the microbial biomass was observed mainly upstream of the structures irrespective of the orientation. This location of microbial biomass is contrary to reports on growth of biofouling being governed by low surface shear (considering that the lowest shear is observed downstream of the structures).

The initiation of biofouling is suggested to be comparable to particulate deposition, whereby the microbes attach upon contacting the obstacles. Considering the fact that upstream of the structure, a nutrient rich zone is 
present due to constant replenishment of the feed, this could also fuel the growth of the biofilm at this spot. Regions of very low substrate concentrations have been observed in simulations downstream of the biofilm patches suggesting a depletion in nutrients due to poor convective forces [13]. This could influence the growth of the biofilm with increasing biomass upstream.

The biofouling of structured membranes was compared to a net shaped spacer under similar fouling conditions. Figure 9 shows images of a fouled spacer with the flow from right to left taken at different periods during the experiment. The pictures show again onset of biofilm formation upstream of the spacer junctions ( $g b$ ). Figure $g c$ shows the fouling at the end of the experiment with the biofouling observable in front of the spacer junctions and to a lesser extent on the filaments. This observation agrees with the results obtained using the micro structured membranes in terms of biofilm positioning. It is however in contradiction to reports regarding the positioning of biofilm formation [20].
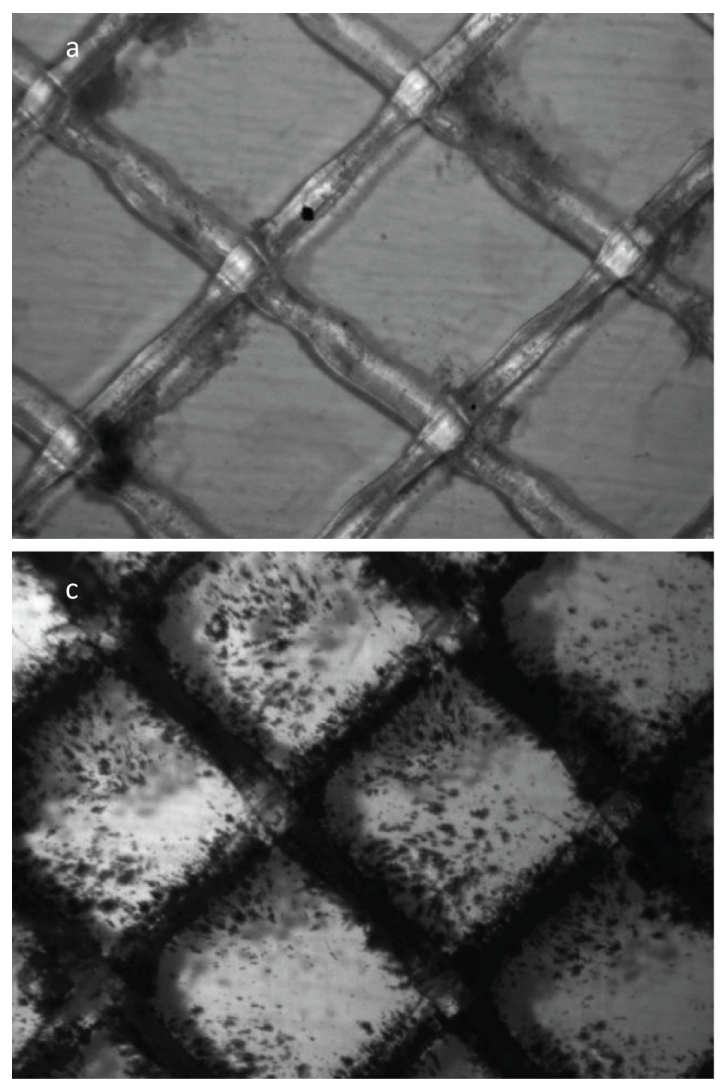
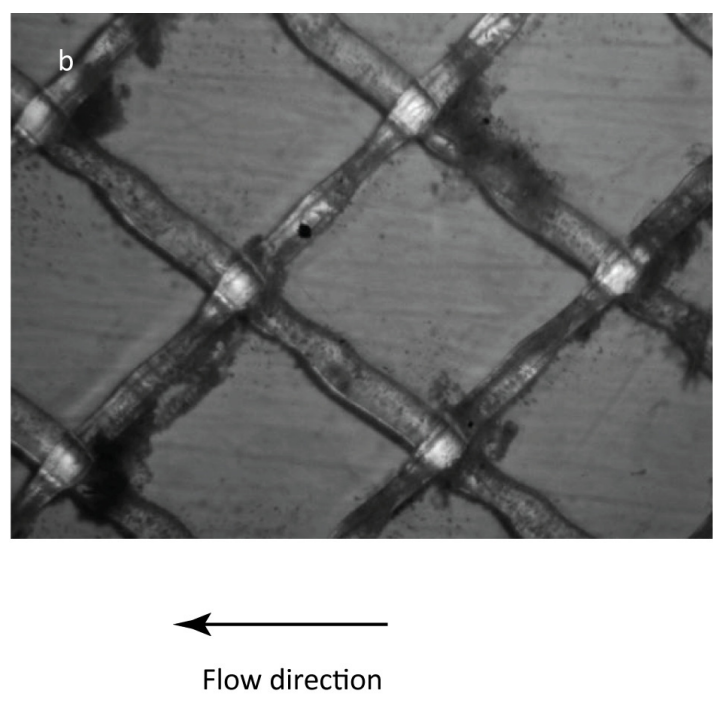

Figure 9. Images of fouled net shaped spacer (feed flow from right to left) showing biofouling as darker areas on spacer filaments a) 3rd day, b) 4th day and c) 6th day of fouling. 


\subsection{Particulate fouling}

To distinguish between deposition only and not biofilm growth, experiments were carried out using inert polystyrene particles. The feed solution containing $10 \mathrm{mg} / \mathrm{L}$ of polystyrene particles in tap water was circulated through the module for $10 \mathrm{~h}$ to allow for particle deposition on the structures. Figure 10 shows the images made at the end of the experiment with the feed flow from right to left in all cases. The images show deposition of particles upstream of the structures regardless of the orientation. Particulate fouling on the structures suggest that there is a dead zone (where particles are convectively forced onto the surface of the structure) in front of the structures leading to the formation of deposits at these points. The structures function as obstacles against the liquid flow, and the particles on contacting the obstacle are deposited onto the surface.

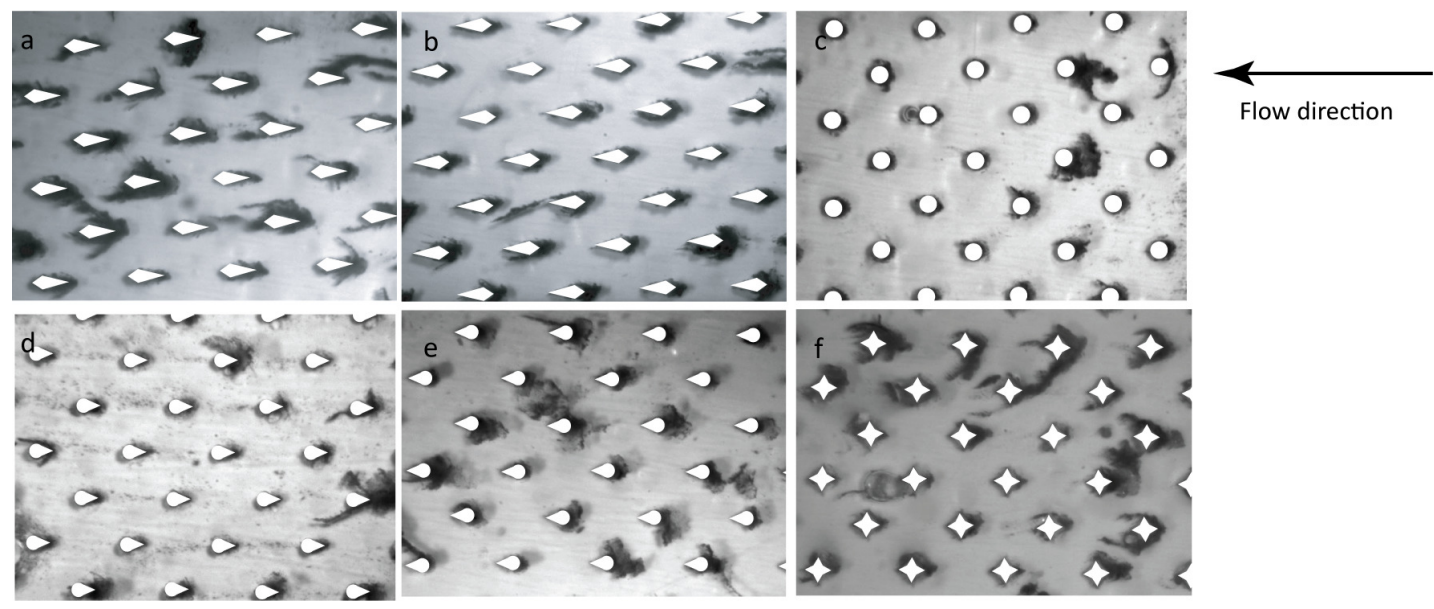

Figure 10. Images of fouled structured membranes (feed flow from right to left in all cases) showing particulate fouling as dark areas

Visually, it can be seen that a lower amount of foulants is observed with the particles in comparison to the biofouling. This can be attributed to the biomass being able to adhere and grow thereby increasing in mass and resisting the liquid shear. On the other hand, for the particulate fouling, there is a limited mass of particles that can be deposited on the surface of the structures, after which there is equilibrium between the deposition and detachment of particles from the structure surface. The position of initial particle deposition strongly correlates with observations on biofouling. 


\section{Conclusions}

Membranes with four different geometrical obstacles (free standing structures) were replicated and the biofouling properties were determined. This was compared to biofilm formation on the filaments of a net shaped spacer under similar experimental conditions. 2D CFD simulations were performed of the four different structures to observe the fluid hydrodynamics around these obstacles.

The simulations showed the formation of re-circulation zones downstream of the structures for both the star and circular geometries. The tear drop and kite shaped structures showed a continuous streamline with direct reattachment of the flows behind the obstacle. The local surface shear on the structure walls showed the lowest shear rates behind the structure (downstream of the flow) and the highest shear rates on the sides. The shear rate on the front of the structures was higher than at the back. Biofilm formation on the structures showed initiation of biofilm growth upstream, resulting in larger mass of microbial biomass as compared to downstream. This is independent of the orientation of the structures as shown by reversing the flow direction for the different geometries. A net shaped spacer was used as a benchmark model for comparison of the biofilm formation. Biomass growth was observed upstream of the filaments in the spacers used with growth of the biofilm observed on the front side of the spacer junctions. This is contrary to previous reports suggesting biofilm formation downstream of the spacer junctions [20].

The positioning of biofilm formation has been observed to be on the structures rather than the membrane which is in accordance with suggestions that biofouling forms on spacers [5]. However, there was no observable relation between the local wall shear and biofilm formation. The zone upstream of the structures could lead to easier attachment of the biomass which is assumed to proceed according to particulate fouling. These new observations support the need for an extensive and comprehensive research 
effort to correlate hydrodynamic conditions, micro-topology and particle (biomass) surface properties.

\section{$P$ a g e $\mid 78$}




\section{References}

(1) Shannon, M. A., Bohn, P. W., Elimelech, M., Georgiadis, J. G., MarÄ@as, B. J., and Mayes, A. M. Science and technology for water purification in the coming decades. Nature, 2008, 452 (7185), 301-310.

(2) Flemming, H. C., Schaule, G., Griebe, T., Schmitt, J., and Tamachkiarowa, A. Biofouling - The Achilles heel of membrane processes. Desalination, 1997, $113(2-3), 215-225$.

(3) Subramani, A., Kim, S., and Hoek, E. M. V. Pressure, flow, and concentration profiles in open and spacer-filled membrane channels. Journal of Membrane Science, 2006, 277 (1-2), 7-17.

(4) Ahmad, A. L., Lau, K. K., and Abu Bakar, M. Z. Impact of different spacer filament geometries on concentration polarization control in narrow membrane channel. Journal of Membrane Science, 2005, 262 (1-2), 138-152.

(5) Vrouwenvelder, J. S., Graf von der Schulenburg, D. A., Kruithof, J. C., Johns, M. L., and van Loosdrecht, M. C. M. Biofouling of spiral-wound nanofiltration and reverse osmosis membranes: A feed spacer problem. Water Research, 2009, 43 (3), 583-594.

(6) Tran, T., Bolto, B., Gray, S., Hoang, M., and Ostarcevic, E. An autopsy study of a fouled reverse osmosis membrane element used in a brackish water treatment plant. Water Research, 2007, 41 (17), 3915-3923.

(7) Ahmad, A. L. and Lau, K. K. Impact of different spacer filaments geometries on 2D unsteady hydrodynamics and concentration polarization in spiral wound membrane channel. Journal of Membrane Science, 2006, 286 (12), 77-92.

(8) Cao, Z., Wiley, D. E., and Fane, A. G. CFD simulations of net-type turbulence promoters in a narrow channel. Journal of Membrane Science, 2001, 185 (2), 157-176. 
(9) Lau, K. K., Abu Bakar, M. Z., Ahmad, A. L., and Murugesan, T. Feed spacer mesh angle: 3D modeling, simulation and optimization based on unsteady hydrodynamic in spiral wound membrane channel. Journal of Membrane Science, 2009, 343 (1-2), 16-33.

(10) Ranade, V. V. and Kumar, A. Fluid dynamics of spacer filled rectangular and curvilinear channels. Journal of Membrane Science, 2006, 271 (1-2), 1-15.

(11) Koutsou, C. P., Yiantsios, S. G., and Karabelas, A. J. A numerical and experimental study of mass transfer in spacer-filled channels: Effects of spacer geometrical characteristics and Schmidt number. Journal of Membrane Science, 2009, 326 (1), 234-251.

(12) Shakaib, M., Hasani, S. M. F., and Mahmood, M. CFD modeling for flow and mass transfer in spacer-obstructed membrane feed channels. Journal of Membrane Science, 2009, 326 (2), 270-284.

(13) Picioreanu, C., Vrouwenvelder, J. S., and van Loosdrecht, M. C. M. Threedimensional modeling of biofouling and fluid dynamics in feed spacer channels of membrane devices. Journal of Membrane Science, 2009, 345 (1-2), 340-354.

(14) Li, F., Meindersma, W., De Haan, A. B., and Reith, T. Novel spacers for mass transfer enhancement in membrane separations. Journal of Membrane Science, 2005, 253 (1-2), 1-12.

(15) Li, F., Meindersma, W., De Haan, A. B., and Reith, T. Optimization of commercial net spacers in spiral wound membrane modules. Journal of Membrane Science, 2002, 208 (1-2), 289-302.

(16) Willems, P., Kemperman, A. J. B., Lammertink, R. G. H., Wessling, M., van Sint Annaland, M., Deen, N. G., Kuipers, J. A. M., and van der Meer, W. G. J. Bubbles in spacers: Direct observation of bubble behavior in spacer filled membrane channels. Journal of Membrane Science, 2009, 333 (1-2), 38-44. (17) Vrouwenvelder, J. S., van Paassen, J. A. M., Wessels, L. P., van Dam, A. F., and Bakker, S. M. The Membrane Fouling Simulator: A practical tool for 
fouling prediction and control. Journal of Membrane Science, 2006, 281 (1-2), 316-324.

(18) Neal, P. R., Li, H., Fane, A. G., and Wiley, D. E. The effect of filament orientation on critical flux and particle deposition in spacer-filled channels. Journal of Membrane Science, 2003, 214 (2), 165-178.

(19) Gimmelshtein, M. and Semiat, R. Investigation of flow next to membrane walls. Journal of Membrane Science, 2005, 264 (1-2), 137-150.

(20) Vrouwenvelder, J. S., Picioreanu, C., Kruithof, J. C., and van Loosdrecht, M. C. M. Biofouling in spiral wound membrane systems: Three-dimensional CFD model based evaluation of experimental data. Journal of Membrane Science, 2010, 346 (1), 71-85. 


\section{Chapter 5. $\mathrm{CO}_{2}$ Nucleation In Membrane Spacer Channels Remove Biofilms And Fouling Deposits}

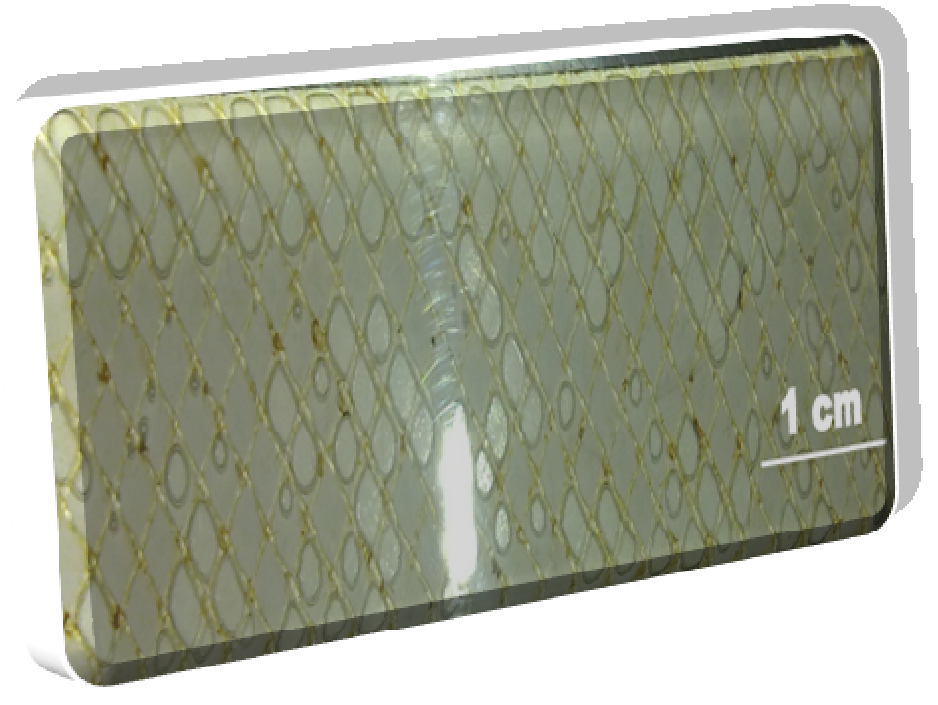

This manuscript will be submitted in revised form to Journal of Membrane Science

$$
\text { P a g e } \mid \mathbf{8 2}
$$




\section{Introduction}

Membrane fouling is presently a significant problem in the application of membrane systems for the production of drinking water. Fouling can be divided into particulate fouling, either organic or inorganic, and biofouling. Biofouling which is defined as accumulation of matter on a surface by growth and/or deposition to a level that causes operational problems including increased pressure drop across the system which indirectly results in a reduction in the permeate production [1-3]. The formation of a biofilm also enhances the tendency for particulate fouling and scaling [4-5]. This in turn leads to increased economic costs of running the system due to the need to either mechanically or chemically remove the biofilm from the membrane, increased pressure to maintain permeate production and replacement of membrane modules. This is a major concern for nanofiltration and reverse osmosis plants due to the formation of such biofilms on the membranes within spiral wound modules.

Backwash techniques are applied in the removal of fouling from the surface of membranes. However, this is not applicable in spiral wound reverse osmosis and nanofiltration modules. In practice, the technique is mainly applied in hollow fibre ultrafiltration modules. Backwashing involves flow reversal from the permeate side towards the feed side of the membrane system. Such a mechanical cleaning process might be effective in removing foulants from within the membrane pores and cake from the membrane surface. Backwash techniques have also been combined with air sparging to improve the removal of foulants from the membrane surface [6-7]. Furthermore, a high crossflow velocity can be used in a forward flush to mechanically remove foulants from the membrane surface. Forward flush is basically pumping permeate water at high pressures through the feed system in a bid to remove foulants from the membrane surface [8]. To further enhance the efficacy of such a cleaning technique, the flushing system can be done with alternating directions of liquid flow (from feed or retentate side). Forward flush techniques are useful in removing colloidal matter from the surface of 
membranes due to high surface shear generated on the surfaces of these membranes.

Gas sparging has been proposed for the removal of foulants from the membrane surface. Gas sparging can be applied via injection of air during the course of filtration to reduce fouling deposition and also intermittently to remove already formed deposits [9]. Sparging has proven to be quite cheap and effective in cleaning membrane surfaces and has been applied in the cleaning of different types of water processes ranging from removal of particulates and proteins in wastewater treatment to oils in membrane emulsions [7, 10-11]. Gas sparging is typically applied in MF/UF with the suggestion that it works best for tubular and flat sheet membranes and to a lesser extent in spiral wound modules [12]. Recently there have been a number of studies in the application of gas sparging in nanofiltration spiral wound modules for removal of biofouling $[1,11]$. There is a strong dependence of sparging efficacy on the frequency and duration of the sparging step. Channeling of the gas flow due to the preference for paths of minimum resistance can result in incomplete cleaning of the membrane module [13].

Chemical cleaning processes have been used to inactivate and remove biomass from membrane systems. Presently, this is one of the most widely employed techniques in removal of foulants from RO and NF spiral wound modules [14]. This usually involves the dosing of biocidal chemicals in the feed water of a membrane system in order to destroy the biofilms [15-17]. Several different chemical agents have been documented ranging from acidic cleaning to caustic cleaning and enzymatic cleaning techniques [14, 18]. The choice of chemical used in cleaning depends on the feed water characteristics and membrane properties. Typically, acidic cleaning can be effective in removal of calcinated salts while alkaline can be used to remove organics from membrane surfaces. However, even when these chemicals are able to inactivate the biofilms, there could be debris from the biomass which is not sufficiently removed. Insufficient removal of debris gives rise to an accelerated formation of the biofilms during subsequent return to normal 
water production $[1,10]$. Besides this, these chemical agents are known to reduce the lifespan of the membranes [17].

This paper introduces the concept of using $\mathrm{CO}_{2}$ saturated water in the cleaning cycle of a membrane/spacer module. The principle revolves around the fact that there is spontaneous formation of bubbles (nucleation) within the module due to local pressure differences as well as the presence of nucleation sites on the surface of the spacers. This method tries to improve module cleaning due to the production of bubbles in the entire feed channel. It is our aim to describe the details of the method and compare the new method with the two other currently used methods: clean water forward flush as well as water/ $\mathrm{N}_{2}$ sparging. 


\section{Materials and methods}

\subsection{Setup}

The experiments were performed using the setup shown in Figure 1. The setup is based on the filtration setup described by van de Ven et al [19]. The flow cell is custom made and consists of two pieces of $1 \mathrm{~cm}$ thick PMMA plates. One plate contains a channel of height $0.85 \mathrm{~mm}$, with sides $2 \mathrm{~cm} \times 17$ $\mathrm{cm}$. The second plate contains five $1 \mathrm{~mm}$ holes on both ends of the channel for feeding. Both plates are held together by a steel jacket which encloses the entire structure. The flow cell is a modified version of the membrane fouling simulator described by Vrouwenvelder et al. [20]. The cell was modified by making it fully transparent to improve lighting conditions for imaging.

The three flow cells were placed in parallel and connected to a recirculation line return to the feed vessel with valves to ensure constant flow through the

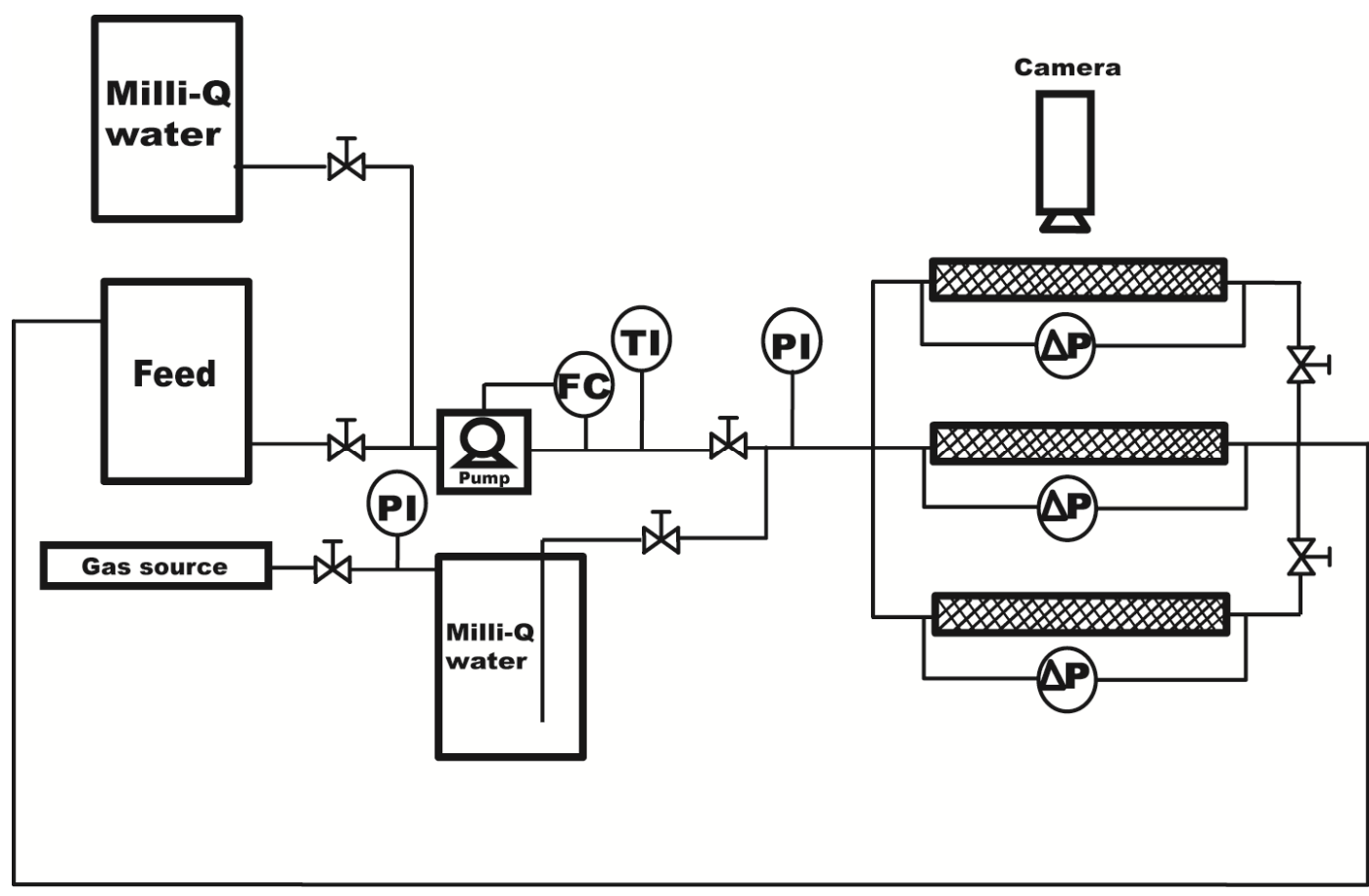

Figure 1. Illustration of fouling and cleaning setup

cells. Three flow cells were fouled in parallel for comparability during the cleaning process, since three different cleaning methods are to be tested. The 
feed flow rate was maintained with a mass flow controller (Bronkhorst, The Netherlands) regulated pump (Imatec, Germany). Inline temperature and pressure sensors were used to monitor the experimental conditions. A pressurized vessel with valves containing Milli- $Q$ water was placed in the line leading into the flow cells. A camera (Pixelfly VGA, PCO AG, Germany) attached to magnifying lenses was used (Optem Zoom ${ }_{125} \mathrm{C}$, Quioptiq, USA) in observing and recording the movement of bubbles within the flow cell [[13]]. The system operates at a maximum frame rate of $50 \mathrm{~Hz}$. The cell was illuminated from the rear with a cold light source (Euromex microscope B.V., Arnhem, The Netherlands).

\subsection{Materials}

A net shaped spacer of thickness $0.7 \mathrm{~mm}$ was placed over an $\mathrm{ACM}_{5}$ membrane of thickness $0.15 \mathrm{~mm}$ (both from TriSep, California, USA) and placed within the channel. $\mathrm{CO}_{2}$ was obtained from a central supply and dissolved in water inside the pressurized vessel. $\mathrm{N}_{2}$ gas was obtained from a central supply and fed directly into the flow cell. The feed solution was canal water obtained from the Twente Canal (Enschede, The Netherlands). Sodium acetate (Merck) was added to the feed solution at a concentration of 150 $\mu \mathrm{CC} / \mathrm{l}$. Clean water used in the experiments was obtained from a Synergy Milli-Q apparatus (Millipore, USA).

\subsection{Methods}

\subsection{1 $\mathrm{CO}_{2}$ saturation}

Initially, the $\mathrm{CO}_{2}$ was bubbled for 1 hour through the vessel to strip the water of other dissolved gases while also carbonating the Milli-O water. Afterwards, the vessel was pressurized with $\mathrm{CO}_{2}$ at 1 bar overpressure. This was allowed to stir for an extra 24 hours before usage.

\subsubsection{Hydraulic resistance}

To determine the hydraulic resistance of the cell, Milli-O water was pumped through the cell at increasing flow rates while recording the differential pressure across the cell. The hydraulic resistance of the flow cells was defined 
as the slope of the graph obtained by plotting the measured differential pressure $(\mathrm{Pa})$ against the feed flow rate $\left(\mathrm{m}^{3} / \mathrm{s}\right)$. The hydraulic resistance was determined prior to fouling, after fouling, and after the cleaning steps. The maximum crossflow velocity used in resistance determination was $0.05 \mathrm{~m} / \mathrm{s}$, to ensure that the determination of hydraulic resistance has minimal influence on the developed biofilm.

\subsubsection{Fouling}

The membrane spacer was fouled by circulating canal water through the cell at a flow rate of $1 \mathrm{~g} / \mathrm{s}$ which translates to an average cross flow velocity of $0.0625 \mathrm{~m} / \mathrm{s} .150 \mu \mathrm{gC} / \mathrm{l}$ sodium acetate was added to $25 \mathrm{l}$ of canal water to act as an easily assimilative organic carbon source for growth of the biofilm. This feed was circulated across three cells connected in parallel. These fouling conditions were maintained for a period of 7 days for adequate growth of the biofilm.

\subsubsection{Cleaning}

For cleaning of a fouled membrane spacer, the specific cleaning solution is pumped through the cell at a rate of $2.5 \mathrm{~g} / \mathrm{s}$ (translates to a velocity of 0.16 $\mathrm{m} / \mathrm{s}$ ) for a period of 15 minutes. During cleaning, the pressure drop was monitored across the flow cell. The cleaning efficacy was determined by measuring the hydraulic resistance before and after the cleaning step. Three different solutions were compared - Milli- $\mathrm{O}$ water (rinsing), Milli- $\mathrm{O}$ water with nitrogen gas (sparging) and carbonated Milli- $Q$ water (nucleating).

\subsubsection{Image analysis}

The flow paths of the bubbles within the flow cell were traced with an image processing tool, ImageJ (freeware, NIH). Image sequences were obtained during the cleaning steps. The sequence of images used in determining the bubble coverage and flow path was obtained at a frame rate of $50 \mathrm{~Hz}$ for $\mathrm{ca}$. 6.5 seconds. ImageJ was used to subtract the background from the image sequence. This was done by duplicating the image sequence, deleting the first frame from one and the last frame from the other. The two image sequences were then subtracted from one another thus eliminating the solitary objects. 
ImageJ is used to threshold and binarize the image sequence. The image sequence is then summed; overlaying all the frames together within one frame. Summation of the entire image sequence into a single image was used to determine the overall path of the bubbles within the flow channels. 


\section{Results and discussions}

\subsection{Fouling}

Figure 2 shows the pressure and flow measurements used in determining the hydraulic resistance of the flow cells. The flow was increased stepwise while recording the pressure drop across the cell. The hydraulic resistance is then obtained from the slope of the relationship between pressure and flow $(\Delta \mathrm{P} / \Delta \phi)$, see Figure $2 \mathrm{~b}$.
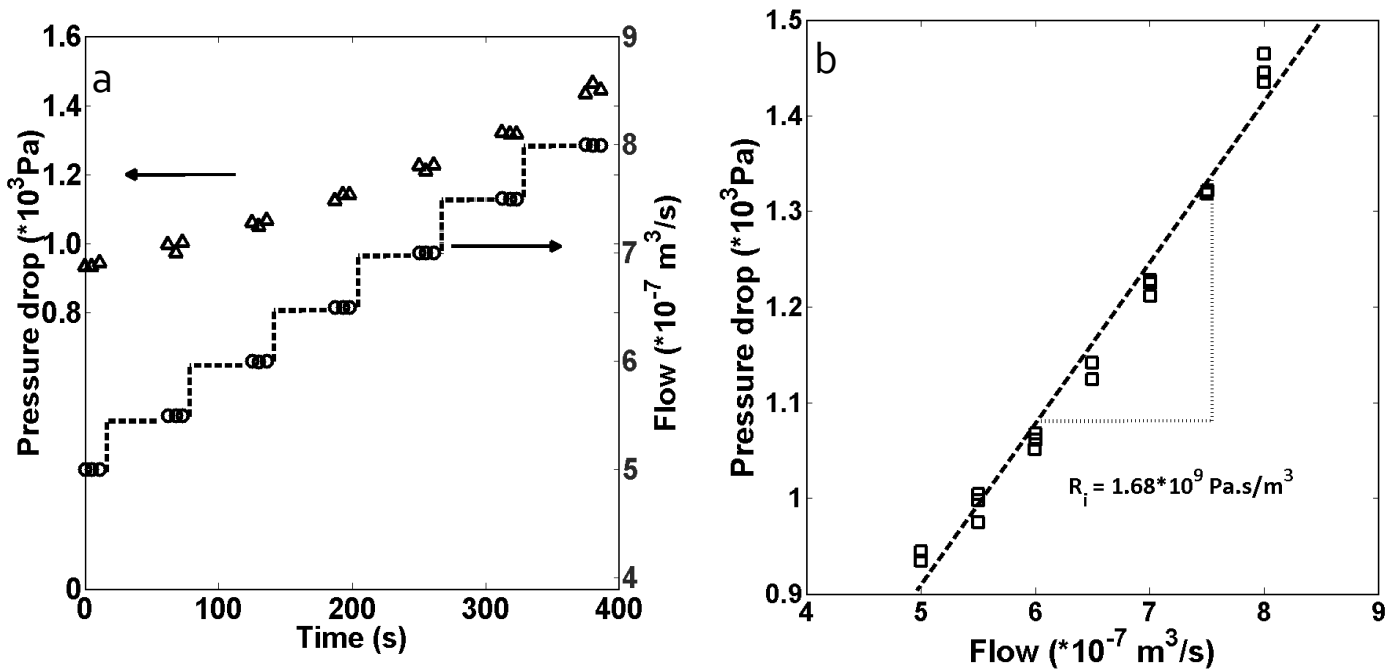

Figure 2. Typical hydraulic resistance measurement with stepwise flow increase, (b) flow vs pressure linear approximation

Table 1 shows the hydraulic resistances measured at three different periods during the course of the experiments. The initial hydraulic resistance was measured for the three test cells containing the membrane and clean spacers. All the three cells had similar hydraulic resistances at approximately $1.65 * 10^{9}$ $\mathrm{Pa} . \mathrm{s} / \mathrm{m}^{3}$. This was followed with fouling of the cells at a feed flow rate of $1 \mathrm{ml} / \mathrm{s}$ of canal water spiked with $150 \mu \mathrm{g} / \mathrm{l}$ of sodium acetate which translates to $0.0625 \mathrm{~m} / \mathrm{s}$ crossflow velocity across the cell. During the fouling experiment, there is initial pressure increase across the cell due to particulate fouling on the spacers. The deposition related pressure increase then stalled for a while, reproducibly in all three cells. The presence of particulate fouling can be observed on the spacer nodes at the end of this first phase. During the lag 
phase there is no visually observable change in the deposition of foulants on the membrane/spacer. The third phase of fouling commences with the growth of the biofilm which causes a continuous increase in pressure drop across the cell (Figure 3). As compared to the hydraulic resistance, the particulate fouling and subsequent biofouling increases the resistance by more than $100 \%$ (Table 1.) Figure 4 shows visual appearance of the fouled spacers as compared to the initial virgin spacers.

TABLE 1: Hydraulic resistance of 3 flow cells using different cleaning methods

\begin{tabular}{|l|c|c|c|}
\hline \multirow{2}{*}{\multicolumn{1}{|c|}{$\begin{array}{c}\text { Cleaning } \\
\text { methods }\end{array}$}} & \multicolumn{3}{|c|}{ Hydraulic resistance $\mathrm{R}\left({ }^{*} 10^{9} \mathrm{~Pa} . \mathrm{s} / \mathrm{m}^{3}\right)$} \\
\cline { 2 - 4 } & Initial $\left(\mathrm{R}_{\mathrm{i}}\right)$ & Fouled $\left(\mathrm{R}_{\mathrm{f}}\right)$ & Cleaned $\left(\mathrm{R}_{\mathrm{c}}\right)$ \\
\hline Water rinsing & 1.7 & 3.2 & 2.6 \\
\hline Water $+\mathrm{N}_{2}$ sparging & 1.6 & 3.3 & 1.9 \\
\hline Water $+\mathrm{CO}_{2}$ nucleation & 1.7 & 3.4 & 1.6 \\
\hline
\end{tabular}

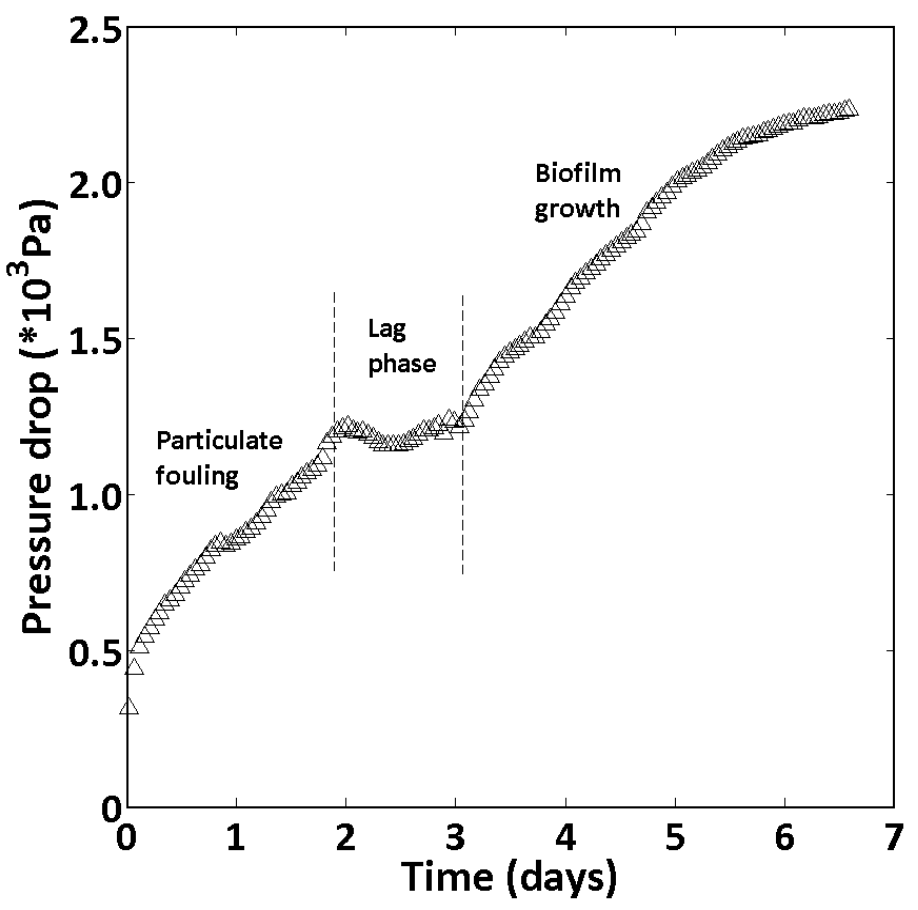

Figure 3. Development of pressure along spacer filled channel during flow experiment with surface water showing an initial state of particulate fouling, an intermediate lag phase, followed by subsequent biofilm growth 
The final hydraulic resistances measured at the end of the fouling experiments (after 7 days) are given in Table $1\left(R_{f}\right)$. This fouling can also be seen in images taken of the fouled test cells (Figure 4). This fouling layer deposited on the spacer filaments, in particular on the filament nodes, is stable and not removed by the flow stepping used to determine the hydraulic resistance of the spacer channel.

\subsection{Cleaning}

After the determination of the hydraulic resistance of the fouled cells, the cells were cleaned using the 3 different methods. The cleaning was carried out by clean water (rinsing), water/ $\mathrm{N}_{2}$ (sparging) or water saturated with $\mathrm{CO}_{2}$ (nucleation). For comparison, all the three cells were cleaned with the same vessel pressurized at 1 bar over pressure connected to the fouled cells via the same valve for all three cases. This is to ensure similar liquid flow rates within the cells. The presence of gas bubbles is expected to increase the velocity, however considering a calculated volume increase of $4 \%$, there is assumed to be minimal change in velocity. As can be seen from Table 1 , the hydraulic resistance after each cleaning shows remarkable differences.

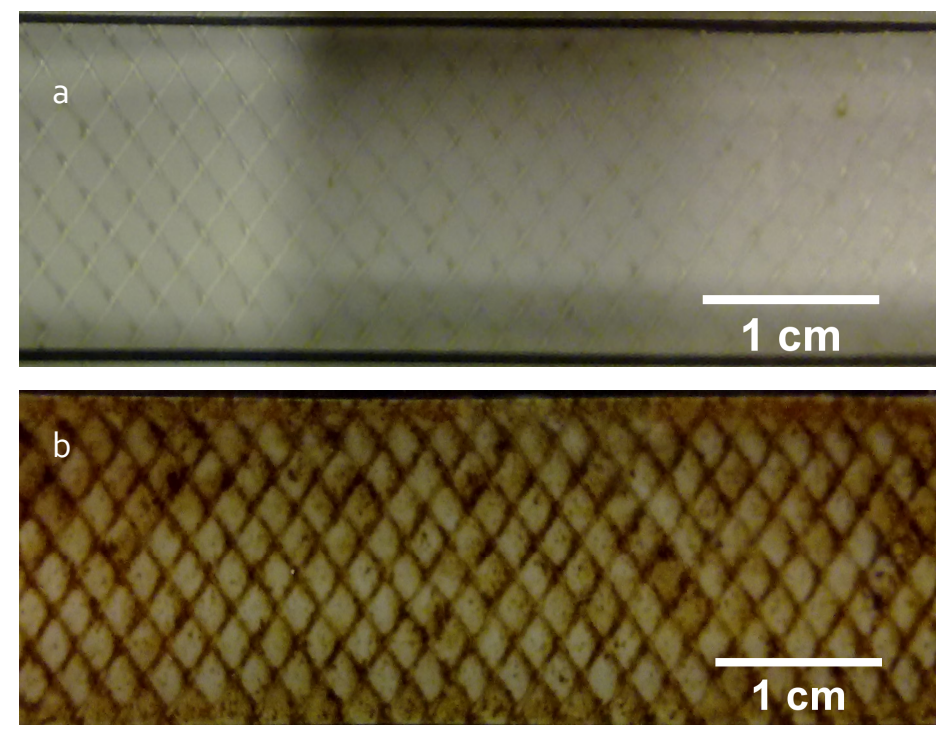

Figure 4. Optical representations of a spacer filled channel before (a) and after fouling for 7 days (b). 
The test cell cleaned with water (rinsing) resulted in partial cleaning only as shown by the incomplete recovery of initial resistance. The cleaning efficiency of only water was found to be about $40 \%$ in terms of fouling removal, measured as the reduction in the hydraulic resistance after cleaning. This result is comparable to that observed by Kennedy et al [21]. The high cross flow velocity of the water (2.5 times the velocity used in the fouling period) across the test cell accounts for the partial cleaning of the fouling from the surface of the membrane/spacer.
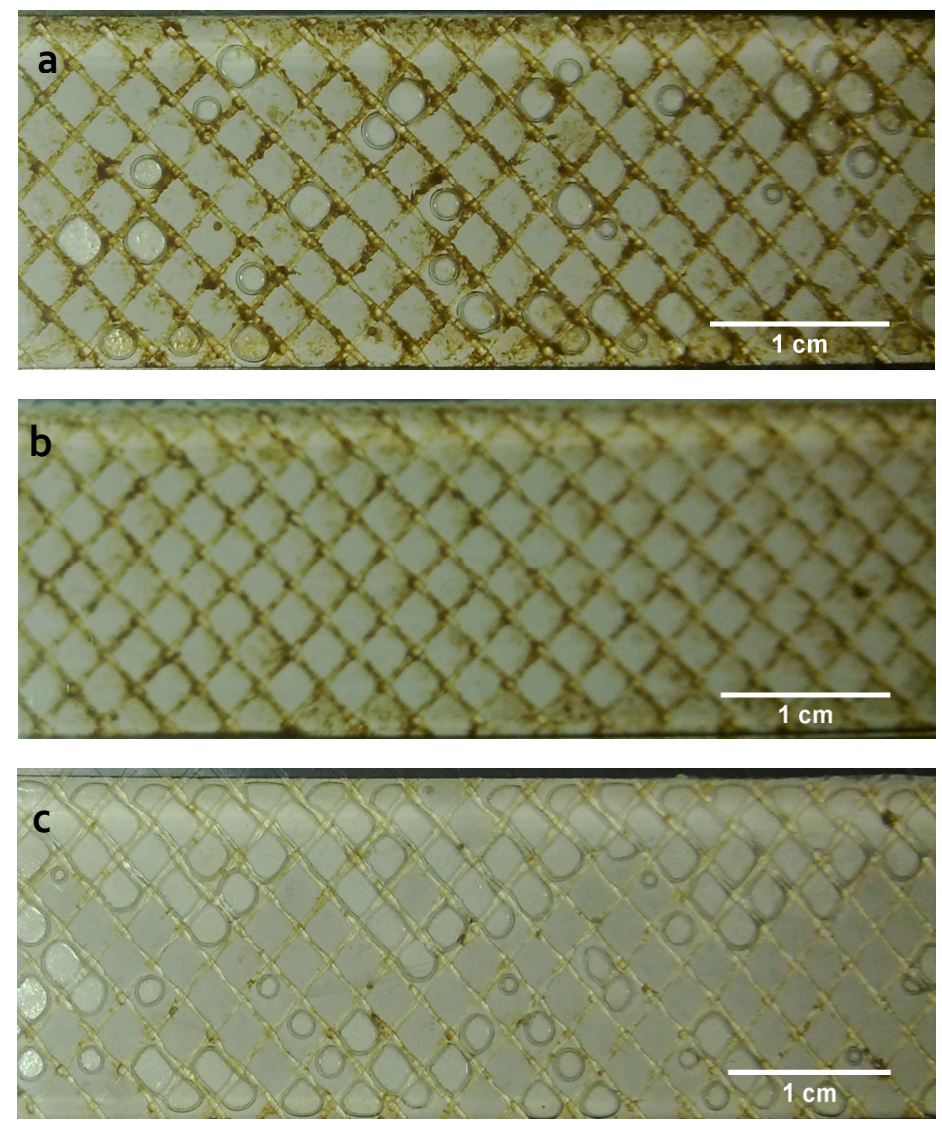

Figure 5. Images of flow cells after cleaning protocol - (a) water rinsing, (b) water $/ \mathrm{N}_{2}$ sparging and (c) water $/ \mathrm{CO}_{2}$ nucleation

The second test cell which was cleaned with $\mathrm{N}_{2}$ sparging showed better cleaning results. The cleaning efficiency was approximately $85 \%$ in terms of fouling removal (measured as the reduction of hydraulic resistance). This is comparable to what is reported by Cornelissen et al [10]. They determined that air sparging is able to restore the membrane resistance close to the initial 
value. The presence of gas bubbles in the flow channel increases the shear forces on the surface of the spacers and the membrane resulting in better cleaning effects [22].

The third test cell was cleaned with $\mathrm{CO}_{2}$ saturated water and showed the best cleaning results. The efficiency of this new cleaning method in terms of fouling removal and thus restoration of clean water hydraulic resistance was about $100 \%$. Visually, gas bubbles can be observed to form within the entire flow channel distributed over the length and width of the feed channel. In contrast to the observations from the water $/ \mathrm{N}_{2}$ sparging, no stagnant bubbles or bubble channelling was observed within the cell. Such stagnant bubbles exclude new bubbles and block further bubble scouring. This is a result of the continuous nucleation and growth of bubbles within the cell and explains the additional effectiveness of the method. Figure 4 shows the flow cells after the cleaning procedures ( $\mathrm{A}$ - cleaned with Milli- $\mathrm{O}$ water, $\mathrm{B}$ - cleaned with Milli- $\mathrm{O}$ water $/ \mathrm{N}_{2}$ and $\mathrm{C}$ - cleaned with Milli-O water $/ \mathrm{CO}_{2}$ ). There is a clear visual difference in the cells, with Figure ${ }_{5} \mathrm{C}$ showing a much whiter (cleaner) membrane/spacer in comparison to the other cells.

The cleaning protocol employed lasted for 15 minutes, however, visual observation suggests that the cleaning is done within the first minutes. This indicates that water $/ \mathrm{CO}_{2}$ cleaning is a potentially more feasible industrial process due to a reduction in downtime as well as a reduction in cleaning costs. A conservative determination of the $\mathrm{CO}_{2}$ emission by applying this protocol in a $80 \mathrm{~m}^{3} / \mathrm{h}$ permeate production plant and cleaning the modules for 5 minutes weekly with water saturated with $\mathrm{CO}_{2}$ at 2 bar equals about $1 \%$ of the energy related equivalent emission during normal permeate production. However, this determination neglects the gains due to lower chemical usage, lower downtime and better overall plant efficiency.

\subsection{Bubble coverage}

Visually, we observed a reduction in stagnant bubble immobilization and as a result less problems with channelling in the cleaning experiments with water $/ \mathrm{CO}_{2}$. This effect may be responsible for the improvement in fouling 
removal and can be visualized by image analysis. Figure 6 compares the movement of bubbles in the cell cleaned with water and nitrogen gas and the cell cleaned with carbon dioxide saturated water. Flow within the cells is from left to right of the channels.

The images are a sum of the image sequences obtained during the course of cleaning (ImageJ) and show the overall presence of bubbles within the cell as brighter areas.

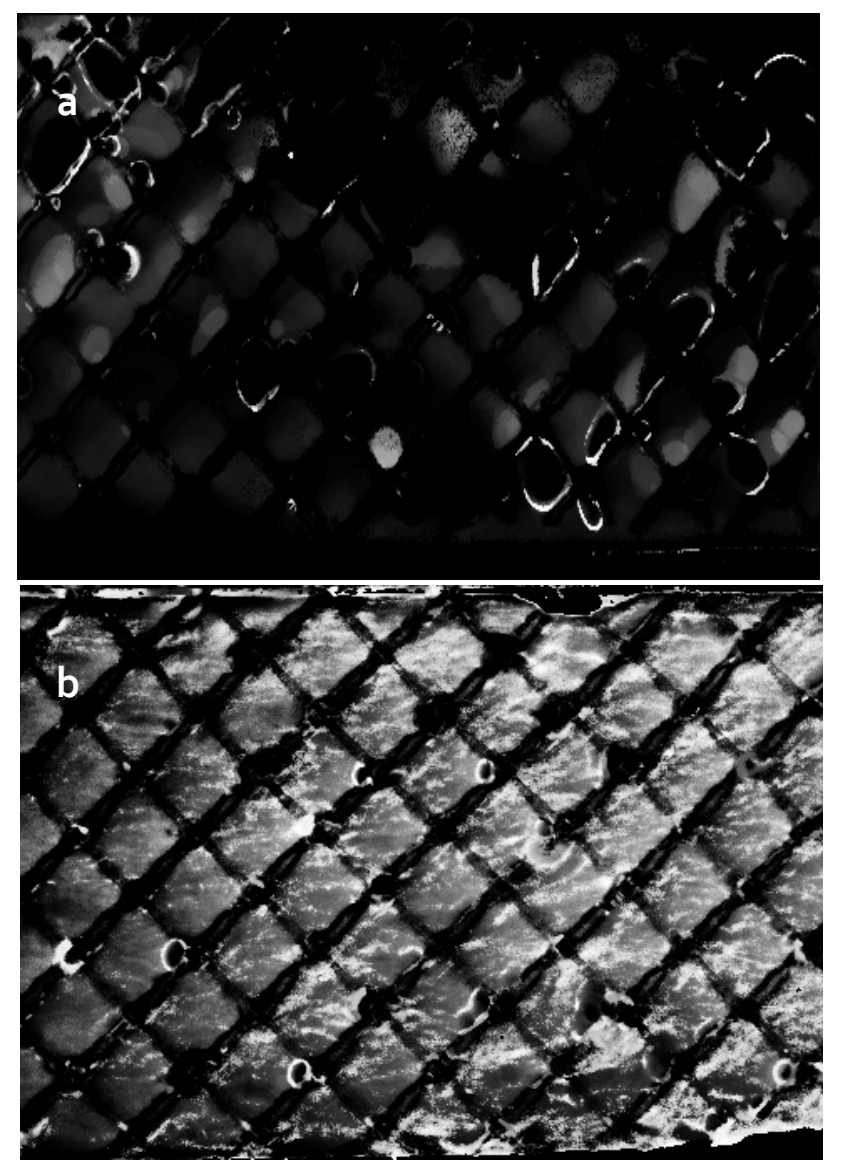

Figure 6. Summation of images showing a) $\mathrm{N}_{2} /$ water flow and b) $\mathrm{CO}_{2}$ and water flow within spacer filled channels. 
Regions with lower intensities (more grey) correspond to areas with increased passage of bubbles. As can be seen from Figure $6 a$, the movement of the nitrogen bubbles shows a preferential path which ultimately results in local differences in cleaning efficiency of the membrane/spacer surface. Figure 6a demonstrates that the bubbles flow through some particular regions only. This can be seen by the dark patches within the image which points to areas which have seen little or no bubble presence. This has been reported by Willems et al [13], who have studied the flow of gas bubbles within a spacer filled channel. They observed the preferential flow of $\mathrm{N}_{2}$ bubbles within the channel depending on the flow rate employed. Figure $6 \mathrm{~b}$ on the other hand shows the bubble presence for the water $/ \mathrm{CO}_{2}$ system. Due to the continuous formation of gas bubbles and continuous detachment of the bubble from the spacer in every part of the feed channel, there is no preferred path for the movement of the bubbles, leading to a higher bubble coverage area. There is a general high intensity all over the cell which is due to full bubble coverage.

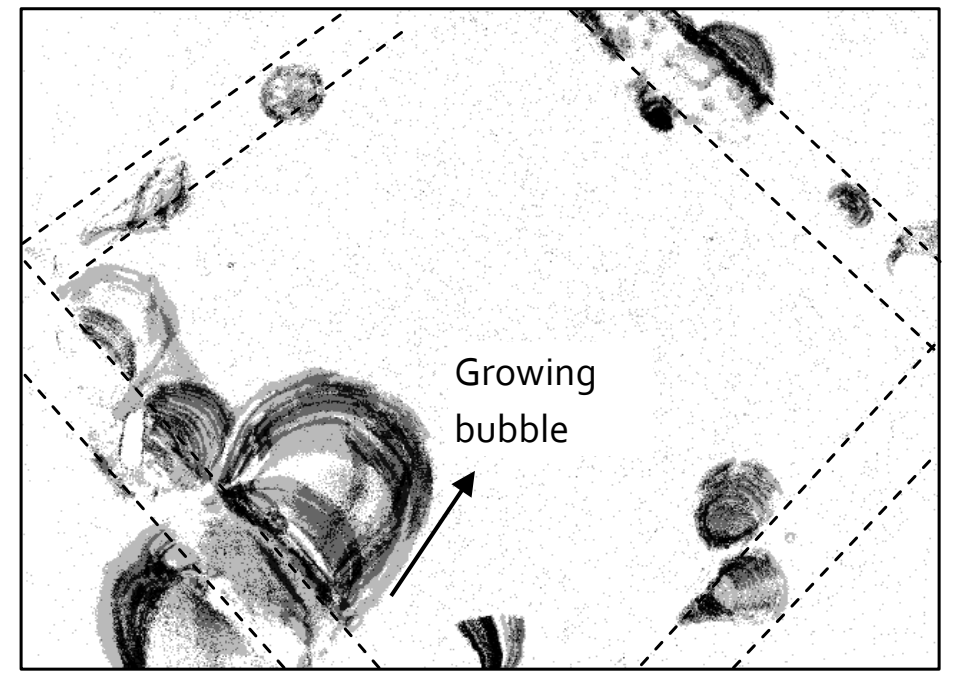

Figure 7. Contour lines of growing bubbles on spacer filament with different dark lines representing evolution in time (dashed lines indicate spacer filaments)

Figure 7 shows a summation of 15 frames on one spacer cell. The bubble nucleation and growth can be seen as increasing concentric rings on the spacer surface. The formation of the bubbles are mostly on the same spots on the spacer surface suggesting that imperfections on the surface of the spacer are used as nucleation sites for the $\mathrm{CO}_{2}$ bubble formation [23]. This suggests 
that the presence of fouling sites on the spacer/membrane could lead to the formation of bubbles in those regions thus leading to more effective cleaning of the fouled areas. Upon their formation, the bubbles are swept along with the flow due to their coalescing with larger bubbles [23].

The frequency of cleaning and procedure still needs to be optimized and may strongly depend on the feed water quality. The influence of surface roughness on bubble formation could lead to better cleaning with the described method due to bubble formation on/within the biofilm. The increase in carbon footprint due to the use of water $/ \mathrm{CO}_{2}$ for cleaning was observed to be very low in comparison to normal plant operation. However, in a complete life cycle analysis, we anticipate that the $\mathrm{CO}_{2}$ based cleaning will outperform today's cleaning practice. In fact, with the demonstrated cleaning efficacy one opens technical routes to potentially avoid the expensive, sensitive, and chemically-intensive pre-treatment to desalination processes. 


\section{References}

(1) Vrouwenvelder, J. S. and Van Der Kooij, D. Diagnosis, prediction and prevention of biofouling of NF and RO membranes. Desalination, 2001, 139 (1-3), 65-71.

(2) Ridgway, H. F. and Safarik, J. Biofouling of reverse osmosis membranes. Biofouling and Biocorrosion in Industrial Water Systems, 1991, 81-111.

(3) Flemming, H. C. Reverse osmosis membrane biofouling. Experimental Thermal and Fluid Science, 1997, 14 (4), 382-391.

(4) Vrouwenvelder, H. S., Van Paassen, J. A. M., Folmer, H. C., Hofman, J. A. M. H., Nederlof, M. M., and Van Der Kooij, D. Biofouling of membranes for drinking water production. Desalination, 1998, 118 (1-3), 157-166.

(5) Al-Ahmad, M., Abdul Aleem, F. A., Mutiri, A., and Ubaisy, A. Biofuoling in RO membrane systems Part 1: Fundamentals and control. Desalination, 2000, 132 (1-3), 173-179.

(6) Serra, C., Durand-Bourlier, L., Clifton, M. J., Moulin, P., Rouch, J. C., and Aptel, P. Use of air sparging to improve backwash efficiency in hollow-fiber modules. Journal of Membrane Science, 1999, 161 (1-2), 95-113.

(7) Guigui, C., Mougenot, M., and Cabassud, C. Air sparging backwash in ultrafiltration hollow fibres for drinking water production. Water Science and Technology: Water Supply, 2003, 3 415-422.

(8) Ebrahim, S. Cleaning and regeneration of membranes in desalination and wastewater applications: State-of-the-art. Desalination, 1994, 96 (1-3), 225238.

(9) Verberk, J. O. J. C., Hoogeveen, P. E., Futselaar, H., and Van Dijk, J. C. Hydraulic distribution of water and air over a membrane module using AirFlush ${ }^{\oplus}$. Water Science and Technology: Water Supply, 2002, 2 297-304.

(10) Cornelissen, E. R., Vrouwenvelder, J. S., Heijman, S. G. J., Viallefont, X. D., Van Der Kooij, D., and Wessels, L. P. Periodic air/water cleaning for 
control of biofouling in spiral wound membrane elements. Journal of Membrane Science, 2007, 287 (1), 94-101.

(11) Ducom, G., Matamoros, H., and Cabassud, C. Air sparging for flux enhancement in nanofiltration membranes: Application to O/W stabilised and non-stabilised emulsions. Journal of Membrane Science, 2002, 204 (1-2), 221236.

(12) Cui, Z. and Taha, T. Enhancement of ultrafiltration using gas sparging: A comparison of different membrane modules. Journal of Chemical Technology and Biotechnology, 2003, 78 (2-3), 249-253.

(13) Willems, P., Kemperman, A. J. B., Lammertink, R. G. H., Wessling, M., van Sint Annaland, M., Deen, N. G., Kuipers, J. A. M., and van der Meer, W. G. J. Bubbles in spacers: Direct observation of bubble behavior in spacer filled membrane channels. Journal of Membrane Science, 2009, 333 (1-2), 38-44.

(14) Al-Amoudi, A. and Lovitt, R. W. Fouling strategies and the cleaning system of NF membranes and factors affecting cleaning efficiency. Journal of Membrane Science, 2007, 303 (1-2), 4-28.

(15) Flemming, H. C., Schaule, G., Griebe, T., Schmitt, J., and Tamachkiarowa, A. Biofouling - The Achilles heel of membrane processes. Desalination, 1997, $113(2-3), 215-225$.

(16) Whittaker, C., Ridgway, H., and Olson, B. H. Evaluation of cleaning strategies for removal of biofilms from reverse-osmosis membranes. Applied and Environmental Microbiology, 1984, 48 (2), 395-403.

(17) Kim, D., Jung, S., Sohn, J., Kim, H., and Lee, S. Biocide application for controlling biofouling of SWRO membranes - an overview. Desalination, 2009, $238(1-3), 43-52$.

(18) Zondervan, E. and Roffel, B. Evaluation of different cleaning agents used for cleaning ultra filtration membranes fouled by surface water. Journal of Membrane Science, 2007, 304 (1-2), 40-49.

(19) van de Ven, W. J. C., Sant, K. v., Punt, I. G. M., Zwijnenburg, A., Kemperman, A. J. B., van der Meer, W. G. J., and Wessling, M. Hollow fiber 
dead-end ultrafiltration: Influence of ionic environment on filtration of alginates. Journal of Membrane Science, 2008, 308 (1-2), 218-229. (20) Vrouwenvelder, J. S., van Paassen, J. A. M., Wessels, L. P., van Dam, A. F., and Bakker, S. M. The Membrane Fouling Simulator: A practical tool for fouling prediction and control. Journal of Membrane Science, 2006, 281 (1-2), 316-324.

(21) Kennedy, M., Siriphannon, S., Van Hoof, S., and Schippers, J. Improving the performance of dead-end ultrafiltration systems: Comparing air and water flushing. Water Science and Technology: Water Supply, 2001, 1 97-106. (22) Ndinisa, N. V., Fane, A. G., and Wiley, D. E. Fouling control in a submerged flat sheet membrane system: Part I - Bubbling and hydrodynamic effects. Separation Science and Technology, 2006, 41 (7), 1383-1409.

(23) Jones, S. F., Evans, G. M., and Galvin, K. P. The cycle of bubble production from a gas cavity in a supersaturated solution. Advances in Colloid and Interface Science, 1999, 80 (1), 51-84. 


\section{Chapter 6. Conclusions and Outlook}

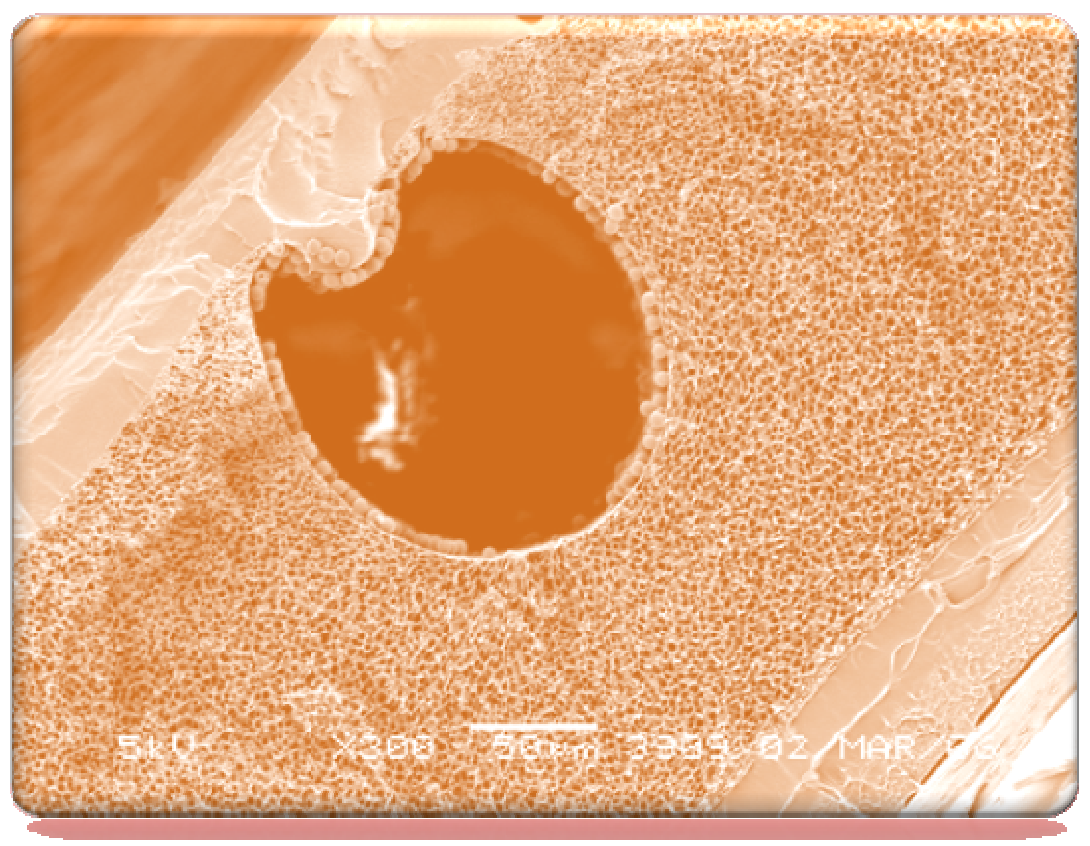




\section{Conclusions}

In chapter 2, the setup used in real time visual characterization of membrane fouling was described. PS $\mu \mathrm{M}$ was used to template membranes with embedded channels, which were sealed and subsequently observed in cross section. Using SEM analysis and pure water flux experiments, characterization of both the channelled and flat sheet membrane (made from same recipe) showed similar membrane properties. With a model feed solution containing $6 \mu \mathrm{m}$ polystyrene particles dispersed in Milli-O water, fouling of the membrane was characterized locally (visually) and globally (pressure and flow). The particle trajectories and velocities were also obtained by analysing short image sequences. Visual characterization of the fouling showed an initial cake growth towards the channel exit, resulting in local increase in resistance. This increasing resistance favours the cake growth at channel inlet, leading to a more homogenous cake thickness.

Considering that natural filtration feed solutions are better described as mixed feed solutions, the fouling properties of bidisperse solutions on embedded channel membranes was studied. The influence of particle composition (3.3 and $5.7 \mu \mathrm{m}$ ) on fouling was described in chapter 3 . The average experimental cake porosity decreased showing a minimum at 50\% fraction of larger particles. The specific cake resistance obtained from the experiments was compared to the theoretical specific cake resistance obtained using a modified Kozeny Carman relation. Both showed a similar trend with a decreasing specific resistance with increasing fraction of larger particles. However, the theoretical specific cake resistance gave lower absolute values. This was suggested to be due to ordering within the experimental cake with the cake being more ordered closer to the membrane and more randomly packed closer to the bulk flow. This correlates with the observation of lower absolute values of experimental porosity in comparison to the theoretical. 
The influence of spacers in spiral wound modules was studied in chapter 4. Using PS $\mu \mathrm{M}$, four different structures (round, tear drop, kite and star) were replicated onto a membrane surface. (Bio)fouling of these structured membranes was compared to a regular net shaped spacer. Biofilm formation was observed upstream (frontal) of the structures and spacer nodes, contrary to reports suggesting biofilm formation downstream of the spacers. Computational fluid dynamics simulations were used to study the hydrodynamics around the objects replicated onto the membrane. Local wall surface shear on the structures showed a minimum downstream of the flow with the maximum on the sides of the objects. There was no observable relationship between the wall shear and biofouling position. The hypothesis that biofouling acts like particulate fouling with the microbes meeting an obstacle and attaching to the surface was confirmed by results of particulate fouling.

Chapter 5 describes a novel cleaning method. In this part, three different cleaning methods were compared in the removal of (bio)fouling in membrane/spacer filled channels. Pure water (rinsing) showed a $40 \%$ reduction in fouling observed within the channels. However, sparging (water $/ \mathrm{N}_{2}$ ) gave better results with a reduction of $85 \%$ of the fouled membrane spacer channel. The best result was obtained with water $/ \mathrm{CO}_{2}$ (nucleation), which resulted in a reduction of $100 \%$ of the initial fouling. Air sparging has lower efficiencies due to the presence of stagnant bubbles and preferential flow paths within the channels. However, using the carbonated water mixture, there is continuous bubble nucleation and growth within the channels thus ensuring no bubble stagnation. The formation of $\mathrm{CO}_{2}$ bubbles was observed at specific locations on the spacer suggesting that (bio)foulants could induce bubble nucleation which will improve the cleaning process. 


\section{Outlook}

\subsection{Microfluidic filtration}

The real time in situ technique developed in chapter 2 provides a platform for further research into the fundamentals of fouling. Using this technique, membrane fouling can be characterized. The influence of particle surface properties on deposition and cake formation can be examined in further detail. The versatility of PS $\mu \mathrm{M}$ method used in preparing the embedded channel membranes can be exploited in making membranes with different surface properties. This could be coupled to the surface modified particles and the fouling propensity studied.

The feed solution used in this study consisted of particles dispersed in Milli-O water, the influence of feed water charges on fouling would be of interest. In this regard, varying the ionic strength of the feed solution could be used to observe the change (if any) on the deposition characteristics. It has been reported that increasing ionic strength leads to an increase in the fouling rate as well as influencing the characteristics of the cake [1]. Visual characterization can be used to observe directly the influence of changing ionic strength on the cake structure.

Backwash and gas sparging are two techniques which can be used to remove foulants from the membrane surface. For backwash, the cake is lifted off the membrane and swept away, this can be visualized using this system. Preliminary experiments suggest that the cake is not entirely swept away, but rather the ordered aspects of the cake remain. Figure 1 shows images of fouled chip during backwash. After 5 seconds of backwash, the cake was observed to have been broken up with the greater part having been flushed out of the chip (fig. 1b). Figure 2a shows a close up image of the fouled chip after 30 seconds of backwash, suggesting "complete" removal of the cake. However, with the second backwash (fig. 2b), a linked layer is lifted up but not swept out of the chip. Using this system, pulses can be made and the influence on the cake studied. Gas sparging can be used in cleaning membrane surfaces and this can be studied using this method. Particle 
recirculation has been observed around the bubbles during sparging experiments. Detailed $\mu$ PIV could be used in elucidating the interactions between bubbles and particles during cleaning. This can be used to optimize sparging techniques used in fouling removal.
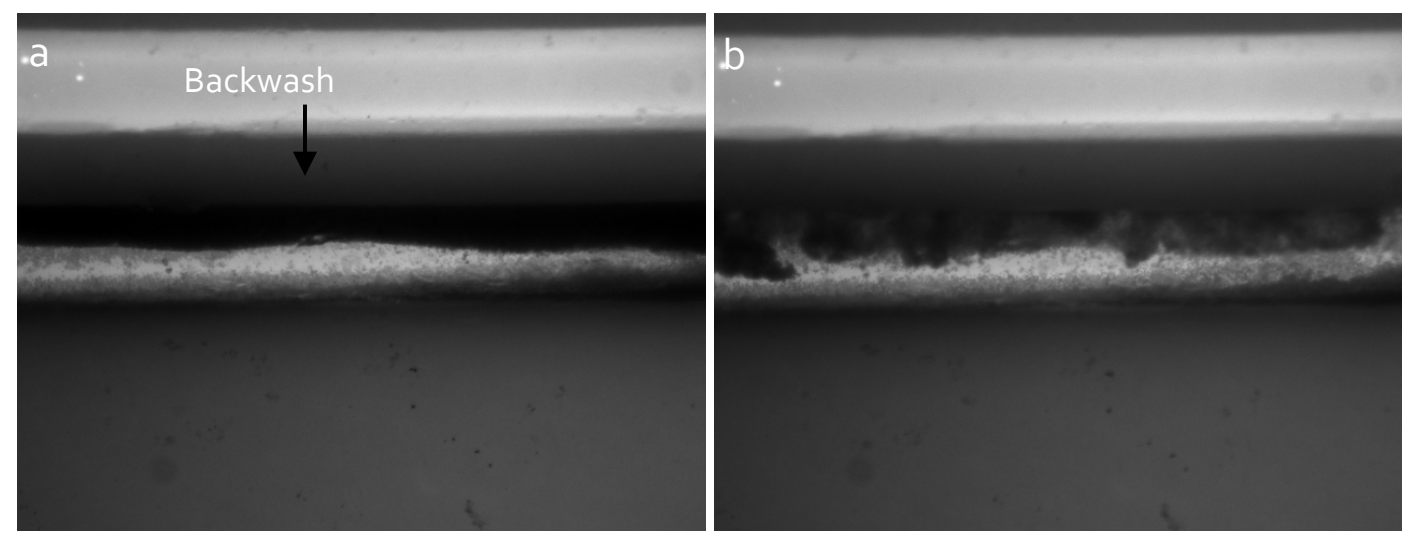

Figure 1. Fouled chip before and after $5 \mathrm{~s}$ of backwash
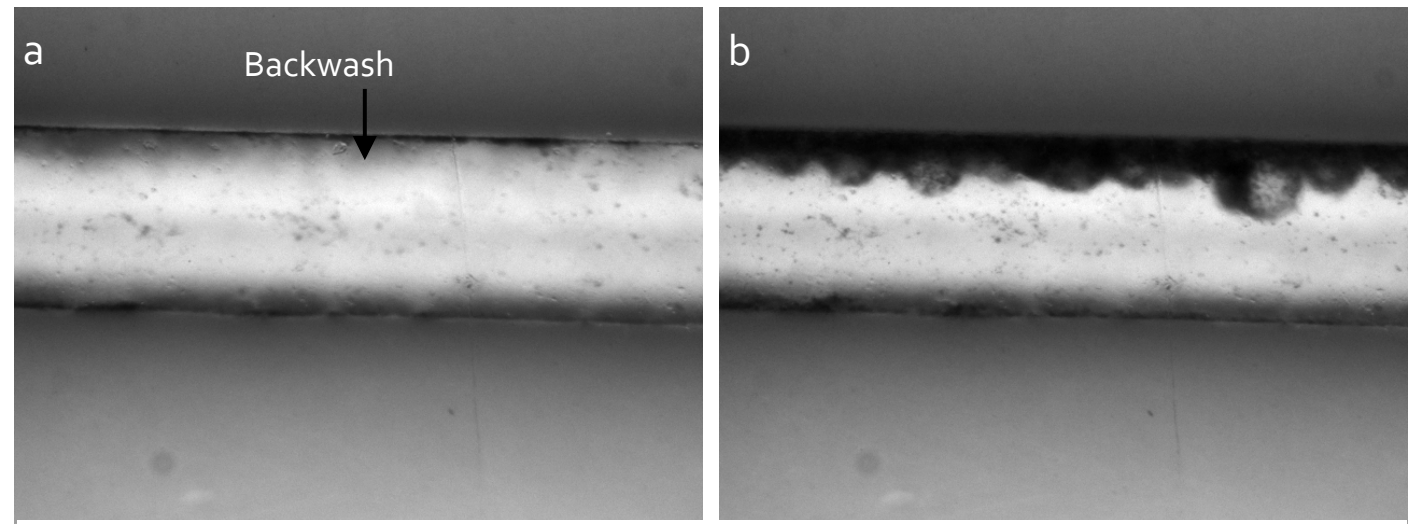

Figure 2. Close up of fouled chip (a) after initial backwash and (b) during second backwash pulse

\subsection{Free standing spacers}

The structured membranes discussed in chapter 3 were initially conceived as a replacement for membrane spacers by using free standing structures. Due to the height required for this, better filling of the mould is required. Presently, mould filling is carried out in a solvent rich atmosphere. Casting of the solution under different atmospheres (like $\mathrm{CO}_{2}$ ) has shown interesting results in terms of improving mould filling. Inadequate filling of the mould results in structures with entrapped bubbles, or incomplete replication (see fig. 3). This could affect the integrity of structures resulting in their inability to withstand 
the stress within spiral wound modules. By using these structures to replace spacers, there is the freedom to design the structures to fit with the required system.

The geometry of these structures can be easily tuned depending on the fouling propensity of the feed solution. Considering that the structures are free standing, the pattern and positioning of the structures can be easily manipulated. The positioning of the structures can be used to enhance
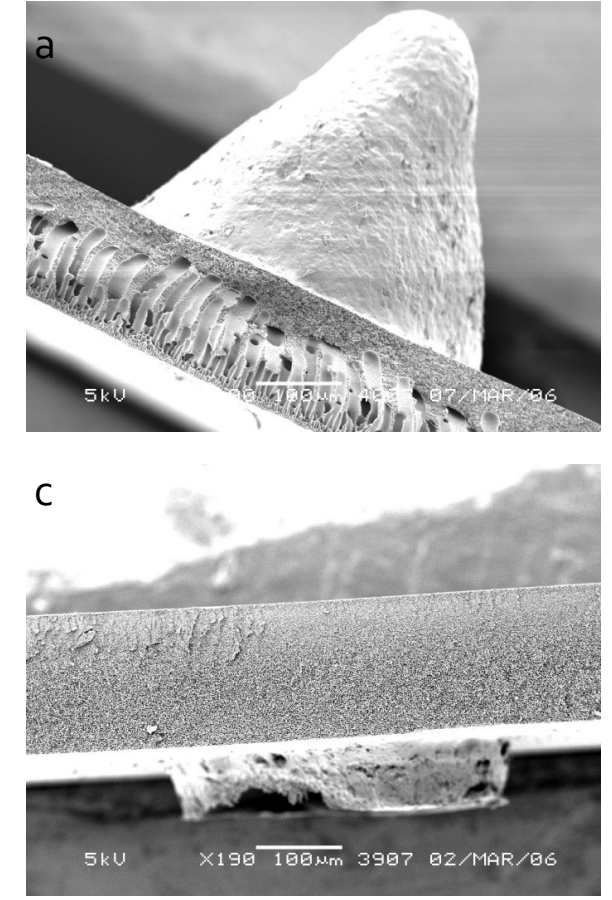

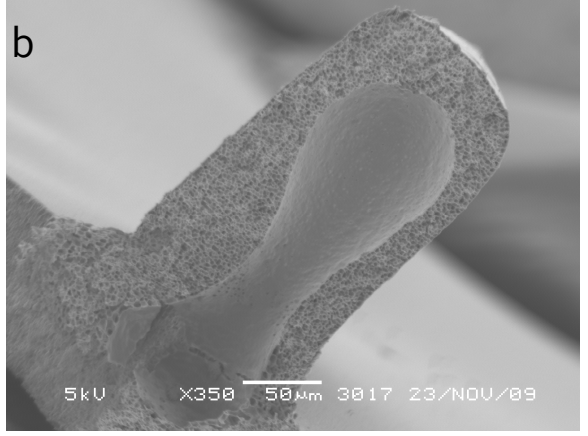

Figure 3. a) Structured membranes prepared from powder blaster mould, b) Cross section of structured membrane showing entrapped bubble within the structure and c) Incomplete filling of mould well resulting in no structure.

surface shear within the spacer filled channel. There is also the added advantage of the permeability of these structures, providing enhanced surface area available for filtration.

\subsection{Biofouling on structures}

It was observed in chapter 3 that the formation of a biofilm is observed upstream (front) of obstructions. This totally runs against the reports of biofouling located in the stagnant zone behind the spacer nodes. Considering that the fouling experiments carried out in chapter 3 were under constant flow conditions, it would be interesting to observe the influence of changing velocities on the positioning of the biofilm. COMSOL simulations show an increasing stagnant zone with increasing velocities (both in front and behind 
the structures), this could be used to determine the influence of such stagnant zones on biofouling. It has been suggested that the presence of such stagnant zones could lead to fouling formation [2].

The study of biofouling would be particularly interesting given the low amount of researchers actively involved presently. A better understanding of the fundamentals of biofilm formation would further enhance the applicability of membrane filtration systems and in membrane bioreactors. PIV analysis could initially be used to determine the hydrodynamics near the structured membrane. Given the hypothesis in chapter 3 that biofouling acts like particulate fouling, it would be interesting to further study this. The surface properties of the structures (charge, porosity) can be altered and the effect on biofilm attachment and growth observed.

\section{$2.4 \mathrm{CO}_{2}$ cleaning properties}

The effectiveness of $\mathrm{CO}_{2}$ saturated water for the removal of (bio)fouling from membrane/spacer filled channels has been demonstrated in chapter 4. This effectiveness justifies further research. The fundamental aspects of the cleaning process are of particular interest. Acids (citric acid) are normally used in membrane cleaning due to their biocidal activity, the acidic nature of $\mathrm{CO}_{2}$ saturated water could be a factor in the effective cleaning using this method. To determine the influence of such $\mathrm{pH}$ changes on spacer cleaning, particulate fouled membrane/spacer channels could be used, since the influence of the acid is minimized.

The effect of the $\mathrm{CO}_{2}$ cleaning protocol on membrane properties is also of interest. Long term experiments using this cleaning method, preferably with liquid permeation could be used to determine the effects (if any) of $\mathrm{CO}_{2}$ nucleation on the membrane. The long term experiments could be used to determine the effects of the cleaning protocol on biofilm formation and adaptability of the biofilm to the method. 


\section{References}

(1) Bacchin, P., Aimar, P., and Sanchez, V. Influence of surface interaction on transfer during colloid ultrafiltration. Journal of Membrane Science, 1996, 115 (1), 49-63.

(2) Subramani, A., Kim, S., and Hoek, E. M. V. Pressure, flow, and concentration profiles in open and spacer-filled membrane channels. Journal of Membrane Science, 2006, 277 (1-2), 7-17. 


\section{Summary}

The research presented in this thesis is focused on the phenomena of membrane fouling. Membrane fouling is simply described as the deposition of unwanted matter on the membrane surface during the course of operation, which results in reduction in filtration efficiency. This research is aimed at visually characterizing membrane fouling as well as fouling removal.

Typical fouling characterization techniques are either invasive or non-visual. In a bid to better characterize membrane fouling, a novel technique was developed whereby fouling can be observed visually and in real time. Chapter 2 describes the method, with the fabrication of embedded channel membranes using phase separation micromolding (PS $\mu \mathrm{M})$. Using a model feed solution containing $6 \mu \mathrm{m}$ polystyrene particles, deposition on the membrane surface was studied. It was observed that initially, there is the build-up of cake towards the channel exit and with increasing local resistance, there is a change in hydrodynamics leading to build-up closer to the channel entrance.

To better describe "normal" feed solutions, chapter 3 describes study on fouling using a feed solution containing bidisperse suspension (3.3 and 5.7 $\mu \mathrm{m}$ ) of polystyrene particles. Increasing the fraction of larger particles in the suspension resulted in an initial reduction in cake porosity leading to a minimum at number fraction of 0.5 . On the other hand, the specific cake resistance showed a continuing decline with addition of larger particles. These results compared favourably with theoretical calculations of cake porosity (using Tokumitsu's method) and specific cake resistance (using Kozeny Carman relation). However, the experimental results gave lower absolute values which could be due to better ordering of the cake closer to the membrane.

There have been reports of feed spacers contributing to (bio)fouling. This is interesting considering that spacers are used in spiral wound modules as "surface shear generators". In chapter four, we study the flow and (bio)fouling around micro structured membranes designed to mimic spacer nodes. It was 
observed that the biofilm formation and growth occurred upstream of these structures contrary to reports in literature. Particulate fouling of the structures suggested that biofilm initiation is similar to particulate deposition whereby biomass on contacting the structure, adheres and grows leading to a biofilm.

Air sparging is a technique which has been applied in industries for the removal of (bio)fouling from the spiral wound module. In chapter five, a novel sparging technique was compared to typical sparging and forward flush in terms of removal of biofouling from membrane/spacer channels. Dissolved $\mathrm{CO}_{2}$ was applied as a cleaning agent with nucleation of the gas within the channels due to pressure drop as well as imperfections on the spacer surface acting as nucleation sites. It was observed that forward flush resulted in $40 \%$ restoration of channel resistance while the water/N2 sparging resulted in 80 $\%$ restoration. Water/CO2 nucleation resulted in $100 \%$ restoration of the channel resistance due to better distribution of the bubbles within the channel. 


\section{Samenvatting}

Het in dit proefschrift gepresenteerde onderzoek richt zich op membraan vervuiling. Membraan vervuiling is gedefinieerd als de depositie van materiaal op het membraan oppervlak gedurende het gebruik, resulterend in een afname van de filtratie efficiëntie. Onderzoek van vervuiling vindt doorgaans plaats middels invasieve en niet-visuele technieken. Het onderzoek beschreven in dit proefschrift is gericht op visuele karakterisering van zowel membraan vervuiling als vervuiling verwijdering.

In een poging om membraan vervuiling beter te karakteriseren is een methode ontwikkeld waarbij vervuiling visueel wordt onderzocht in real-time. Hoofdstuk 2 beschrijft de methode waarbij membranen met kanaaltjes worden gefabriceerd middels "phase separation micromolding (PS $\mu \mathrm{M})$ ". De depositie van $6 \mu \mathrm{m}$ polystyreen deeltjes op het membraan oppervlak is bestudeerd. $\mathrm{Er}$ is vastgesteld dat initieel een groei van vervuiling optreedt achterin het kanaal en dat, met toenemende lokale weerstand van de vervuilinglaag (cake), er een verschuiving is in de hydrodynamica waardoor de vervuiling vervolgens voorin het kanaal toeneemt.

In hoofdstuk 3 worden vervuiling experimenten beschreven met suspensies van polystyreen deeltjes van 3.3 en $5.7 \mu \mathrm{m}$. Een toename van de fractie van grotere deeltjes in de suspensie resulteerde in een afname van de cake porositeit, met een minimum porositeit voor een suspensie met aantal fractie 0.5 voor grotere deeltjes. De specifieke cake weerstand neemt geleidelijk af met toenemend aantal fractie voor grotere deeltjes. Deze resultaten komen goed overeen met theoretische berekeningen van cake porositeit (middels Tokumitsu's methode) en de specifieke cake weerstand (middels Kozeny Carmans vergelijking). Daarentegen geven de experimentele resultaten lagere absolute waarden die verklaard kunnen worden door een betere ordening in de cake op het membraan.

In de literatuur zijn publicaties die de bijdrage van voeding spacers aan (bio)vervuiling beschrijven. Dit is een interessant gegeven omdat spacers in 
'spiral wound modules' als 'surface shear generators' gebruikt worden. In hoofdstuk 4 bestuderen we de snelheid en (bio)vervuiling van microgestuctureerde membranen, specifiek ontworpen om spacer nodes te imiteren. In contrast met de literatuur werd juist stroom opwaarts een biofilm formatie en groei van deze sturcturen geobserveerd. Deeltjes vervuiling van deze structuren wijst erop dat biofilm inititatie vergelijkbaar is met deeltjes depositie waarbij biomassa bij contact met de structuur eraan plakt en tot een biofilm groeit.

'Air sparging' is een techniek die in de industrie werd toegepast om (bio)vervuiling te verwijderen van de 'spiral wound module'. In hoofdstuk 5 werd een nieuwe 'sparging' techniek vergeleken met de originele techniek en met voorwaarts spoelen met als doel (bio)vervuiling van het membraan/spacer kanaal te verwijdern. Opgelost $\mathrm{CO}_{2}$ werd als schoonmaakmiddel toegepast waarbij nucleatie van het gas optrad in de kanalen ten gevolge van drukdaling en oneffenheden op het 'spacer' oppervlak. Voorwaarts spoelen resulteerde in $40 \%$ herstel van de kanaal weerstand terwijl water $/ \mathrm{N}_{2}$ sparging een herstel van $80 \%$ liet zien. Water $/ \mathrm{CO}_{2}$ nucleatie resulteerde in $100 \%$ hersel van de kanaal weerstand ten gevolge van een betere distributie van de bellen in het kanaal. 


\section{Acknowledgements}

I would like to appreciate two very important people in my life, two people who have in their different but lovely ways have helped me to get to this stage. Aludiya, as I was starting this long study journey, we also embarked on our own long personal journey together. Having you alongside me, has given me the support I need to muddle through. Bobo, I come back in the evenings, mad at my setup for misbehaving and what do you do.... you just give me that award winning smile. No matter what the day was like, I can't help but smile and play with you. You both have been the bomb.

Popsie and momsie, it wouldn't be complete if I don't acknowledge how much you have done for me. Financially and otherwise, you have been there for me, I hope to have made you proud at least. Same goes for my brothers, Chuma - finally you will stop asking me when I will answer the questions, Okezie - you were there when I started, hopefully you are rejoicing with me now in heaven (reserve me a mansion), Chidi - yes this is what I have been doing for the last 4 years.

I can't fail to appreciate the opportunity to have been a part of this group for the past four years (only $:-$ ). When I met Walter, we just tabked about all sorts of membrane things (at the time, I knew NOTHING about them) and what do you know, four years later (I still don't) the journey is coming to an end. A big thanks to Matthias for the frowitful discussions along the way and the opportunity to have been part of this group (and for waiting for me to finish before leaving).

Rob, having you to talk to whenever / have stupid questions during this time has been just super cool. I have to say, you have to be the best supervisor a gay could ash for, thanks for all the answers (now you still have to answer a few more today.... assume you are reading this on 27th May). During the course of writing up this book, you have had to read and re-read what I have written several times all in a bid to make it scientific and ensure that people reading this believe that ( am a genius (at least ( wish they do). Thank you (both you and Cindy) also for taking the time to translate the summary into Dutch /trust me Google translator was just not cutting it). Lest ( forget, congratulations on the new position, if anybody deserves it, you do. 
Another big holla to the folles who I have shared the office with in the past years. It all started in the chicken box (aptly named due to appearance) with Matias. The summer was really something in there with both of us taking turns to bring liquid nitrogen to coob the office (yes, it was that hot). From there, we went downstairs and were joined by Al-hadidi (the Uemeni). It was nice sharing an office with you gays. On to meander where Wilbert joined me and Katja (more about her later). Thanks Wilbert for abways having smart answers. Giri and Wendy (for a short while) joined us later and all together made the office the place to be in meander (don't doubt me, just ash around). And much much later, came Enver (fresh brains for me to eat).

In this period, I have been lucky to be around two wonderful ladies (if you are in the defence, look at my right and left). It was quite interesting that on my very first day along came this blond Polish lady who was also starting and was living on top of me fuhhmm, she had a room above mine). Together we muddled through the initial stages, documents to be filled out, strugghing through a new and strange topic and even shopping together. It has been quite nice to have a friend in you - Katarzyna and of course today (defence day) she is sitting right beside me still.

And now to the postponed second lady. Who would have guessed that Katja is a talkative? When we first started sharing the office, I was the talker in the office but believe me /I know nobody will except (hristoph), after a while ( realized she talks as much as me.' I think we spent so much time just tabking that it is amazing we still had time to work. Katja, I enjoyed our time together very much aside from wabking up the stairs (well, ( enjoyed the cola's). I was quite lucky to share an office with you, however, I am jealous.......

Looking back to the years, I never envisaged that I will do a PhD. However, I remember speaking to a certain lady some 5 years ago and she encouraged me to do it and by so doing Dr. Marian Vermue started me on this journey. Thanks to that conversation, I can stand here today with the title Dr and all the rights attached to it.

I am also very grateful to the members of the promotion committee for helping to make this day possible (and survivable). To have had scientists of your calibre at my defence is a real honour. Thank you to Dr. Pierre Aimar for making the journey here. I am also grateful to Prof. Remko Boom, Prot. M. Wessling, Prot. H. van Dijh, and Dr. J.C.T. Eijkel for being a part of this day. Once more, thanks to my promotor and co-promotor for being here today. My 
paranymfs also get a double mention, thanks to you both - Karina Kopec and Katja Simons (the two lady $K^{\prime} s$ ) for standing beside me.

There have of course been so many other people to talk to along the way. Zeynep, Symonka, Can, Olga, Paul, and Hukun, all of you have in one way or the other made these four years fly by; be it in switching off the light, tabking or helping me out of trouble. Thanks also goes to John Heehs, now is it possible that I could have found my way around the lab and all that stuff without going to John, wan hartelijh bedankt Meneer Appleby. Another special thanks to the Peter Wessels and Antoine for productive discussions and collaboration on the cotoo project. Antoine also made sure / never had to worry about money $\odot$.

And of course a special mention to another two special ladies - Hi Greet, hello Suzanne. I am one of those lucky people who are so important that I had two super secretaries to help me out of trouble. It started with Greet, from the very first day always helping to answer my questions and solve all the issues. Then when it became too much for her, Suzanne had to help her, taking the load of me off her back. It was quite nice always having both of you to run to whenever the problems of paper work arose. However, even Suzanne gave up and sent me back to Greet. Thanks a lot to both of you.

How do you define one's family? No matter the definition you use, I have had some pretty wonderful members in my family. When I was in Wageningen, I had a close family there - my pastor (Farai), his wife (Busi). After I left there and came to Enschede, I met another super set of people; this is my way of appreciating all of you for the support along the way. Oga mi (His Excellency, Honorable, Pastor Deacon and my sister (Christy)), thanks for all the prayers.

The greatest thanks goes to my father in heaven. You promised wisdom to all who ash of You and unto me, You made it available in abundant measure. I cannot appreciate enough how good You have been to me.

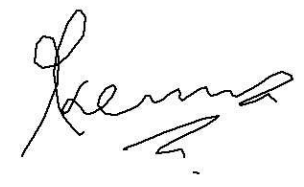

